Linköping Studies in Science and Technology.

Dissertations, No. 1546

\title{
Smartware electrodes for ECG measurements -Design, evaluation and signal processing
}

\author{
Linda Rattfält
}

Department of Biomedical Engineering

Linköping University, SE-581 85 Linköping, Sweden

http://www.imt.liu.se

Linköping, October 2013 
Smartware electrodes for ECG measurements -Design, evaluation and signal processing

\author{
(c) 2013 Linda Rattfält \\ Department of Biomedical Engineering \\ Linköpings universitet \\ SE-581 85 Linköping \\ Sweden
}

ISBN 978-91-7519-507-0

ISSN 0345-7524

Printed in Sweden by LiU-Tryck, Linköping

During the course of the research underlying this thesis, Linda Rattfält was enrolled in Forum Scientium, a multidisciplinary doctoral programme at Linköping University, Sweden. 


\section{Håll koll på hjärtat med smarta EKG-elektroder}

Befolkningen i västvärlden blir allt äldre och i samband med detta ökar även andelen av åldersrelaterade sjukdomar. Dessa åkommor står redan för en stor del av hälso- och sjukvårdsresurserna och därför har man nationellt och internationellt efterfrågat alternativa strategier för att kunna tillgodose det kommande vårdbehovet på ett kostnadseffektivt sätt. En av strategierna är att med hjälp av användarvänlig mätutrustning hemifrån kunna följa upp tex hjärtåkommor så att de kan behandlas innan tillståndet eventuellt blir akut.

Den här avhandlingen berör forskning som syftar till att skapa en tillförlitlig mätmetod av hur hjärtat arbetar, varhelst personen befinner sig, med hjälp av smarta elektroder. Speciellt berörs hur de smarta elektrodernas prestanda är i jämförelse med konventionella elektroder som används inom vården samt hur man kan använda signalbehandling för att förbättra mätkvaliteten.

Hjärtats elektriska aktivitet kan mätas med ett så kallat elektrokardiogram, EKG, genom att fästa två eller fler elektroder på kroppen och koppla dessa till ett mätsystem. Vanligtvis används elektroder med klisterlappar som placeras på exakta platser på kroppen. Den här typen av mätning är välspridd och anses viktig inom vården, men lämpar sig inte för hemmabruk eftersom elektrodförberedelser och placering inte kan säkerställas. Istället föreslår vi att man kan använda smarta elektroder, tex gjorda av textil eller i form av screentryck. Elektroderna skulle sedan kunna användas i mer användarvänliga sensorer, tex i linningar på kläder eller i form av en gjördel som man tar på sig vid mättillfället. De smarta elektrodernas egenskaper spelar stor roll då man mäter ett EKG. Om man använder fel material eller utförande, kan elektroden i sig skapa störningar som förstör mätningarna. Därför har vi testat hur de alternativa elektroderna fungerar jämfört mot vanliga elektroder som används idag. Våra tester visar att flera av de smarta elektroder vi testat är nästan lika stabila som vanliga elektroder. Dock medför de smarta elektroderna ofta ett större motstånd, så kallad impedans, för signalen att ta sig igenom till själva mätsystemet, något som är viktigt att tänka på när mätsystemet utformas.

Förutom att göra användarvänliga sensorer av smarta elektroder, anser vi att man kan minska graden av störningar genom att man samlar in flera signaler samtidigt och väger samman dem till en förhoppningsvis mer tillförlitlig signal. Detta kan göras på många sätt och två sätt presenteras i avhandlingen. Det första sättet använder statistik för att urskilja olika delsignaler i den inspelade signalen. På det här sättet kan man få en delsignal som avspeglar hjärtats aktivitet och en annan som exempelvis innehåller brus. Vid en jämförelse mot två andra metoder fick vi att vår metod kunde detektera flest brusiga EKG-signaler som var inspelade med textila elektroder under rörelse. Nästa metod bygger på att man jämför signalerna som man har registrerat med en modell av hur ett hjärtslag ser ut i ett EKG. På så vis får man ett mått på hur lik varje del av signalerna är ett hjärtslag. Vidare 
kan man jämföra andra egenskaper som signalerna har och låta de som har mest tillförlitlig information få störst inverkan på det slutliga resultatet. Vid en jämförelse med en standardmetod för att hitta hjärtslag i EKG-signaler, presterade vår metod lika eller bättre för alla de testade rörelserna. 


\section{Abstract}

The aim of this thesis work has been to study textile and screen printed smartware electrodes for electrocardiographic (ECG) measurements both in terms of their electrode properties and possibility to further improve their robustness to movement induced noise by using signal processing. Smartware electrodes for ECG measurements have previously been used in various applications but basic electrical electrode properties have not sufficiently been looked into. Furthermore, we believe that there is a possibility to reduce disturbances in the smartware ECG by adding redundant sensors and applying sensor fusion signal processing.

Electrical properties of conductive textiles have been evaluated in terms of stability and electrode impedance. Three yarns and textile electrode surfaces were tested. The electrodes made from pure stainless steel and 50\% stainless steel/ $50 \%$ polyester showed acceptable stability of electrode potentials. All electrode measurements were performed on skin.

Furthermore, we produced six screen printed electrodes and their electrical performance was investigated in an electrochemical cell. The tested inks contained carbon or silver particles in the conduction lines, and $\mathrm{Ag} / \mathrm{AgCl}$ particles in the electrode surface. Results show that all electrodes were stable in time, with a maximum drift of a few $\mathrm{mV}$ during 30 minutes. The silver ink is superior to the carbon based in terms of electrode impedance at the higher frequencies.

To extract viable physiological information from noisy signals, canonical correlation analysis (CCA) was applied on multi-channel ECG signals recorded with textile electrodes. Using CCA to solve the blind source separation (BSS) problem, we intended to separate the ECG signal from the various noise sources. The method (CCABSS) was compared to averaging of the ECG channels and to the independent component analysis method (ICA). In the dataset consisting of noisy ECG recordings, the signal was uninterpretable in $7 \%$ after CCABSS. Corresponding values for averaging and ICA were $33 \%$ and $17 \%$, respectively.

Smartware applications often include heartbeat detection while moving, a measurement situation which is prone to produce noise corrupted ECG signals. To compensate for this, we used an event detector based on a multi-channel input, a model of the event and weighted correlation. For measurements at rest and static muscle tension, the sensitivity of the event detector was $97 \%$ and $77 \%$ respectively. Corresponding values for the golden standard detector Pan-Tompkins were $96 \%$ and $52 \%$, respectively. 



\section{List of publications}

\section{Included papers}

Paper I Rattfält L, Lindén M, Hult P, Berglin L, Ask P. Electrical Characteristics of Conductive Yarns and Textile Electrodes for Medical Applications, Medical \& Biological Engineering \& Computing 2007;12:1251-57.

Paper II Rattfält L, Björefors F, Wang X, Nilsson D, Norberg P, Ask P, Properties of screen printed electrocardiography smartware electrodes investigated in an electrochemical cell, BioMedical Engineering Online, 2013;12:64

Paper III Rattfält L, Ahlstrom C, Berglin L, Lindén M, Hult P, Ask P, Wiklund U. A Canonical Correlation Approach to heartbeat Detection in Textile ECG Measurements, Proceedings of the Medical Signal Processing Conference (MedSip), Glasgow, Scotland (2006)

Paper IV Rattfält L, Lindén M, Hult P, Ask P, Borga M, Robust heartbeat Detector Based on Weighted Correlation and Multichannel Input. -Implementation on ECG Recorded With Textile Electrodes. International Journal of E-Health and Medical Communications 2013;4:61-71

\section{Related publications}

- Rattfält L, Björefors F, Wang X, Nilsson D, Norberg P, Ask P Electrical characterization of screen printed electrodes for ECG measurements, 15th Nordic-Baltic Conference on Biomedical Engineering and Medical Physics, Aalborg, Denmark (2011)

- Rattfält L, Björefors F, Wang X, Nilsson D, Norberg P, Ask P Electrical characterization of screen printed electrodes for ECG measurements. In 11th AUTEX conference (Association of Universities for Textiles). Mulhouse, France; 2011:871-873.

- Rattfält L, Ahlstrom C, Eneling M, Ragnemalm B, Lindén M, Hult P, Ask P. A platform for Physiological Signals including an Intelligent Stethoscope, Proceedings of the 4th European Congress of the International Federation for Medical and Biological Engineering, Antwerp, Belgium. (2008) 
- Rattfält L, Chedid M, Hult P, Lindén M, Ask P. Electrical Properties of Textile Electrodes, Proceedings of the 29th Annual International Conference of the IEEE EMBS Cité Internationale, Lyon, France (2007).

- Rattfält L, Hagström C, Lindén M, Hult P. Implementation of a Technical System in Distributed Care - Attitudes and Possibilities, Proceedings of Nordic Baltic Conference in Biomedical Engineering and Medical Physics, Umeå, Sweden, (2005)

- Hult P, Ahlstrom C, Rattfält L, Hagström C, Pettersson N-E, Ask P The Intelligent Stethoscope, The 3rd European Medical and Biological Engineering Conference Prague, Czech Republic (2005) 


\section{Acknowledgments}

I would like to show my gratitude to Prof Per Ask for his guidance and support throughout the progression of this thesis work. I would also like to acknowledge phD Peter Hult and phD Maria Lindén for introducing me to physiological measurement and to phD Fredrik Björefors for inspiring me to finalize this work.

Valuable contributions to this work comes from Christer Ahlström, thank you! I am also grateful to Lena Berglin for providing the textile samples and Acreo for their knowledge and production of the printed electrodes.

Thanks to the Physiological measurements group at the department, and the technical and administrative staff from which I have received the best of support.

Thank you former and present colleagues at the department for making the working environment a true pleasure!

Thank you Birgitta Janerot Sjöberg and David Nilsson for your valuable comments in the writing process.

A special thanks to Stefan Klintström, head of Forum Scientium, where I have been enrolled for his engagement, spirit and inspiring optimism. I have also been supported by AgoraLink, NovaMedTech, Örebro county council, VINNOVA and the Swedish research council, Vetenskapsrådet.

Last but not least: Thank you Ninnen, Anna, Anneli and Sara for being such good friends!

Thank you Margareta and Monica for being good role models.

Thank you mum and dad, for always supporting me in my endeavors. I am lucky to be your daughter.

Thank you Karin and Jenny, for always watching my back. I am happy to be your sister.

Thank you Julia and Sofie, for reminding me of my purpose in life, I am grateful to be your mum.

I would like to dedicate this thesis to Tommy, who has supported me beyond all limits, no matter what. You inspire me to always do my best! My love to you grows stronger for each day! 



\section{Abbreviations}

$\begin{array}{ll}\text { AV-node } & \text { Atro- ventricular node } \\ \text { BSPM } & \text { Body surface potential map } \\ \text { BSS } & \text { Blind source separation } \\ \text { CCA } & \text { Canonical correlation analysis } \\ \text { CCABSS } & \text { Blind source separation solved by canonical correlation analysis } \\ \text { CMRR } & \text { Common mode rejection ratio } \\ \text { ECG } & \text { Electrocardiogram } \\ \text { EEG } & \text { Electroencephalogram } \\ \text { EMD } & \text { Electrode motion disturbance } \\ \text { EMG } & \text { Electromyogram } \\ \text { ICA } & \text { Independent component analysis } \\ \text { OCP } & \text { Open circuit potential } \\ \text { PES } & \text { Polyester } \\ \text { PHS } & \text { Personalized healthcare system } \\ \text { PPV } & \text { positive predictive value } \\ \text { PT } & \text { Pan-Tompkins (heartbeat detector) } \\ \text { rms } & \text { root mean square } \\ \text { SA-node } & \text { Sino- atrial node } \\ \text { SHE } & \text { Standard hydrogen electrode } \\ \text { SS } & \text { Stainless Steel } \\ \text { SW } & \text { Smartware } \\ \text { WC } & \text { Weighted correlation approach } \\ & \end{array}$





\section{Table of Contents}

$\begin{array}{ll}\text { Abstract } & \text { iii }\end{array}$

List of publications $\quad$ v

Acknowledgments vii

Abbreviations $\quad$ ix

1 Introduction $\quad 1$

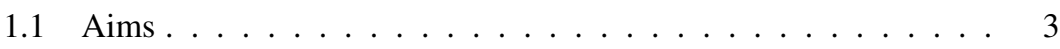

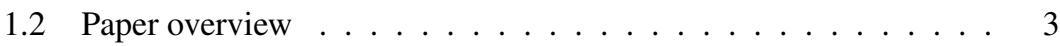

1.3 Thesis outline ................... 5

2 The heart as a signal source $\quad 7$

2.1 The heart .................... 7

2.1.1 Anatomy and Physiology . . . . . . . . . . . 7

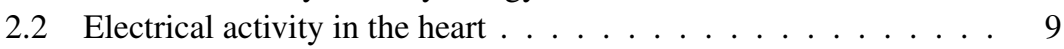

2.2.1 The cardiac cell at rest . . . . . . . . . . . . . 9

2.2.2 Action potentials in cardiac muscular tissue . . . . . . . 10

2.2.3 Conduction of action potentials . . . . . . . . . 11

2.2.4 The body as a volume conductor . . . . . . . . . . . 12

2.3 The electrocardiogram . . . . . . . . . . . . . . 12

2.3.1 Lead positions . . . . . . . . . . . . . . 14

3 ECG measurements and electrode properties $\quad 17$

3.1 Electrical model of the skin-electrode interface . . . . . . . . . . 18

3.2 The smartware electrical model . . . . . . . . . . . . . . . . 19

3.3 The electrode-electrolyte interface . . . . . . . . . . . 20

3.3 .1 Interface potentials . . . . . . . . . . . . 21

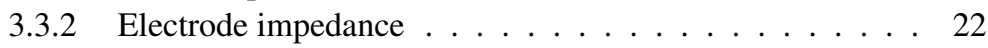

3.4 The skin-electrolyte interface . . . . . . . . . . . . 23

4 Smartware ECG electrodes $\quad 25$

4.1 State of the art ECG electrodes . . . . . . . . . . . . . 25

4.2 Textile materials for ECG electrodes . . . . . . . . . . . . . 26

4.2.1 Materials and fibers . . . . . . . . . . . . . 26

4.2 .2 Yarns ........................ 26 


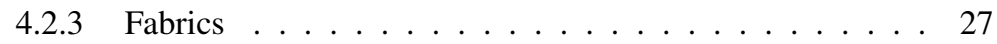

4.2 .4 Conductive Yarns . . . . . . . . . . . . . . 28

4.2.5 Possible applications for conductive textiles . . . . . . 30

4.3 Textile electrodes .................. . . . 31

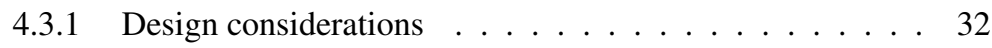

4.3.2 Electrode placement/displacement . . . . . . . . 33

4.3.3 Textile electrodes as a part of a measurement system . . . 34

4.4 Previous research on performance of textile electrodes . . . . . . 35

4.5 Our contribution to textile electrode research . . . . . . . . . . 37

4.5.1 Yarn resistance measurements . . . . . . . . . . . 37

4.5.2 Textile electrode potential measurements . . . . . . . 38

4.5.3 Electrode impedance measurements . . . . . . . . . . 40

4.6 Screen printed ECG electrodes . . . . . . . . . . . . . . . . . 41

4.6.1 Screen printing methods . . . . . . . . . . . 42

4.6 .2 Inks . . . . . . . . . . . . . . . . . . . . . . . . 43

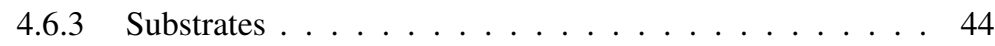

4.6.4 The screen printed electrode . . . . . . . . . . . . 45

4.7 Previous research on printed electrodes and related work . . . . . 46

4.8 Our contribution to printed electrodes research . . . . . . . . . . . 48

4.8.1 Testing electrode potential . . . . . . . . . . . 48

4.8.2 Results of electrode potential measurements . . . . . . . . 50

4.8.3 Testing electrode impedance . . . . . . . . . . . 51

4.8.4 Results of electrode impedance measurements . . . . . . . 51

5 Signal processing of the smartware ECG

5.1 The smartware ECG signal and common sources of disturbance . 55

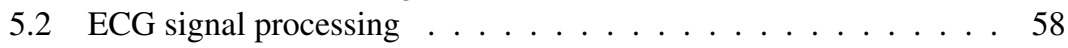

5.2 .1 Pre-processing . . . . . . . . . . . . 59

5.2 .2 Heartbeat detection . . . . . . . . . . . . . 60

5.2 .3 Post-processing . . . . . . . . . . . . . 61

5.3 Previous research in smartware electrode ECG signal processing . 61

5.4 Our contribution on textile electrode ECG signal processing . . . 62

5.4.1 Blind source separation by canonical correlation analysis . 62

5.4.2 Variance weighted sliding correlation method . . . . . . 65

6 Discussion $\quad \mathbf{7 5}$

6.1 Electrodes . . . . . . . . . . . . . . . . 75

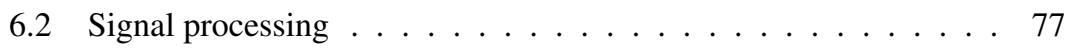

6.3 Future studies and outlook ............... 78

$\begin{array}{lll}7 & \text { Papers } & 93\end{array}$ 


\section{Introduction}

Over the next decades, the population in the European countries is expected to live longer and hence will the prevalence of age related disease increase [32]. At the same time, the healthcare resources will be limited, creating a necessary need to reconsider how healthcare is provided. Today, an average of $9 \%$ of the gross domestic product in European countries is spent on healthcare [1]. Furthermore, $75-85 \%$ of the healthcare related costs in developed countries is spent on cardio-vascular disease, diabetes, cancer and obesity [68]. Addressing this group of chronically disorders with the intention of monitoring and treating them before they become acute is forseen to be one part of the solution. However, to do so in an efficient way, healthcare needs to be accessible outside the hospitals.

It is often talked about as a paradigm shift that healthcare is moved from hospitals and care centers to our homes. The care can be considered to be distributed to places outside of hospitals. Distributed care or ubiquitous care is in this regard a concept which most probably will be implemented in the future. However, it is not only the location of care giving that have to be reconsidered, also how the care is provided. For example, by repeatedly accessing the health status parameters of a patient, changes in the over all condition can be acted upon before they become acute. This patient centered approach is an example of what often is called personalized health, also a concept which is foreseen to be part of the future healthcare regime [68].

To actively involve patients in their own care will both encourage to monitor and to improve their health status [10]. In order to collect such data, a personalized healthcare system, PHS, is needed. What this system might consist of differs from one condition to another, but can for example include an electrocardiographic recorder, blood pressure apparatus or pulsoximetry measurements. An introduction to wearable PHS is given in $[30,61]$ and to emphasize the strong research interest in PHS, a recent review article included 120 wearable sensor systems that were reported in the literature between 2008 and 2011 [8]. Disregarding all technical related demands on such a system (for example robustness and reliability) there are also a handful of emotional criteria that need to be met in order for the 
patients' will to adopt the technology. Bergmann et al. [10] reports that for patients with cardio-vascular disease it is also important that the equipment needs to be compact, not affect daily activities, reduce repeated visits to hospitals and to have minimal risk of detachment.

In this context, smartware (also referred to as smartwear), might be one solution to provide an unobtrusive way of collecting, storing and transmitting physiological data [4]. Smartware is a wide concept, ranging over a variety of sensor solutions and measurement modalities with the thing in common that they are in some sense being worn by the user. A wide range of measurement modalities and electrochemical sensors suitable for smartware are reviewed in [30, 118]. Smartware measurements often include a trade off between optimal measurement conditions and usability. In ECG measurements it can for example be the pretreatment of skin, gelled electrodes, correct placement of electrodes or movement disturbances. However, new sensor solutions also provide opportunities that can be exploited by for example using redundancy of electrodes, accessing clinically valuable data which otherwise would not be known.

It is in the scope of smartware that the content of this thesis lies. Being one possible part of a new type of healthcare strategy, both when it comes to where the care is performed, and also how it is performed. Within the subject of technical development of smartware, several components need to be considered. Collecting, storing, transmitting and using the information efficiently need to be done in a convenient, discreet, robust and comfortable way. Presented in this thesis, two of the components are addressed; evaluating the electrical performance of two types of smartware sensors for ECG measurements and investigating how redundancy in the number of smartware electrodes can be used with sensor fusion signal processing in order to compensate for the non-optimal measurement situation.

The electrode is a crucial part of the measurement system in ECG recordings. If not correctly designed and applied, the registered signals might be highly distorted [71]. Applied directly to the skin, it conveys the ionic current induced in the body via an electrolytic layer to electron borne current within the measurement system. In this interface between skin and electrode, several electrochemical phenomena can occur which induce potentials or distort the original ECG signal [24, 37]. Furthermore, due to some of the requirements of smartware sensors, for example washability, the commonly used praxis of using adhesive electrodes are not evident in distributed measurements, making the prerequisites non-optimal. Electrical performance of smartware electrodes is hence of great importance for the over all signal quality.

Regular ECG recordings with conventional electrodes will still be done within the hospitals in controlled environments by expert technicians, but for hearbeat monitoring during normal conditions, i.e. at home, a smartware ECG system is a suitable measurement modality. Even though there are many advantages with such a system, it might also introduce obstacles which need to be resolved. Practically, 
the smartware ECG might differ from the conventional one in several ways due to:

- sensor placement

- absence of skin pre-treatment makes the system more prone for disturbances

- registrations should be possible even during movement

- the increased amount of information needs to be handled efficiently.

Signal processing provides possibilities to compensate to some extent for such factors. Presented in this thesis are two signal processing approaches for improving the robustness to noise in hearbeat detection applications. The first method uses a canonical correlation approach to solve the blind source separation problem. The second one uses a variance based noise measure to weight the impact of a single channel of a model correlated multi-channel ECG.

\subsection{Aims}

The research questions that provide the basis of this thesis are:

i). To investigate the electrical characteristics of textile electrodes.

ii). To design and study electrochemical properties of screen printed electrodes.

iii). To design and evaluate signal processing methods for hearbeat detection from smartware ECG recordings.

\subsection{Paper overview}

The thesis contains four publications in two categories related to smartware: The first category focusing on the electrical performance of smartware electrodes for ECG measurements, textile and screen printed, and the other one to use the possibility of adding extra electrodes to use the redundancy in sensor number to compensate for the non-optimal measurement situation. A short paper summary is found below:

Paper I Electrical characterization of yarns and textiles In this introductory study, the aim was to investigate the electrical behavior of three conductive yarns and three types of textile electrodes. The yarns were off-the-shelf yarns normally used in for example shielding clothing and textiles and were made of pure stainless steel (SS), a blend of polyester (PES) and SS and a PES yarn with a silver plated copper filament. Investigated parameters were thread resistance due to length and applied force. Three electrodes, one 
from each yarn were used to perform potential drift and impedance measurements. All electrode measurements were performed on skin. Results showed that the pure SS electrode performed the best, closely followed by the SS/PES blended electrode. All yarns were proportional regarding length vs. resistance. However, for the SS/PES blend, the yarn had a decreasing resistance with increasing applied force in the investigated range.

Paper II Electrical characterization of screen printed electrodes Screen printed electrodes in six types of configurations were investigated in an electrochemical cell and evaluated due to their electrode potential drift and electrode impedance. The included inks were silver and carbon based, used for conduction lines and a $\mathrm{Ag} / \mathrm{AgCl}$ ink for the electrode surface. They were printed on a plastic substrate with a covering varnish layer over the conduction lines, only displaying the electrode surfaces. To test the impact of print thickness, some specimens were prepared with a second layer of electrode surface ink or varnish. The electrodes were submerged in physiologic saline solution and the open circuit potential was registered for 30 minutes followed by impedance measurements in the range of 0.05 to $2 \mathrm{kHz}$. The results show good electrode stability and fair electrode impedance values.

Paper III Sensor fusion using canonical correlation analysis Electrocardiographic data were recorded by seven textile electrodes placed around the thorax while performing different activities with the goal of tracing the heart rate ( $n=5$ with 6 protocol tasks). The dataset was looked upon as a blind source separation (BSS) problem and canonical correlation analysis (CCA) was used to solve it. The strength of this method is that it uses the timedependency in the signal since the canonical correlation is done on the dataset and a one unit time delay of itself. This method is more efficient than independent component analysis (ICA) approach which is normally used in BSS problems. The study concluded that the proposed method gave a lower percentage of signal loss $(7 \%)$ compared to averaging $(33 \%)$ and by solving the BSS problem by ICA $(17 \%)$. However, the result from the CCABSS algorithm is presented in source components, not being stated which component that contains the heartbeat information, nor is the information regarding the expected signal morphology used. The aim of having a single output signal and adding the knowledge of the ECG morphology inspired study IV.

Paper IV Sensor fusion using a weighted correlation approach ECG signals recorded with 9 textile electrodes were used to create a modified standard 12 channel dataset. From each recorded channel, a waveform model was extracted and used for correlation of the rest of the signal to create heartbeat 
candidates. The heartbeat candidates were weighted by a variance based factor due to its resemblance to the variation of the hearbeat model. If the weighted hearbeat candidate was higher than a threshold, it was accepted and added to the output signal. The same procedure was made for all channels and their respective output were added in a single output file, creating peaks where the accepted heartbeats occurred. The algorithm's performance was tested on a dataset with 14 healthy male volunteers while performing a protocol consisting of seven different movements and exercises to induce disturbances, both muscular and moving electrodes. Concurrently, a reference ECG was recorded with regular commercial self-adhesive ECG electrodes for annotation purposes. The recorded material was divided in two halves, where one was used to optimize threshold values and the other half to evaluate the performance of the algorithm with respect to a golden standard hearbeat detection algorithm. Both the golden standard algorithm (Pan-Tompkins) and the suggested method performed equally good during rest, however, both sensitivity and positive predictive value were higher for six out of seven protocol tasks inducing disturbances in the signal. In the seventh case they performed equally.

\subsection{Thesis outline}

Since the application throughout the thesis is focused on the ECG (either collecting or using it), Chapter 2 gives a brief survey over heart anatomy and physiology to better understand the signal at hand. Of the same reasons, electrocardiographic measurements are explained in Chapter 3 and especially the importance of the electrodes registering it. Chapter 4 gives an introduction to textile and printed smartware electrodes in Sections 4.2 to 4.3 and 4.6, respectively, and our research is presented in Sections 4.5 and 4.8. In Chapter 5, signal processing research within textile electrode applications is briefly presented together with the two methods presented in the included articles. Finally, in Chapter 6 the content of the thesis is discussed and the four included articles are appended in Chapter 7. 



\section{The heart as a signal source}

\subsection{The heart}

The heart is a fist sized muscle within the thoracic cavity and its center lies approximately $1.5 \mathrm{~cm}$ to the left of the center line [63]. Its task is to pump blood throughout the body. The blood not only supplies the body with oxygen and remove metabolic wastes, it also for example regulates $\mathrm{pH}$, body temperature and hormone transport [110]. During a lifetime one can expect the heart to contract about three billion times, so its endurance and reliability is of great importance.

\subsubsection{Anatomy and Physiology}

The heart is divided into two halves, the left and the right. Both halves consist of an atrium and a ventricle, see Figure 2.1. Both atria are placed above the respective ventricle. The right atria is filled via the two caval veins and is connected to the right ventricle through the tricuspid valve. The right ventricle is connected to the pulmonary artery via the pulmonary valve and pumps its stroke volume into the pulmonary circulation, in parallel to the systemic circulation. The left atria is attached to and filled through the pulmonary veins and connected to the left ventricle via the mitral valve. The left ventricle transports blood to the aortic arch via the aortic valve out to the systemic circulation. The ventricles are separated by a septal wall. The lower tip of the heart is called the apex. The endocardium is the inner surface of the heart muscle wall and the epicardium the outer surface. [110]

Heart muscle cells are slightly different from skeletal muscles cells. Firstly, the cardiac muscle cells are stimulated by the heart's own autorhythmical cells and are hence activated without any conscious actions. Furthermore, the cells have gap junctions allowing the onset of a signal to propagate from cell to cell. Secondly, the contraction period of a cardiac muscle cell is longer, normally around $0.3 \mathrm{sec}$ compared to 0.03 seconds in a skeletal muscle cell. This is due to the slightly different permeability of mainly $\mathrm{Ca}^{2+}$ in the cell membrane, see Section 2.2. [110] 


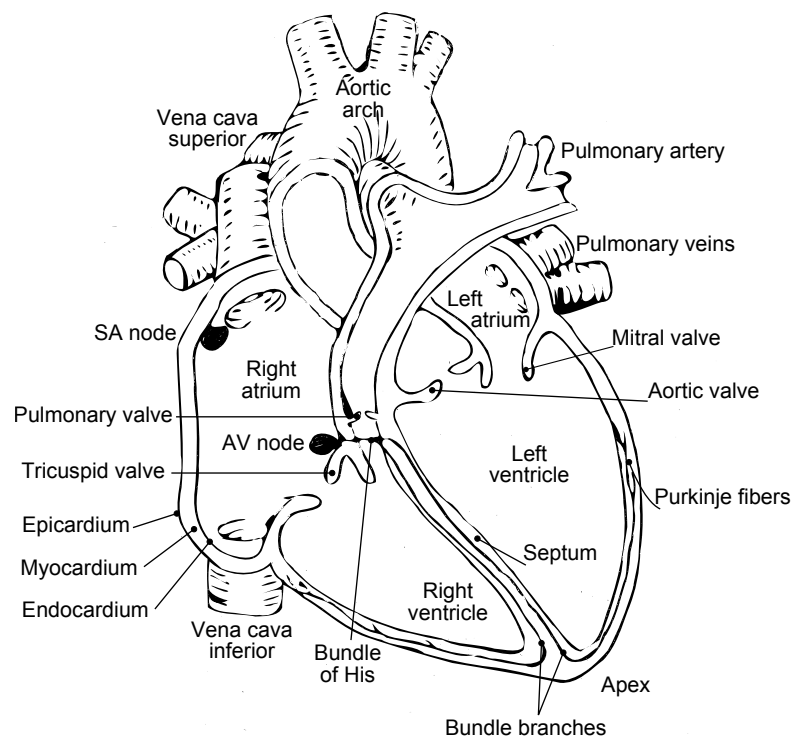

Figure 2.1: The basic heart anatomy.

The orientation of the cardiac muscle cells are highly interesting. In fact, most of the heart wall has three different layers of fibers. Starting from the inside, the first layer is a horizontally circle of fibers around the ventricles. The two remaining layers are helix shaped spirals in both directions. This orientation is important for an efficient contraction of the ventricles. [63]

Within the heart there is a distinguished conduction network of electric autorhythmic cells. The sino-atrial node (SA-node) is a 15 by $5 \mathrm{~mm}$ crescent shaped bundle of autorhythmic cells in the inner wall of the right atrium. The atrio-ventricular node (AV-node) is situated in the wall between the atria and ventricles. It is connected to the bundle of His in the septum, which divides into two branches, the left and right bundle branches. Furthermore, the branches into the myocardium are called the Purkinje fibers, see Figure 2.1. [110, 63]

There are two modes in a heartbeat cycle including two iso-volemic phases. Diastole is the ventricular filling phase when the ventricles actively relaxes and are filled with blood from the atria. Systole is the ventricular contraction phase when the atria are filled and ventricular blood is pumped out into the pulmonary and systemic circulation.

The blood's journey throughout the heart involves several different types of flows and whirls when studied in detail. When the heart contracts, the volume of the chambers change. Simplified, the flow is driven by the resulting pressure differences between the contracting heart compartments and the connected vessels. 


\subsection{Electrical activity in the heart}

All muscle contraction is triggered by proceeding electrical activity. In skeletal muscles, each fiber is connected to a motor unit, a part of the nervous system which controls a certain amount of fibers. In cardiac muscle tissue, the triggering is set by specialized autorhythmic cells in the heart's conduction system. To understand the genesis and conduction of electricity in the heart, one must start by considering a cardiac muscle cell and its onset by an action potential.

\subsubsection{The cardiac cell at rest}

The cell membrane consists of a bilayer of phospholipids which is the barrier between the cell and the surrounding tissue and fluids. However, a total barrier prevents both communication between cells and transportation of oxygen, nutrition and waste products. There exists several ways to enable transport and communication. Presented here are the parts which concern the electrical activity and conduction within cardiac tissue.

The membrane has ion channels which allow ions to diffuse along their electrochemical gradient. There are mainly two types of ion channels; leakage channels and gated channels. As the name reveals, a leakage channel is always open. Different channels exist for the various ions. In a normal membrane there are many more leakage channels sensitive to Potassium ions, $\mathrm{K}^{+}$, than for example to Sodium ions, $\mathrm{Na}^{+}$, (approximately 50 -100 times), and the membrane has a higher $\mathrm{K}^{+}$permeability. This phenomenon is important for the resting membrane potential.

The other type of channel is gated which in turn can be divided into voltage gated, ligand gated or mechanically gated ion channels. When describing the action potential, only the voltage gated channel is of importance. The voltage gated channel opens if a certain potential difference appears over the cell membrane, and thus increases the permeability of a certain ion, an important feature in action potentials.

At rest, the most prevalent ions in the cytosol (the inside of a cell) is $\mathrm{K}^{+}$and negatively charged proteins. The extra cellular fluid consists mainly of $\mathrm{Na}^{+}$and chloride ions, $\mathrm{Cl}^{-}$. Even though the main parts of the fluids are in electric equilibrium, there is a potential drop over the cell membrane. This depends on the ions and proteins which obey two kinds of equilibria, due to their concentration and due to their electrical charge. Without gated channels, $\mathrm{K}^{+}$ions would diffuse out of the cell due to its high concentration in the cytosol and the high permeability in the membrane. But by doing so, the outside will be positively charged and an electric force levels it by diffusion of a positively charged particle into the cell. As mentioned before the permeability is much higher of $\mathrm{K}^{+}$than that of $\mathrm{Na}^{+}$, so the $\mathrm{K}^{+}$ion will reenter the cell again. In reality, other ions also play a role in the 
final potential over the membrane, but due to the relatively high permeability of $\mathrm{K}^{+}$, this is the ion which plays the main role in the resulting resting membrane potential. A typical resting potential of a cardiac cell membrane is $-90 \mathrm{mV}$. [63]

\subsubsection{Action potentials in cardiac muscular tissue}

An action potential is a threshold triggered, rapid, change of membrane potential of a cell. The cell remains slightly positively charged for a period of time until it reassumes its initial state, see Figure 2.2.

When the cell is exposed to a certain outer potential, the voltage gated channels will open, allowing $\mathrm{Na}^{+}$to flow into the cell. This influx is both in accordance with the electrical and concentration gradients and is very fast. This is called the depolarization phase of the action potential.

When the voltage gated channels close, there is a potential of $+20 \mathrm{mV}$ over the cell membrane and a plateau phase starts. Here the permeability of Calcium ions, $\mathrm{Ca}^{2+}$, increases and a slow influx of $\mathrm{Ca}^{2+}$ starts. At the same time, the permeability of $\mathrm{K}^{+}$decreases, which matches the influx of $\mathrm{Ca}^{2+}$. The potential over the membrane is close to zero during this phase. In cardiac cells, the plateau phase lasts about $250 \mathrm{~ms}$ compared to $1 \mathrm{~ms}$ in skeletal muscle tissue. Eventually, the influx of $\mathrm{Ca}^{2+}$ stops while $\mathrm{K}^{+}$is still flowing out of the cell, resulting in a decreasing membrane potential. When equilibrium is reached, the potential difference is once again $-90 \mathrm{mV}$. The last part of the action potential is called the repolarization phase. $[11,63,110]$

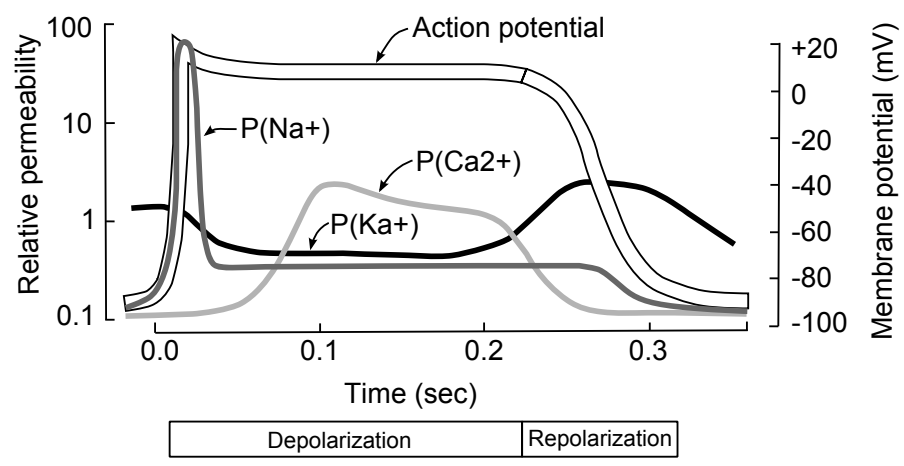

Figure 2.2: Action potential of a heart muscle fiber together with the relative permeability of three ions over the heart muscle cell membrane during depolarization and repolarization. This material is reproduced from [110] with permission of John Wiley \& Sons. 


\subsubsection{Conduction of action potentials}

The cardiac muscle cells are connected via two types of junctions, see Figure 2.3. The desmosomes hold the cells together and the gap junctions allow action potential to spread from one cell to an adjacent [110]. The gap junction consists of a hundred fluid filled tubular proteins called connexones where ions and small molecules can diffuse between the cells. The importance of gap junctions are many. They allow a fast propagation of the action potential and also form synchronized units of cells. If one cell is depolarized, all connecting cells will also depolarize consecutively and the action potential is propagated throughout the whole heart.

One could also believe that the repolarization phase is a propagating phenomenon, but it is a consequence of the depolarization rather than something that is triggered by outer circumstances. However, since the depolarization is propagated, the repolarization also appears to do so. [63]

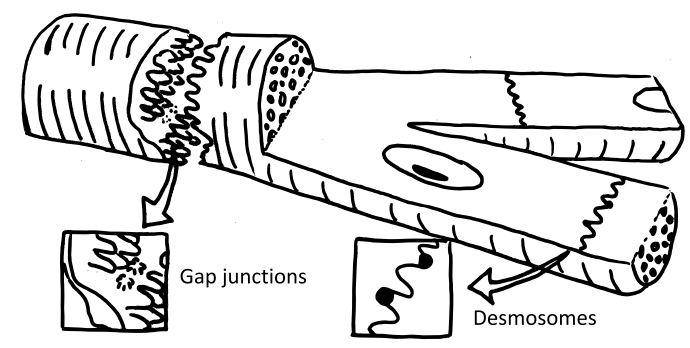

Figure 2.3: The cardiac muscle cell. The y-shaped cell is connected to its neighbours by desmosomes and gap junctions. This material is reproduced from [110] with permission of John Wiley \& Sons.

The SA-node in the right atrium spontaneously produces $70-80$ beats/min and is also influenced by the sympathetic- and parasympathetic nervous system in order to adjust the heart rate to a proper working point. The action potential propagates along the muscle fibers of the atria. The atria and ventricles are electrically insulated, except from the AV-node, in the lower right atrium. When the action potential reaches the $\mathrm{AV}$-node, it is slowed down until it finally reaches the bundle of His and the bundle branches. This delay may seem inadequate, but it is crucial since it allows the atria to contract and thus gives extra filling to the ventricles with blood before the ventricular contraction begins. The depolarization in the septum starts in the left ventricular inner wall and it continues on both sides to the apex and the outside of the heart via Purkinje fibers. At this stage the conduction velocity is fast, reaching $3 \mathrm{~m} / \mathrm{s}$, which is much faster than cell-to-cell conduction, thereby allowing a nearly simultaneous contraction.

It is not only the SA-node that is autorhythmic, the whole conduction system can generate action potentials but with varying frequencies. Listed in Table 2.1 are 
some intrinsic frequencies together with respective conduction velocities.

\begin{tabular}{|r|c|c|}
\hline Location & conduction velocity $(\mathrm{m} / \mathrm{s})$ & intrinsic frequency (onsets/min) \\
\hline SA-node & 0.5 & $70-80$ \\
AV-node & $0.02-0.05$ & 50 \\
Bundle of His & $1-1.5$ & \\
Purkinje fibers & $3-3.5$ & $20-40$ \\
\hline
\end{tabular}

Table 2.1: Conduction velocities and intrinsic frequencies of the heart's conduction system. [63]

In a normal functioning heart, the heartbeat is triggered by the SA-node since its rhythm is faster than the other pacemakers'. If for some reason it does not work or the frequency is too low, the AV-node will take over the pacing and so on.

\subsubsection{The body as a volume conductor}

The charge distributions in the cells during a heartbeat can be summarized over the whole heart. It can thus be modeled as a dipole which generates a time-varying electric field. The field can be represented by a vector, often called the dominant vector.

The heart is embedded in the body and for simplicity reasons, the body tissue can be regarded as homogeneous. The electrical model of the heart can therefore be regarded as a dipole in a homogeneous infinite sphere. [63] This property is used when studying the heart's electrical activity by placing electrodes on the skin which is described in Chapter 3.

\subsection{The electrocardiogram}

Consider the heart as a dipole according to Section 2.2.4 with a dominant membrane vector. Throughout a cardiac cycle, the dominant vector will alter both its magnitude and direction. If two electrodes are placed on the body surface, a projection of the vector is captured as the potential difference between the electrodes. The potential variations due to cardiac activity in a certain projection is called an electrocardiogram, ECG.

The classical ECG has the appearance according to Figure 2.4, where every part of the curve corresponds to individual events in the heart cycle.

In Figure 2.5, the genesis of the ECG curve is described. Before the onset of an action potential, there is little electrical acitvity, resulting in a flat line in the ECG (a). When the SA-node is electrically depolarized, initiating the atria to contract, the dominant vector (though small due to the small muscle mass in the atria) will be faced downwards toward the AV-node. This results in a positive deflection 


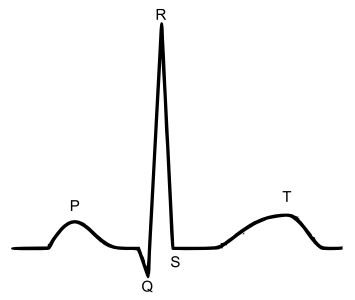

Figure 2.4: The ECG waves.

(a)

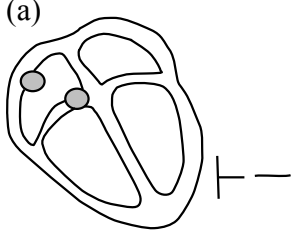

(b)

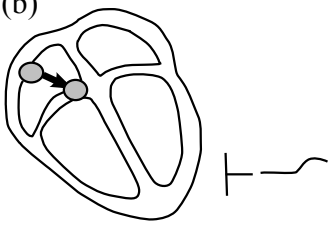

(e)

(d)

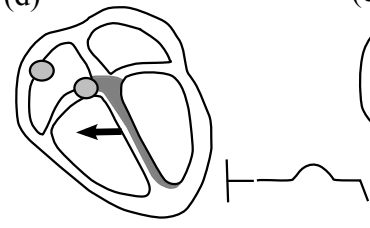

(g)

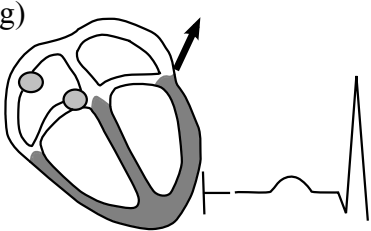

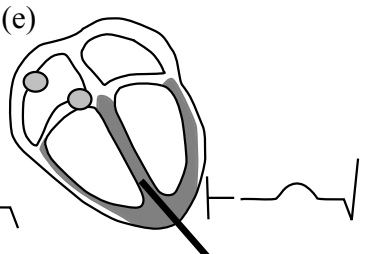

(h) (c)

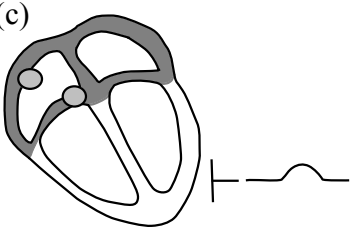

(f)

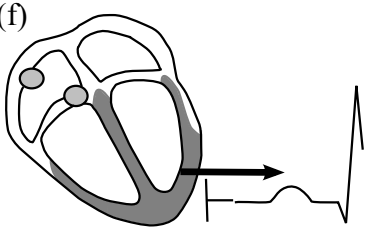

Figure 2.5: ECG genesis, see description in the text. From [106] with permission.

in the ECG curve if the electrode is placed according to the figure, the P-wave (b). In the time between the atrial and the ventricular depolarization, the ECG returns to the baseline (c). Once in septum, the ventricular depolarization starts in the left inner wall toward the right ventricle. The resultant is pointing from the electrode, resulting in a negative curve form compared to baseline called the Q-wave (d). As the propagation from the septum continues to the ventricle walls, the resultant vector is directed toward the electrode. The change is rapid and the amplitude is larger due to conduction speed and larger muscular mass. In the ECG curve, ventricular depolarization is reflected in the R-peak (e). The depolarization continues to the upper parts of the heart and the ECG becomes negative once again (f)-(g). Following the ventricular depolarization is a period where the ECG returns 
to the baseline before the repolarization of the ventricles. Perhaps surprisingly, the repolarization occurs first at the outer wall (due to the fact that the outer cells permeability of ions are slightly different than the others'), producing a resultant pointing toward the electrode, the T-wave (h). The repolarization of the atria is normally not visible in the ECG because it is drowned in the large R-wave. [106]

\subsubsection{Lead positions}

The ECG curve appearance depends on the location of the electrode. Only potential differences non perpendicular to the exploring electrode can be registered. The projection of the ECG can thus be altered by placing the electrodes around thorax. To derive a pulse, it is sufficient to detect an $\mathrm{R}$ wave, but for distinguishing if a myocardial infarction is present, several electrodes might be necessary.

There is a variety of electrode positioning systems, and only three of them will be introduced here. The first is Einthoven's triangle. The model uses the assumption that the heart is a fix dipole and the thorax is a homogeneous infinite sphere. Furthermore, it can be shown that if electrodes are placed on the limbs according to Figure 2.6(a), the bipolar leads will represent the electric activity projected on a equilateral triangle. [63]

The three bipolar limb leads are denoted I, II and III and are calculated as:

$$
\begin{aligned}
I & =V_{L A}-V_{R A} \\
I I & =V_{L F}-V_{R A} \\
I I I & =V_{L F}-V_{L A}
\end{aligned}
$$

Where $V_{L A}, V_{R A}$ and $V_{L F}$ are the potential recorded from the left and right arm and from the left foot.

The Einthoven positioning system gives information about the frontal plane in three directions. Even though redundant, three more leads (and directions) can be derived by letting the middle point between two electrodes serve as one measuring point and the third electrode as the other, see Figure 2.6(b). These are called the augmented (a) unipolar limb leads and are denoted aVR, aVL and aVF. This way of deriving leads was presented by E. Goldberger and are sometimes also called Goldberger augmented leads. With this positioning system, the reference point is rather stable throughout the cardiac cycle. 


$$
\begin{aligned}
& a V R=V_{R A}-\frac{V_{L A}+V_{L F}}{2} \\
& a V L=V_{L A}-\frac{V_{R A}+V_{L F}}{2} \\
& a V F=V_{L F}-\frac{V_{L A}+V_{R A}}{2}
\end{aligned}
$$

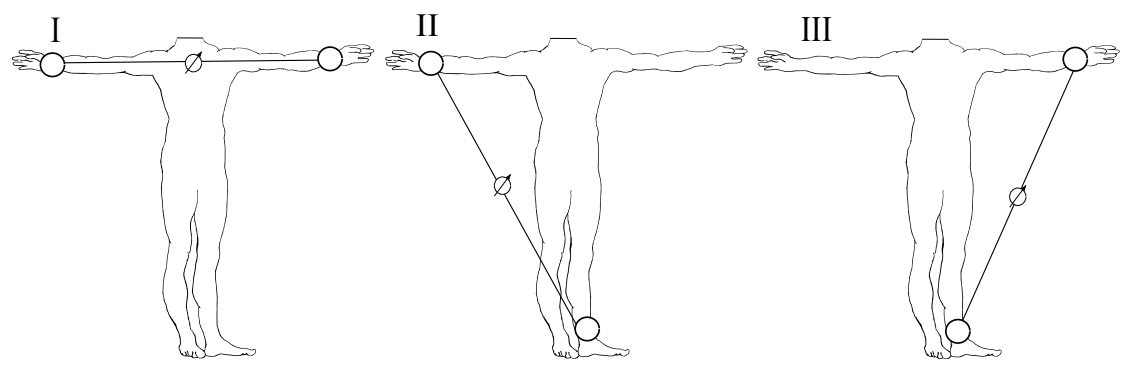

(a) Einthoven's triangle and the extremity leads.

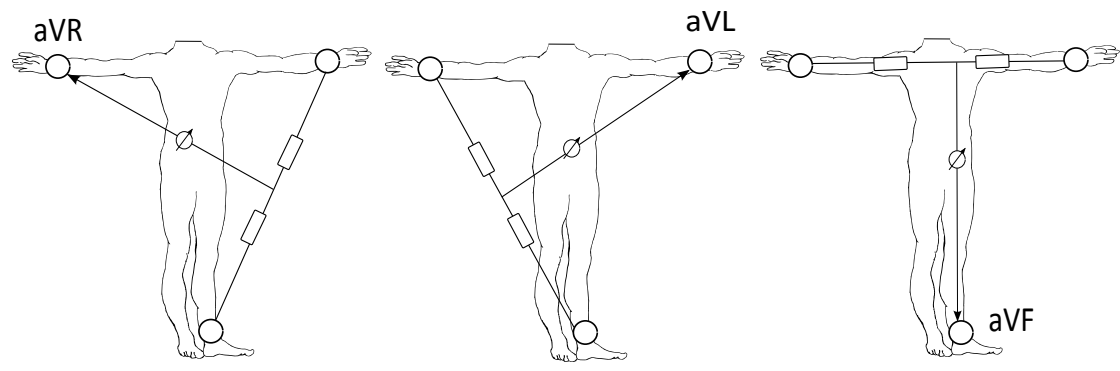

(b) Augmented extremity leads.

Figure 2.6: Most prevalent lead positions.

Thirdly, by placing electrodes around the front of the thorax (the precordial leads) according to Figure 2.7, projections in the transverse plane are gained assuming that the reference point is created as the middle point obtained from lead I-III. The precordial leads are commonly denoted V1 through V6.

By combining all leads described above, 12 leads are obtained. These form the basis of modern clinical electrocardiography, even though other leads systems are available for example for stress tests, long term monitoring and vectorcardiography. 


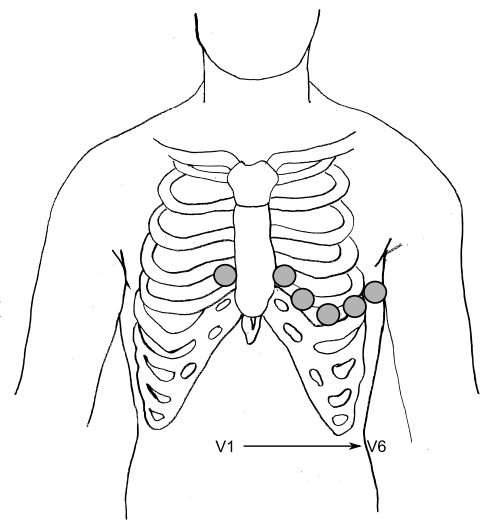

Figure 2.7: Precordial leads. 


\section{ECG measurements and electrode properties}

To obtain reliable measurements of bioelectric events, such as the ECG, the electrodes play a major role in the measurement chain. If used incorrectly, they can introduce distortion several orders of magnitude larger than the ECG signal itself.

The typical measurement system for ECG measurements consists of two or more electrodes attached to the skin and connected to a differential amplifier, see Figure 3.1 .

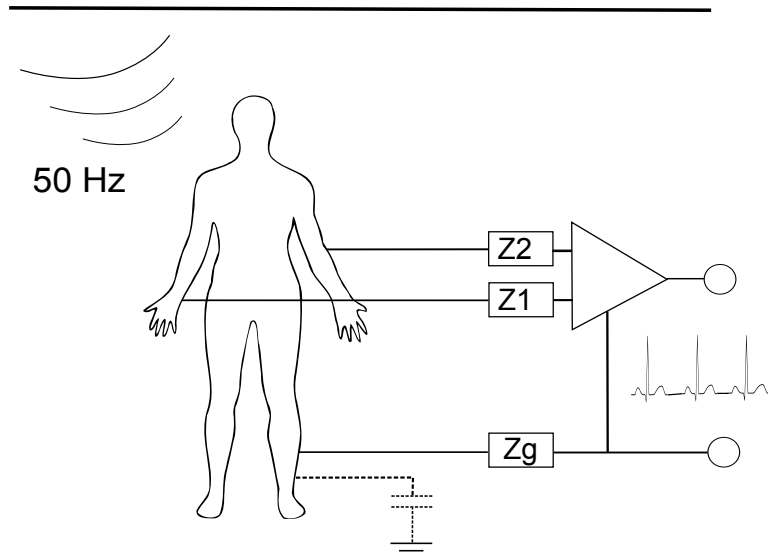

Figure 3.1: Overview of the ECG measurement setup.

Included in the figure is also the capacitive coupling to the mains where the body acts like an antenna. It is the impedances together with the coupling and the characteristics of the amplifier that decide how well the measurement system is working in terms of noise suppression.

In Figure 3.2, the measurement setup is modeled as an electrical circuit, where $Z_{1}$, $Z_{2}$ and $Z_{g}$ are impedances of the skin-electrolyte-electrode interfaces, $E_{s}$ is the source signal and $E_{c}$ is the capacitive coupling to the mains [24]. $E_{c}$ can often be 


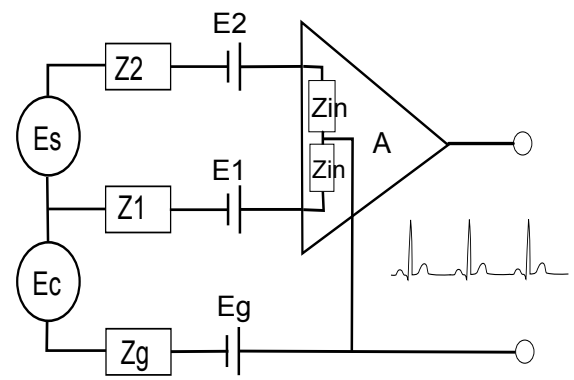

Figure 3.2: Electrical model of the measurements system. $E_{s}$ is the source signal and $E_{c}$ is a disturbance due to capacitive coupling to the mains.

much larger than the original source signal, $E_{s}$. The ability of the measurement system to suppress such disturbances requires knowledge of both the impedances $Z_{i}$ and the characteristics of the amplifier and it will be discussed further in Section 3.3.2.

Regarding the characteristics of the amplifier when it comes to noise suppression from the mains, the main property of interest is its input impedance. However, looking at the ECG amplifier system as a whole, many demands have to be met, for example patient safety, reliability and usability [78, 81].

\subsection{Electrical model of the skin-electrode interface}

Scientists have since the mid 19th century tried to model electrode and tissue behavior in terms of electrical properties, corresponding to $Z_{1}$ and $Z_{2}$ in Figure 3.2. An historical background in the development of electrical models in tissue impedance is given in [69]. Two models decomposing the impedances $Z_{i}$ into electrical equivalents are given in $[36,9]$.

It is worth noting that the impedance $Z_{i}$ include elements which origin from body tissue, skin-electrolyte interface, the electrolyte, the electrolyte-electrode interface and the electrode and leads. In Figure 3.3, a model of an equivalent electrical circuit consisting of the model for skin and tissue from [82] is shown. Note that the skin is modeled as a parallel circuit in order to capture the behavior from for example sweat glands and ducts. The top part comes from [70] describing the electrolyte-electrode interface, including the non ideal capacitor called the constant phase angle impedance. All parameters are explained below. 


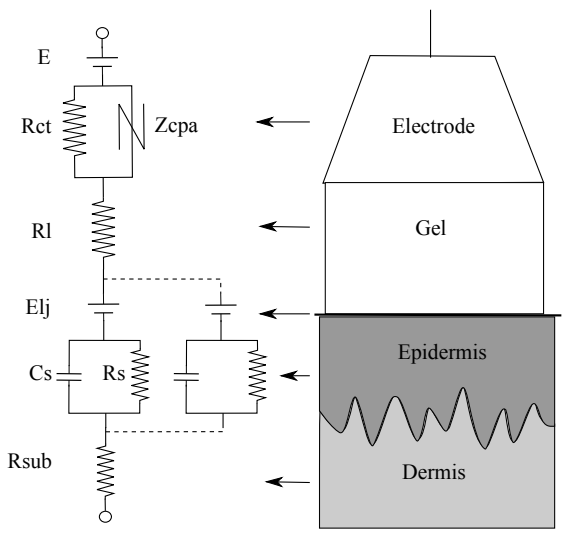

Figure 3.3: Electrical model of the interface from the body to the electrode.

$\begin{array}{ll}\begin{array}{l}\text { Parameter } \\ R_{s u b}\end{array} & \begin{array}{l}\text { Description } \\ \text { Internal body resistance, approximately constant }(\approx 100 \Omega) \\ R_{s}\end{array} \\ C_{s} & \begin{array}{l}\text { Resistance of skin, depends on skin preparations, electrode gel } \\ \text { and time after application. }\end{array} \\ E_{l j} & \begin{array}{l}\text { Capacitance of skin, depends on skin preparation, electrolyte con- } \\ \text { centration and contact area. } \\ \text { Liquid junction potential due to the concentration gradient of ions } \\ \text { between body fluids and the electrolyte. } \\ \text { Resistance of electrolyte. }\end{array} \\ R_{l} & \begin{array}{l}\text { Charge transfer resistance of the oxidation/reduction at the elec- } \\ \text { trode/electrolyte interface. }\end{array} \\ R_{c t} & \begin{array}{l}\text { A constant phase angle impedance due to the double layer be- } \\ \text { tween electrolyte and electrode. }\end{array} \\ Z_{c p a} & \begin{array}{l}\text { Half cell potential of the reaction at the electrode and electrolyte } \\ \text { interface. }\end{array}\end{array}$

\subsection{The smartware electrical model}

Although the principles behind the ECG measurements are the same when using smartware as for regular setups, there are, however, some differences both in the interface between electrode and skin, but also in a more macroscopic view concerning for example lead placement. Here, the differences regarding the electrical model will be discussed. The macroscopic differences will be discussed in Section 4.3 .

Regular electrodes use electrode paste or hydrogels as a means to facilitate the electrical conduction between the skin and electrode. In smartware, it is not evident that these preparations are feasible. One often mentioned way is to use the 


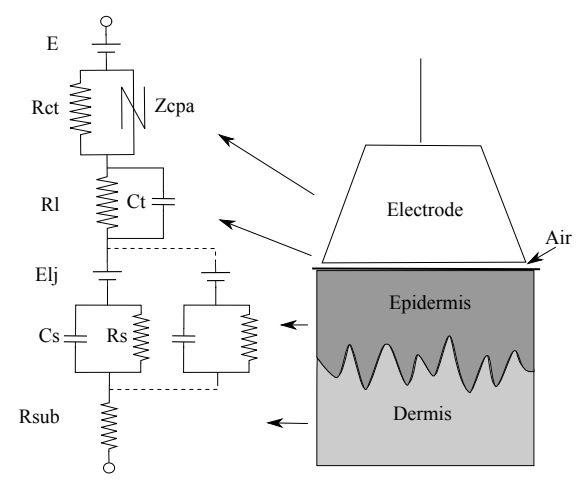

Figure 3.4: Electrical model of setup with a textile electrode.

body vapor or sweat as electrolyte [72, 73]. In Figure 3.4, a proposed circuit model from [9] of a textile electrode is shown. The difference is that there is a capacitor, $C_{t}$, in parallel with the series resistance, $R_{l}$, which origins from the lack of conventional electrode paste or hydrogel.

In the following sections, the different parts of the electrical model in Figure 3.3 will be regarded more thoroughly.

\subsection{The electrode-electrolyte interface}

When a metal is submerged in an electrolyte it can be considered as a half cell where two phenomena potentially can occur. Instantly, a double layer will be established at the interface between metal and electrolyte, where the electrode will have a skewed charge distribution toward the interface. The polarity of the electrode depends on the composition of the electrode and electrolyte. Simultaneously, the electrolyte will have an opposite charge distribution toward the interface. There is also a potential difference due to the dynamic equilibrium for the reaction at the interface.

In the ECG measurement setup, two or more electrodes are attached to the skin and body, which acts as an electrolyte. The half cells are then inter-connected by an electrolyte and create an electrochemical cell and its net potential can be observed with a voltmeter, see Figure 3.5(a). Ideally, metal and electrolyte compositions are the same in the two half cells, but only slight deviations in for example electrolyte composition, electrode material and skin preparation can cause severe disturbances and potentials which origin from the interface between the skin, electrolyte and electrode which are added to the source signal. 


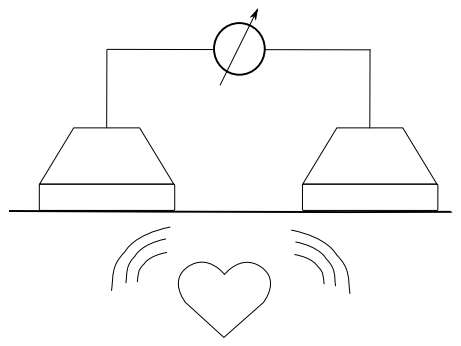

(a)

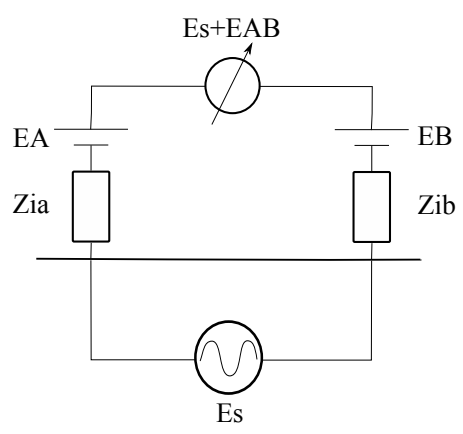

(b)

Figure 3.5: To the left, two electrodes placed on the skin form an electrochemical cell, with the body tissue acting as an electrolyte. To the right, an electrical model of the two electrodes placed on skin. For demonstrational purpose, the half cell potentials are extracted from the model of $Z_{i}$ in Figure 3.3. The measured potential originate from both the heart and from the net contribution from the electrochemical cell.

\subsubsection{Interface potentials}

Since absolute measurement of the potential drop not is possible, it is done with a reference electrode. The standard hydrogen electrode, SHE, is the most commonly used reference electrode in reference tables. Practically, reference electrodes of $\mathrm{Ag} / \mathrm{AgCl}$ or the Calomel electrode are used.

As described in the introduction of this section, the two electrode-skin interfaces in the electrocardiographic setup can be considered as two half-cells connected by body tissue into an electrochemical cell. In order to estimate the net contribution to the desired signal, lets consider the half cell potential for two redox couples, where compounds $A$ and $B$ are assumed to be oxidized, and compound $C$ and $D$ are reduced.

The respective potential of each cell is given by the Nernst equation:

$$
\begin{aligned}
& E_{A}=E_{A}^{0}+\frac{R T}{n F} \ln \frac{a_{A}}{a_{C}} \\
& E_{B}=E_{B}^{0}+\frac{R T}{n F} \ln \frac{a_{B}}{a_{D}}
\end{aligned}
$$

where $E^{0}$ is the standard reduction potential, $T$ is the absolute temperature, $R$ is the gas constant, $n$ is the number of involved electrons, $a$ is the activity of the involved compounds and $F$ is the faraday constant. The net contribution to the electrocardiographic signal is the potential difference of the two half cells.

$$
E_{A B}=E_{A}^{0}-E_{B}^{0}+\frac{R T}{n F} \ln \frac{a_{D} a_{A}}{a_{C} a_{B}}
$$


An example of such a Faradic reaction is between a pure $\mathrm{Ag} / \mathrm{AgCl}$ electrode in a $\mathrm{NaCl}$ electrolyte, (where $n=1$ ) is:

$$
\mathrm{AgCl}+e^{-} \rightleftharpoons \mathrm{Ag}+\mathrm{Cl}^{-} .
$$

Furthermore, the activity of pure solids are assumed to be unity $\left(a_{A}=a_{B}=1\right.$ for $\mathrm{Ag} / \mathrm{AgCl}$ electrodes) which gives the net cell potential as:

$$
E_{A B}=E_{A}^{0}-E_{B}^{0}+\frac{R T}{n F} \ln \frac{a_{D}}{a_{C}}
$$

The net contribution, $E_{A B}$, is displayed in Figure 3.5(b). Since the measurement is made over the whole system, it is not possible to distinguish which potential difference that comes from the wanted heart signal, $E_{s}$, and which that originates from the electrode setup, $E_{A B}$. Ideally, if the same metals and electrolytes are used, there would be no potential contribution. However, there is always going to be impurities on the surfaces and small concentration differences resulting in a non-zero $E_{A B}$.

\subsubsection{Electrode impedance}

The double layer at the electrode/electrolyte interface also introduces a capacitive behavior to the electrode.

Electrode impedance plays a major role in the measurement setup in total for ECG measurements. It can affect the measurements by phase shifts and signal attenuation errors occurring when averaging with resistances between leads (for example augmented leads) and in how the effective common mode rejection ratio is of the amplifier. To reduce these factors, it is necessary to use electrodes with similar impedances and also with as low impedances as possible.

The CMRR is defined as:

$$
C M R R=10 \log _{10}\left(\frac{A}{A_{c m}}\right)
$$

It can be shown (for example in [24]) that the effective common mode rejection ratio is:

$$
C M R R_{\text {tot }}=\frac{1}{\frac{1}{C M R R}+\frac{\Delta Z}{Z_{i n}}}
$$

where $C M R R$ tot is the effective CMRR, $C M R R$ is the amplifier's CMRR, $\Delta Z$ is the impedance difference between two skin-electrolyte-electrode interfaces (cabling impedance is neglected) and $Z_{i n}$ is the input impedance of the amplifier. As 
can be seen it is preferred for the electrode impedances to be similar in size and small compared to $Z_{\text {in }}$.

\subsection{The skin-electrolyte interface}

A liquid-junction is a region between two fluids with different ion concentrations or compositions. The liquids can be separated by a semi-permeable membrane or have such properties that there is a concentration gradient between them. Associated with this interface is a potential drop, a so called liquid-junction potential. The interface between skin electrolytes and for example an electrode gel, can be seen as a liquid-junction, denoted $E_{l j}$ in Figure 3.3. It is described by a version of Nernst equation:

$$
E_{l j}=\left(\frac{u^{+}-u^{-}}{u^{+}+u^{-}}\right) \frac{R T}{n F} \ln \frac{C_{+}}{C_{-}}
$$

where $u^{+}$and $u^{-}$are the mobilities for the cations and anions respectively and $C$ is the concentration. 



\section{4}

\section{Smartware ECG electrodes}

\subsection{State of the art ECG electrodes}

In Figure 4.1, a generic sketch of a conventional ECG electrode is shown. The top consists of a metal knob (dark gray) which is attached to a cable. It pierces the other layers to the bottom, where it is embedded in a conductive media, often a gel or a hydrogel. In between there is a layer of a plastic or paper disk which serves as a stabilizer (light gray) and an adhesive collar which is fastened to the skin. This construction deals with some of the possible sources of distortion. The adhesive skin tape makes the electrode firmly attached to the skin, while the stabilizer keep the skin in its center as still as possible. Still in this sense means that one point of the skin is prevented to move in relation to another within the center of the electrode. The gel improves conduction and serves as a medium to transfer the ionic charge in the skin to electrone borne in the electrode.

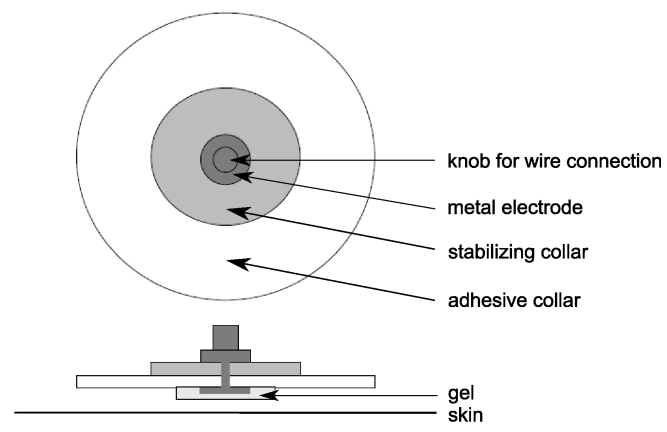

Figure 4.1: Top: the ECG electrode seen from above. Bottom panel, side view.

Depending on the materials used, the performance of the electrode will differ. One important factor is the choice of electrode surface and gel, in order to have an electrically stable electrode. Another factor is for example the plaster and glue which play a major roll for skin irritation in long term use. 


\subsection{Textile materials for ECG electrodes}

For the last decade, research have been intensive regarding conductive textiles. The applications for such fabrics are numerous in both healthcare and sports and it opens a new way of thinking regarding functional materials. In this section, some basic textile theory is presented in order to understand the properties of conductive textiles.

All textiles have different properties regarding strength, comfort, durability, moist absorption, price, elasticity etc. As a simplification it can be said that a textile gets its characteristics in four steps in the manufacturing process. The first is of course due to the materials used, the second is how the materials are converted into a yarn, the third is how the yarn is used to create a fabric and last what kind of final treatment that is applied to the fabric. In the included studies no final treatment have been applied and is not further discussed. The presentation of the textile theory (Section 4.2.1 to 4.2.3) is based on material from Clothing Technology, from fiber to fashion [51].

\subsubsection{Materials and fibers}

The smallest component in a fabric is the fiber. There are two groups of fibers, natural and artificial, also called manmade fibers. The natural fibers can either come from a plant or from an animal, see Figure 4.2. Examples of these are cotton, flax and sisal. Example of animal fibers are wool or silk. Artificial fibers are subdivided in regenerate fibers such as viscose and Lyocell, synthetic fibers (polyamid, polyester, acryl, elastan etc) and inorganic fibers (glass and metal).

The natural fibers more or less come as they are, that is either as staple fibers (finite fibers such as wool or cotton) or as filaments (thread fibers such as silk). The artificial fibers can be of both types.

\subsubsection{Yarns}

Fibers can be used to manufacture yarns. Depending on which type of fibers used, different methods must be applied. As a simplification, yarns can be either bundled together and twined (filament fibers) or spun (staple fibers). In Figure 4.3(a) a filament yarn is shown. Characteristic for this type is its long filaments and rather smooth finish. There are several ways of constructing such yarns. Parameters that can be varied are for example the number of filaments in each bundle, the number of bundles and how tightly they are twined.

A spun yarn consists of staple fibers which have been carded and spun. In comparison to a filament yarn, the spun yarn is hairy when studied in close-up. Parameters that affects the spun yarn is for example the type of fibers used (it is often a mixture of different fibers) and how hard the yarn is spun. A loosely spun yarn is 


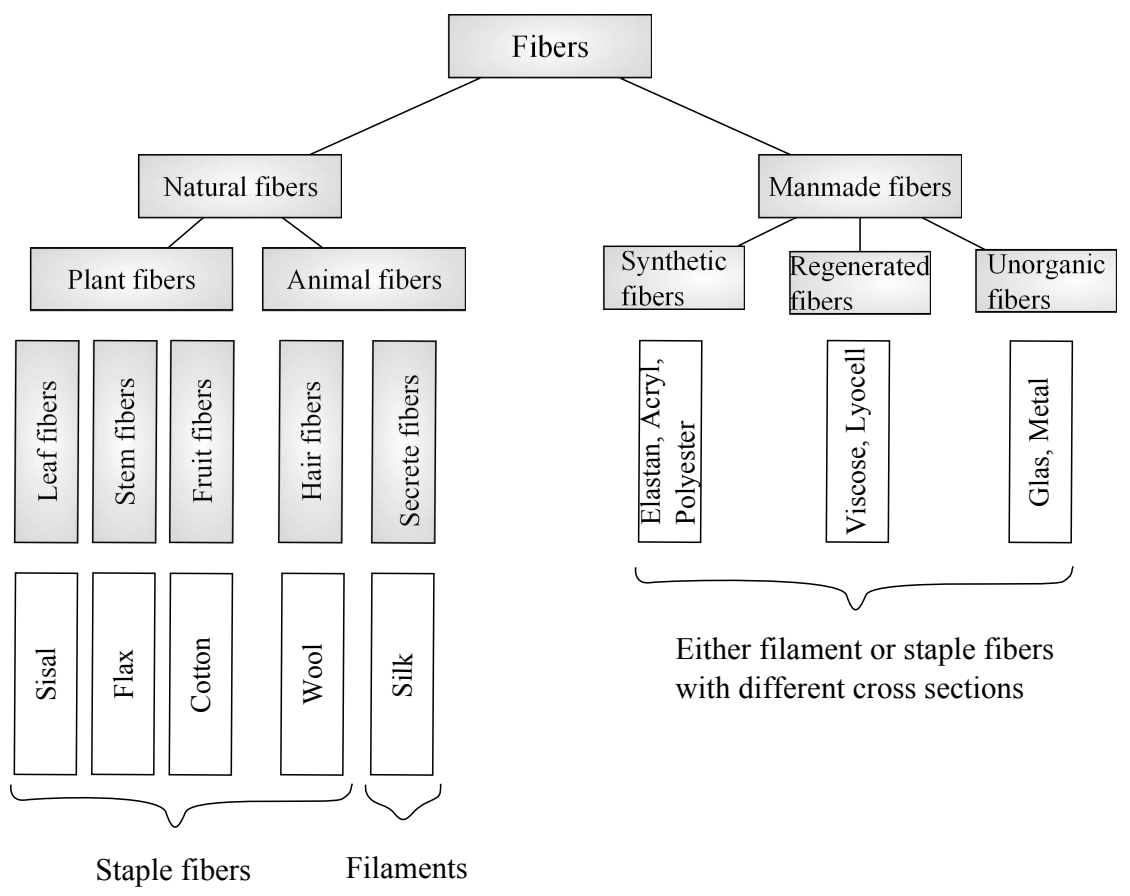

Figure 4.2: Overview of textile fiber categorization.

more bulky but normally more prone to break. Note also that a spun yarn can be one filament in a twined yarn.

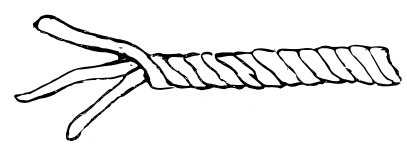

(a) Twined yarn. The long strands are bundled together and the finish is smooth.

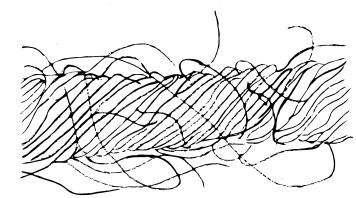

(b) Spun yarn. Staple fibers are parallelized and spun. The finish is hairy.

Figure 4.3: The two most common yarn modalities.

\subsubsection{Fabrics}

There exist numerous ways of making different fabrics, each with its own properties. In general, they can be divided into three groups depending on their structure. A woven fabric is in its simplest form constructed by two sets of parallel yarns perpendicular to each another, see Figure 4.4 (left). The warp is the vertical set 
and the horizontal is the weft which is interlaced with the warp. This type of fabric is nonelastic (if the yarn is not very elastic) and also leaves a flat surface. Depending on the closeness between the warp and weft, the fabric can be of both high and low density. By altering the interlacing pattern, a variety of different weaves can be created. Examples of different weaves are denim, satin, and twill.
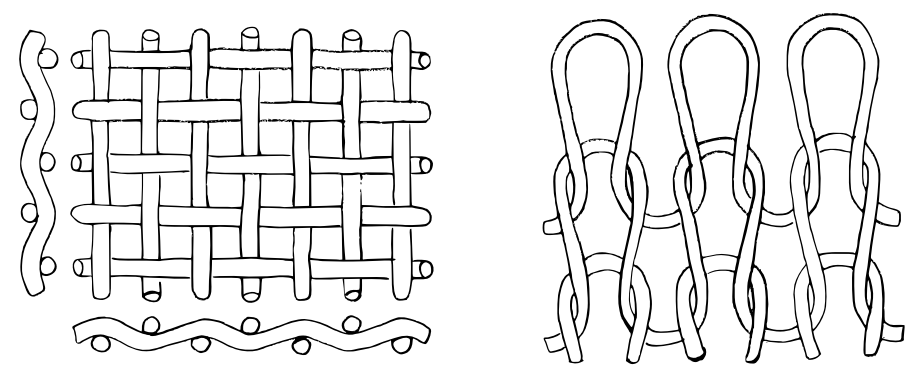

Figure 4.4: The two most common textile structures. On the left is a plain weave structure consisting of two sets of perpendicular strands. The horizontal set is the weft and the vertical is the warp. To the right is a weft knit.

A knitted fabric (often denoted as a tricot) consists of interconnected loops. In a weft tricot the loops are knitted horizontally, whilst in warp knitted fabrics, they are oriented vertically, see Figure 4.4 (right) for a weft knit example. Knitted fabrics are often elastic and their surface finish can be flat, but also in a variety of structures. Examples of knitted fabrics are jersey, terry and piqué.

A third way of constructing a fabric is to use staple fibers directly entangled in a random pattern, which creates a nonwoven fabric. An example of this is felt, where wool fibers are felt up using soft soap.

In the simple case, a fabric is a two dimensional structure. However, worth mentioning is that both woven and knitted fabrics can be constructed in several layers [89]. This will be utilized in for example textile based pressure sensors described in Section 4.2.5.

\subsubsection{Conductive Yarns}

Conductive fibers have been used for years and were originally developed to produce antistatic protective clothing. Nowadays, these fibers are used in several technological domains such as electrical signal transmission and power supply [17]. Conductive textile materials can be used for replacing metals in many applications where the special properties of textiles are preferred to those of metal conductors. To be classified as a conductive yarn, one or more component in the yarn has to be conductive.

Conductive yarn can have a component of either: 
- $100 \%$ metal fibers/filaments or

- fibers/filaments coated with a conductive layer.

The $100 \%$ metal filaments can be used as filaments or cut into staple fibers. These metallic fibers are developed from available metals such as ferrous alloys, nickel and nickel alloys, stainless steel, titanium, aluminum and copper. Metal filaments have a diameter ranging from $1 \mu \mathrm{m}$ to $100 \mu \mathrm{m}$ and are produced by using a bundledrawing process, a shaving process, melt overflow process or a stretch casting process. Hands on experience on some of the commercially available yarns are presented in [89]. In a study by Schwarz et al. [101], electroconductive yarns were constructed by winding pure metal (SS, silver and copper) multi-filaments around a rubber core. The resulting yarn is very elastic and its electrical resistance was measured while stretched, after cyclic straining and multiple washes. The outcome of the study showed that the yarns were keeping the same value of resistance up to $100 \%$ stretch and that cyclic straining and washing increased the resistance somewhat, depending which material the filaments had.

The second method is coating or plating a thin conductive layer on the surface of non conductive fibers. Conductive coated fibers can be achieved through several processes: evaporative deposition process, sputtering process, filling or loading process, and carbonizing process. The produced fibers can achieve high conductivity but suffers from adhesion and corrosion resistance problems. [74, 107]

Conductive polymers have been proposed as suitable coatings for fibers in order to make them conductive. Two often mentioned polymers are polyaniline and polypyrrole.

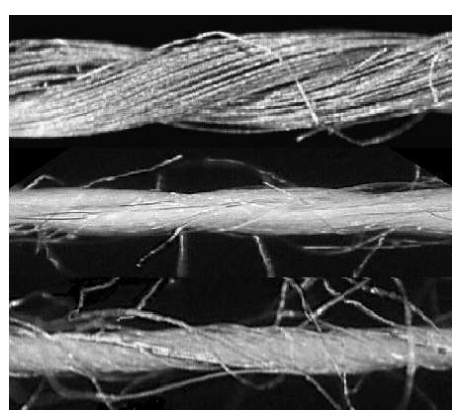

Figure 4.5: Conductive yarn. Adopted from [95] with permission.

In Figure 4.5, three conductive yarns are shown. The upper panel shows a multi filament yarn of $100 \%$ stainless steel. In the middle panel there is a staple fiber yarn with a mixture of $50 \%$ of mass of stainless steel fibers and the other half of polyester. In the bottom panel, a polyester yarn is shown with a mono-filament of silver plated copper twined around it. 


\subsubsection{Possible applications for conductive textiles}

Conductive textiles have during the last decade become an interesting research area since it has applications in medicine $[16,83,86,88]$, health prevention and military interests [119]. One main feature is that the technology can be bodyborne, opening new possibilities for monitoring physiological parameters, signal transmission, embedded communication systems, heat regulation, impact detection etc [14].

Conductive textiles can be used for several purposes. For the last decade, extensive research has been carried out in the domain of textile sensors in biomedicine. In fact, an all textile measurement set up has been described by Carpi et al. [14] where they used conductive polymer plated yarns.

Even though this section is focusing on the textile ECG electrode, some other types of textile components will be presented as a demonstration to what can be achieved. A description over smart textiles (where conductive textiles are a part) is presented in $[109,111]$. Furthermore, textile electrodes will be thoroughly discussed in Section 4.3.

Pressure sensors A textile pressure sensor actually senses a varying capacitance between two conductive layers when a pressure is applied to the surface. A simplification is a three layer surface, where the outer layers are conductive and the middle an insulator. By measuring the capacitance in a mesh like pattern between the top and the bottom, a map over the capacitance, and indirectly the pressure can be obtained. There are also alternative ways to construct such a surface, for example by using conductive paint. Sergio et al. [103] present a pressure sensor used to visualize a fist and the palm of a hand.

Cabling An important part, but easily overlooked, is the cabling between devices. For a truly all textile sensor, the cables needs to be integrated textiles as well. The demands are great and the configuration depends upon the specific task. Cottet et al. [26], have investigated different configurations of signal transmission lines in a woven fabric with good results. However, not primarily intended for body-worn applications, Winterhalter et al. [119] realized a flat textile USB cable, fulfilling all requirements of a regular cable.

Strain sensors A textile strain sensor uses the resistance differences between two locations that is observed when the fabric is stretched. If a mixture of staple fibers is used as in the middle panel in Figure 4.5, the material has a specific resistivity while in a certain state. If the fabric is stretched, the metallic staple fibers are more likely to be in contact with increases. Placed around the thorax, such a sensor can be used as a breathing indicator [83]. Placed on the arms and shoulders, they could provide information regarding body posture and movement. [88] 
Cho et al. [21] reported on a plain knitted movement sensor made out of pure SS yarn. Its characteristics showed an initial increase in resistance when stretching the sample in the warp direction due to the increasing specimen length. After a certain elongation of the sample, the resistance decreased with further elongation, probably because the contact points within the specimen increased and acted as shortcuts. Investigated parameters in the study included to measure the elbow angle.

Buttons and controls Two textile buttons have been realized by Wijesiriwardana et al. [116]. The two underlying sensing techniques are based on having a two-parted electrode and by touching both parts simultaneously, a circuit is closed. The other type of button is based on the same principle as that of a pressure sensor; when two conductive surfaces are separated by a dielectric layer, the capacitance between the two layers will differ if the conductive layers are pressed together.

Heat generation Negru et al. [79] have coated a woven cotton fabric with different concentrations of carbon black particles with the aim of creating a conductive fabric. The square resistance in the experiments proved to be rather high in the $10^{4} \mathrm{k} \Omega / \mathrm{sq}$ range. However, in the concluding remarks the textiles were proposed to be used as heating elements in clothes.

Capacitive ECG Electrodes Capacitive ECG electrodes registers displacement currents instead of using galvanic contact. This approach has made it possible to make ECG registrations totally unobtrusive. Studies where electrodes have been placed in chairs [6] and beds [60] are reported in the literature. However, even though the skin-electrode interface is eliminated, other sources of disturbances are introduced. Since the coupling capacitances are in the $\mathrm{pF}$ order, the system is often prone to pick up parasitic capacitances, putting high demands on the biopotential amplifier [105]. For example, the input impedance of the amplifier should be in the $10 G \Omega$ range [80].

\subsection{Textile electrodes}

A textile electrode in its simplest form is a conductive fabric placed on the skin and connected to a measurement system. The same electrochemical requirements and principles on how an ECG is registered, as described in Chapter 3, applies disregarding electrode type. However, when it comes to design and functionality, there are some differences compared to regular ECG electrodes. In a review article by Xu et al. [121], some of the challenges with textile electrodes were considered and will be further addressed here. 


\subsubsection{Design considerations}

For a textile electrode, at least one component in the textile needs to be conductive. To decrease the electrode impedance, it is favorable to use materials that are good conductors and at the same time have good electrode properties, for example low electrode potential when placed on the skin.

The yarn creation method also affects the properties of a textile electrode. By using a filament yarn, the within electrode resistance will be low. For yarns made out of staple fibers, the metal fibers may pierce the outer layers of stratum corneum and in that sense improve the interface to the skin. For staple fiber yarns and especially if the staples are a mixture of conductive and non-conductive fibers, the electrode resistance might depend on how stretched the yarn is. This feature is unwanted in ECG recordings, but is suitable to use in applications where movement is to be detected. The changing impedance is then correlated to a certain movement. This feature is widely used in smartware. [21, 88]

Woven structures are normally not as stretchable as knitted ones. Depending on the type of weaving technique, intersections between the perpendicular threads vary in density. If the yarn is only partly made out of a conductive yarn, this can effect the within electrode impedance negatively. With a purely conductive yarn however, this should not be a problem.

Oh et al. [85] have identified four types of conductive textiles:

- knitting or weaving conductive threads

- coating of conductive polymers

- electroless plating

- sputtering.

In this thesis only the first type of textile material is used and the investigated specimens are shown in Figure 4.6. In the left panel, a pure SS plain knit is shown. The middle panel show a wave knitted SS/polyester blended fabric and on the right is a woven polyester fabric with a silver plated copper wire twined around the yarn.

Summarized in Table 4.1 are some of the materials and construction techniques reported in literature.

There is no evident way to use electrolytes with textile ECG electrodes corresponding to the electrode gel used with conventional electrodes. Trials have been done with hydrogel membranes added to the electrode surface to decrease the impedance, but that requires change of membranes periodically and after washing [102]. To overcome this, it is often reported that the electrodes should be applied some time prior to the tests, for example in $[5,115]$. This is to take advantage of the sweat generation underneath the electrode surface since sweat includes 


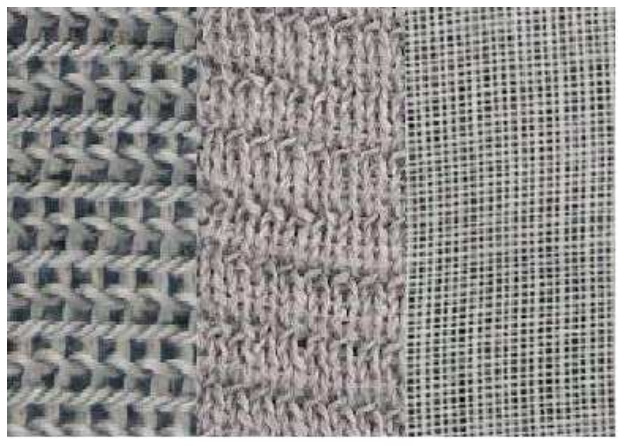

Figure 4.6: Conductive textile electrode structures. Adopted from [95] with permission.

\begin{tabular}{|c|c|c|c|}
\hline \multicolumn{2}{|l|}{ Author } & Material & Construction method \\
\hline \multicolumn{2}{|l|}{ Beckmann et al. [9] } & SS/silver/copper & knit/weave/coating \\
\hline \multicolumn{2}{|l|}{ Marozas et al. [65] } & silver plated nylon thread & embroidery \\
\hline \multicolumn{2}{|l|}{ Hoffmann et al. [43] } & carbon nano tubes & foam \\
\hline \multicolumn{2}{|l|}{ Negru et al. [79] } & carbon black & coated weave \\
\hline $\begin{array}{l}\text { Noury et al. } \\
(\text { VTAMN) }\end{array}$ & [83] & SS/cotton & weaving \\
\hline $\begin{array}{l}\text { Paradiso et al. } \\
\text { (WEALTHY) }\end{array}$ & [88] & blend with $30 \%$ SS & knitting \\
\hline $\begin{array}{l}\text { Ottenbacher et al. } \\
\text { (phmon) }\end{array}$ & {$[86]$} & silver coated fabric & N/A \\
\hline Scilingo et al. [102] & & SS twined around viscose & intarsia weave \\
\hline
\end{tabular}

Table 4.1: Summary of some used materials and construction techniques of textile ECG electrodes reported in literature.

charged molecules and ions and acts as an electrolyte in the skin-electrode interface.

\subsubsection{Electrode placement/displacement}

One of the greatest causes of disturbance in ECG measurements is when the electrode moves in relation to the skin. Normal electrodes use adhesive collars or suction cups to stabilize this interface, but for textile electrodes the fit and placement of the sensor are parameters to optimize. Comert et al. [25] have investigated how different paddings and pressures applied to the electrode improve the detectability of R-waves in a ECG recorded with textile electrodes. The outcome of the study indicated that by padding the electrode, it stabilizes the electrode-skin contact and improves the R-wave detectability. The best results were obtained while using padding and a $15-20 \mathrm{~mm} \mathrm{Hg}$ pressure on the electrode. 
If the predicted main function of the textile ECG is heartbeat detection, standard positions of electrodes can be replaced. Essential is to obtain a robust signal which reflects the heartbeats. Experiments with different placements, for example in the lining of underpants [123] and in bras [112] are reported in the literature and also available on the market [84]. These locations have been identified as suitable to incorporate electrodes in since they are usually already having a tight fit to the body. Furthermore, in a study by Abecherli et al. [2] they emphazised the importance of correct mounting of the textile electrodes in for example a shirt, in order to avoid signal loss due to movement.

Cho et al. [22] have developed four slevless shirts with different so called cutting lines over the ECG sensor. The cutting lines's function was to provide extra stability in the garment near the sensor but also in the directions in which the sensor might be dislocated during movement. The four cutting lines were in the shape of a chest belt, a perpendicular cross (up-down and left-right), an ' $\mathrm{X}$ ' (shoulder to hip) and a curved ' $X$ '. Dislocation from the original placement of the electrodes (corresponding to V3 and V4) were measured after a protocol consisting of six different types of upper body movements. Results showed that the cross configuration outperformed the other setups.

An approach to investigate the optimal lead placements under practical constraints that might be coupled to smartware manufacturing techniques have been made by Finlay et al. [33] by using Body Surface Potential Maps (BSPM). In the study, 192 electrodes were placed in a matrix around the thorax and 5 setups with different electrode areas (the areas were chosen to cohere with different manufacturing demands) were used for registering the ECG. In each setup, electrodes which contained the most ECG information (after signal processing) were identified. The study concluded that it is not always best to include as many electrodes as possible in the studied areas, and the standard lead positions are not necessarily performing the best, however, anterior placement is advocated. In a following study [34], the same authors have, amongst other, investigated the optimal electrode placements for R-peak detection. For this purpose a set of three so called Eigenleads were derived which improved the rms amplitude of the QRS-complex by $39 \%$.

\subsubsection{Textile electrodes as a part of a measurement system}

The textile electrode, like conventional electrodes, is only one part of the measurement setup. In order to register the ECG, the whole system needs to be designed with a holistic perspective, considering all subsystems. The amplifier to which the electrodes are connected needs to be designed/chosen carefully to work well. The electrode-amplifier aspect was studied by Baba et al. [5] with the aim of characterizing electrical properties of unprepared textile electrodes for longterm monitoring in order to specify the prerequisites for the input stage of the amplifier. The recommendations given in the concluding remarks were that the input 
impedance of the amplifier should be at least $300 M \Omega$ to avoid common mode disturbances and avoid distorting phase shifts.

\subsection{Previous research on performance of textile electrodes}

A few studies have been carried out in the area of understanding the properties of textile electrodes, both for ECG and bioimpedance spectroscopy. Although the aim in the following cited articles have been in some sense to prove the usefulness of textile ECG electrodes, the approaches to do so have differed. Normally, the reported results are either in the form of measuring the square resistance, visual comparison to a reference ECG, impedance measurements and identification of parameters in the corresponding electrical model over the skin and electrode system. Attempts to standardize measurements have been done by Beckmann et al. [9] where they use a test setup with a gold electrode, an Agar-Agar model of the skin and the tested electrode to perform two-point measurements of the system.

Listed in Table 4.2 are some of the publications that consider textile electrode properties.

In a study presented by Scilingo et al. [102], textile electrodes were tested at rest. As a contact medium, a hydrogel was placed between the skin and electrode. The textile electrode surface consisted of stainless steel strands twisted around a viscose yarn knitted in a double face technique to get an insulating back piece. The ECG was acquired by using extremity like leads on the base of the arms and hip and polarization effects were measured over time periods of $30 \mathrm{~min}$ and experiments were repeated every day for a week. Conclusions were that electrode potentials not were shown in the power spectrum density analysis and that electrodes were purely resistive in the range between DC and $10^{6} \mathrm{~Hz}$.

Westbroek et al. [114] have investigated the resistance of textile electrodes by means of impedance spectroscopy in an electrochemical cell. Electrode distance, area and electrolyte concentration were investigated for three stainless steel fabric surfaces. Results showed that the resistance of the cell mainly was within the electrolyte, and hence the electrode resistance was low. However, the analysis was focused on the non phase shifting parts of the spectra and the electrode properties under the assumption that current and voltage are phase coherent. In an ECG measurement setup on a subject however, the situation is more complex and phase shifting phenomena are most likely to occur. In the study they also compared performance over time. For the most structured surface and high electrolyte concentration, it showed that adsorption and corrosion altered the electrode resistance after $24 \mathrm{~h}$ of electrolyte exposal, indicating that longterm use might give distorted signals. 


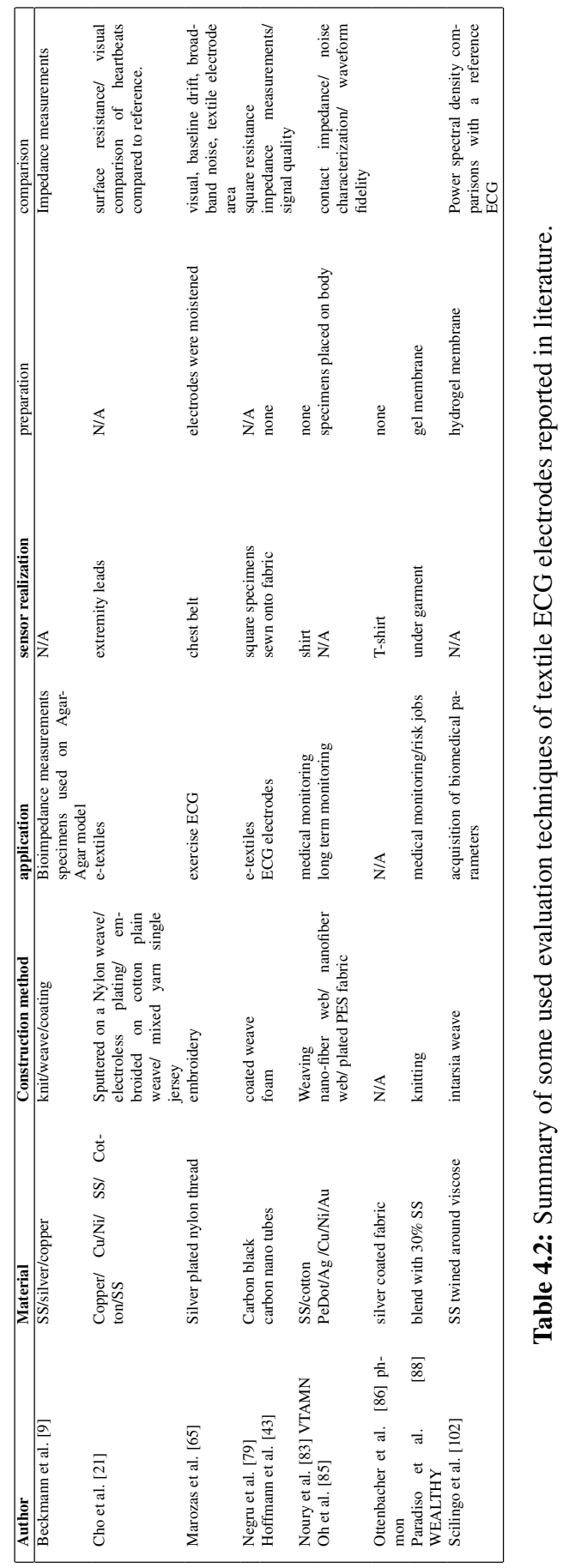


Merritt at al. [76] have reported that by incorporating active electronic components to textile ECG electrodes the performance was comparable to that of conventional electrodes. Some of their specimens also survived a five cycle washing test.

Textile electrodes have also been used for bioimpedance spectroscopy. In a study by Medrano et al. [73], textile electrodes were tested in a bioimpedance measurement setup. The setup is similar to that of an ECG, but it uses an electrode to insert a small current and the other electrode to register the voltage in order to calculate the impedance. The electrodes tested consisted of a knitted silvered polyamide yarn and were $8.5 \times 3.5 \mathrm{~cm}$ in size. The tested frequency area ranged from $5 \mathrm{kHz}$ to $1 \mathrm{MHz}$. Results showed that the capacitive behavior is about 10 times that of a regular electrode, and the resistive part about 5 times higher. They also saw a decrease in capacitive behavior when the humidity between the electrode and skin increased. Furthermore, bioimpedance textile electrodes with silver fibers as conductive medium were compared to $\mathrm{Ag} / \mathrm{AgCl}$ standard electrodes in a study by Marquez et al. [66]. Results show that the textile electrodes performed comparable to the standard electrodes in the frequency range $3-500 \mathrm{kHz}$.

Marozas et al. [65] have shown that textile electrodes not necessarily produce significantly more noise up to $250 \mathrm{~Hz}$ than disposable $\mathrm{Ag} / \mathrm{AgCl}$ electrodes in a study where textile electrodes made out of conductive yarn, stitched with a sewing machine was subjected to analysis of broad band noise.

\subsection{Our contribution to textile electrode research}

We have characterized the electrode properties of three types of conductive textiles. Firstly, a study regarding the textiles' yarns was performed by measuring their resistive properties when length and tension were altered. The samples were the presented yarns in Figure 4.5. Yarn A (top) is a multi-filament $100 \%$ SS yarn. Yarn B (middle) is a spun yarn with the weight ratio of $50 \%$ SS fibers and $50 \%$ polyester. Yarn C (bottom) is a spun polyester yarn with a mono-filament of silver plated copper twined around it.

Furthermore, the electrode properties of the three structures displayed in Figure 4.6 were investigated. Electrode A (left) is plain knitted, resulting in a rather flat surface. Electrode B is wave knitted and the structure creates a highly elastic fabric with ridges that were in contact with the skin. The last tested material, Electrode C is a loosely woven structure. Electrode A consists of Yarn A and so on.

\subsubsection{Yarn resistance measurements}

The yarns' resistivities were measured according to Figure 4.7. The investigated yarn (dashed) was suspended and connected to a measurement bridge (Model 
250DE, Electro Scientific Industries). The tested parameters were resistance according to specimen length $(50 \mathrm{~cm}, 100 \mathrm{~cm}, 150 \mathrm{~cm})$ and applied weights $(0 \mathrm{~g}, 50$ $\mathrm{g}, 200 \mathrm{~g}$ ). Two or three samples of each yarn were used.

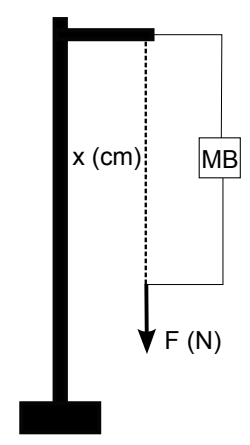

Figure 4.7: Measurement setup for the conductive threads. The thread (dashed) was suspended to a rigid support. Investigated parameters were the resistance due to specimen length, and applied force. In the setup, MB, refers to the measurement bridge used for the measurements.

The results are shown in Figure 4.8. As expected, the resistance was depending on the sample length in a linear manner. However, variations can be found in Yarn B due to its complex structure. When studying the tension's impact on the resistance, an interesting phenomenon was displayed for Yarn B. When a tension is applied, the structure and orientation of the fibers are altered, resulting in an improved conductance. One explanation is that when the yarn is strained the fibers are forced together, including the conductive fibers, and thus improves the over all conductance of the yarn.

\subsubsection{Textile electrode potential measurements}

Textile electrodes were prepared from each fabric with a surface area of $5 \mathrm{~cm}^{2}$. They were slightly moistened with a physiological saline solution and positioned $5 \mathrm{~cm}$ apart on unprepared skin (thigh) and held in place with an elastic rib top fabric. The measurement series started with potential measurements and followed by impedance measurements. Electrodes were then moved $5 \mathrm{~cm}$ and the protocol restarted. In total, ten locations were used, five on each leg. A Ag/ $\mathrm{AgCl}$ electrode pair was used as a reference (Unilect longterm $\mathrm{Ag} / \mathrm{AgCl}$ electrodes, Unomedical Ltd, GB) placed above the knee.

The electrode potential between two conductive textile electrodes was registered with a high input impedance multimeter (Metrahit $15 \mathrm{~s}$ multimeter, ABB Metrawatt, Germany) for 30 minutes at a rate of 1 sample/minute, according to Figure 4.9. The mean drift for the 10 measurement series are shown in Figure 4.10.

It is desired that the electrode potential is as stable as possible. Electrode $\mathrm{C}$ show 

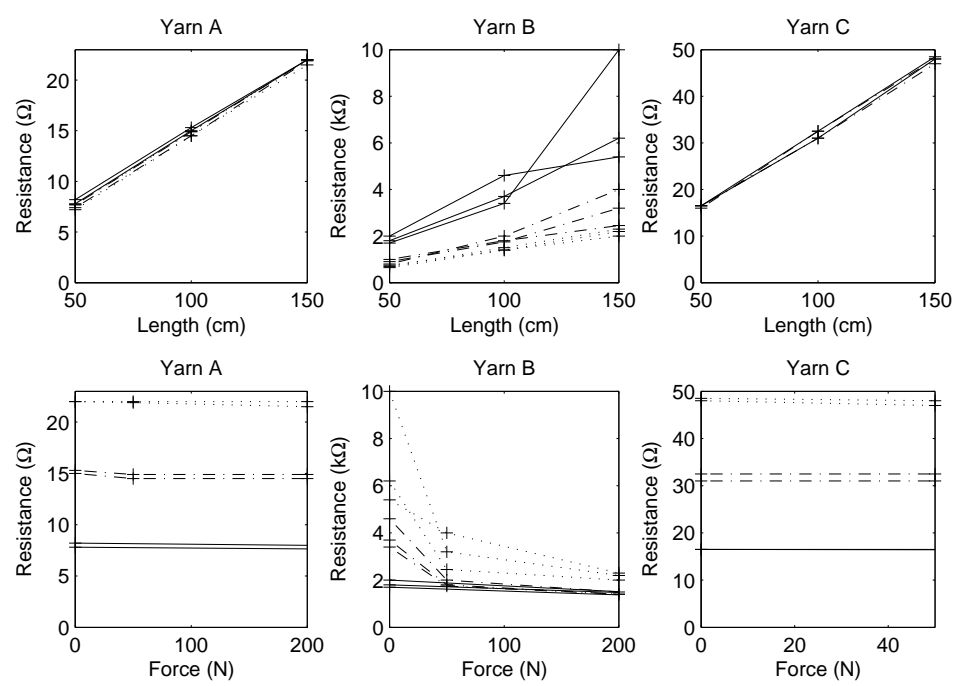

Figure 4.8: Results for the thread resistance measurements. In the upper panel, the resistance is plotted versus the thread length. The lower panel show the resistance versus the applied force. The dotted lines are the $1.5 \mathrm{~m}$ specimen and the dash dotted and full line represent the $1 \mathrm{~m}$ and $0.5 \mathrm{~m}$ specimens, respectively. Adopted from [95] with permission.

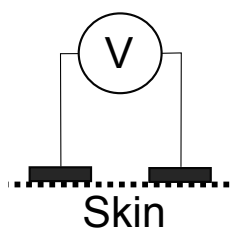

Figure 4.9: Setup for potential measurements of the electrodes applied to the skin. The textile electrodes (black) were placed on skin (dashed) $5 \mathrm{~cm}$ apart and connected to a multimeter.

large variations for some of the measurement series, and is thus not reliable. Electrode B has smaller variations than Electrode C. Electrode A, the pure stainless steel fabric was the most stable of the conductive textiles and also with the lowest drift magnitude. For some of the measurements it was comparable with the reference electrode.

Looking at the structures of the electrode samples, the results are not surprisingly. Electrode $\mathrm{C}$ consists of a yarn with a very small amount of conductor around it. The interface is going to be very dependent on the orientation of the conductive part regarding to the skin.

Electrode B is a tricot with a blend of SS and polyester staple fibers. The electrode is also rather elastic and even though the measurements were made at rest, this 


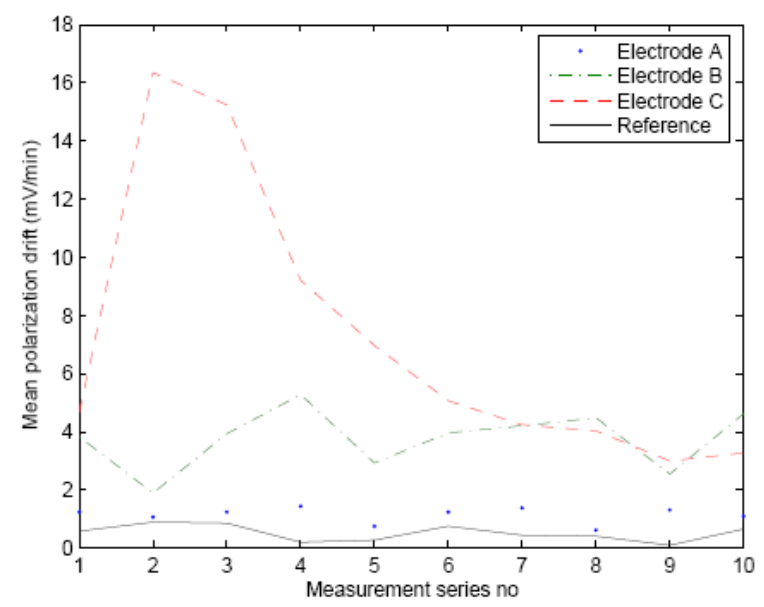

Figure 4.10: Electrode potential drift. Adopted from [95] with permission.

might have inflicted in the results. The composition also implicates that there might be local variations in conductive and insulating parts of the electrodes which is likely to affect the result.

Electrode A consists of pure SS metal, and is most likely to be the easiest texture to predict its behavior. The good conductivity and relatively homogeneous structure makes it perform the best in this experiment.

\subsubsection{Electrode impedance measurements}

The electrode impedance of the textile electrodes was measured with a gain phase meter (3575A, Hewlett Packard, USA). Two electrodes were placed as described in the previous section and connected to a signal generator (model 123, Exact Electronics, Inc, USA). The measurement setup is shown in Figure 4.11. Current density was limited to $0.3 \mathrm{~mA} / \mathrm{cm}^{2}$ and four frequencies were tested $(1,10,100$ and $1000 \mathrm{~Hz}$ ). Each electrode was tested on ten locations, five on each leg. From the gain phase meter, the phase shift, $\theta$, and magnitude quotient, $\mathrm{Q}(\mathrm{dB})$, was obtained. The resulting impedance was then calculated from the formula:

$$
\left|\bar{Z}+R_{r e f}\right|=R_{r e f} \cdot 10^{(Q / 20)}
$$

In accordance with theory, the resistive and capacitive parts are in the same order of magnitude for all samples, as can be seen in Figure 4.12. The results show that Electrode C, the mono-filament of silver plated copper had the highest impedance 


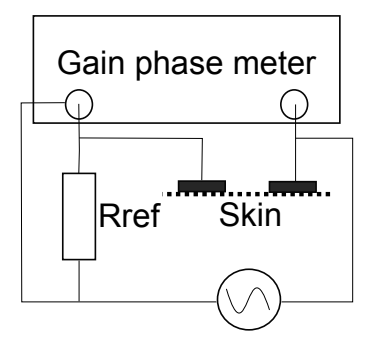

Figure 4.11: Measurement setup for the impedance characterization of the electrodes. The textile electrodes (black) were placed on skin (dashed) $5 \mathrm{~cm}$ apart and connected to a signal generator and a gain phase meter.

and that both Electrode A and B had somewhat higher impedance than the reference electrode.
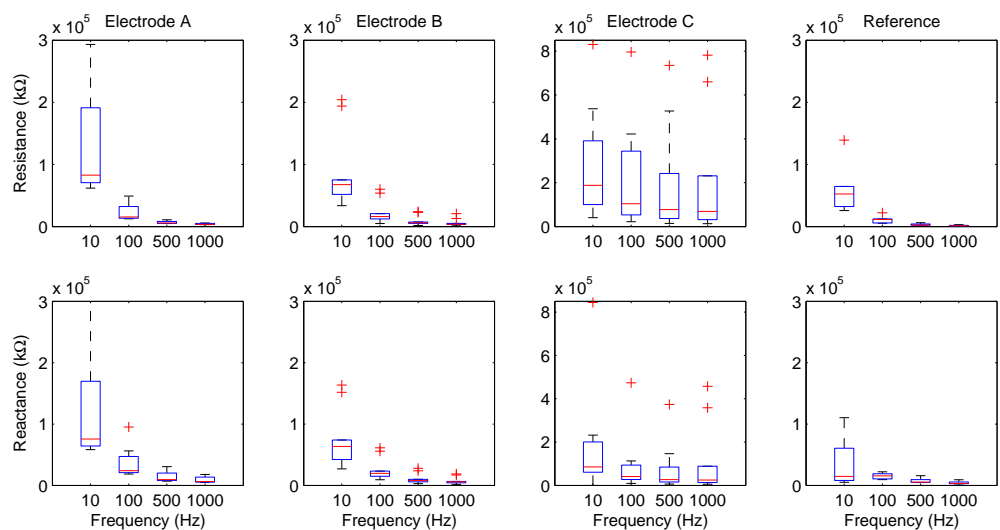

Figure 4.12: Impedance measurements for three textiles and a reference electrode.

The over all conclusion of the study is that Electrode A is preferable of the tested materials in an electrode point of view because of its predictive behavior and relative good electrode properties. Furthermore, Electrode $\mathrm{C}$ shows rather poor characteristics both regarding electrode potentials and impedances. Electrode B has similar impedance characteristics as Electrode A, but performs worse regarding electrode potential stability.

\subsection{Screen printed ECG electrodes}

Screen printing, which in printing terms today is a so called thick-film technology, is an old technique which origins from the end of the 9th century. However, it has developed to be a sophisticated printing method with a variety of applications. 
During the second world war, thick-film technology expanded in the sense that conductive inks were used, initially to make fuses to bombs. 20 years later, IBM and the ink manufacturer DuPont started a cooperation in order to use conductive prints in computers. There are several methods in thick-film technology. Classically, inorganic materials were used such as glass and metal powders. After printing the product needed to be fused, using high temperature (at approximately $900{ }^{\circ} \mathrm{C}$ ) in order for the glass and metal powder to melt and become continuous layers in the print. [40]

The methods used in the remainder in this work however consider polymer thickfilms, which are cured in temperatures less than $200{ }^{\circ} \mathrm{C}$.

Several factors have contributed to the interest in screen printing as a modality to create electrodes, some examples being:

- It is a cost effective manufacturing technique, well suited for mass production.

- Inks have been developed with suitable electrical properties for electrodes.

- Low curing temperatures enable the usage of new substrate materials.

The remainder of this section gives a brief background to screen printing technology, followed by an introduction to screen printed electrodes.

\subsubsection{Screen printing methods}

Distinguishing for screen printing is the use of a stencil placed on a finely woven mesh or screen through which the ink is dispersed and pressed onto a substrate with the aid of a squeegee. There are mainly three screen printing setups (flatbed, flat-to-round and rotary printing) but only the flatbed setup will be considered here. Figure 4.13 shows a flatbed screen printing setup.

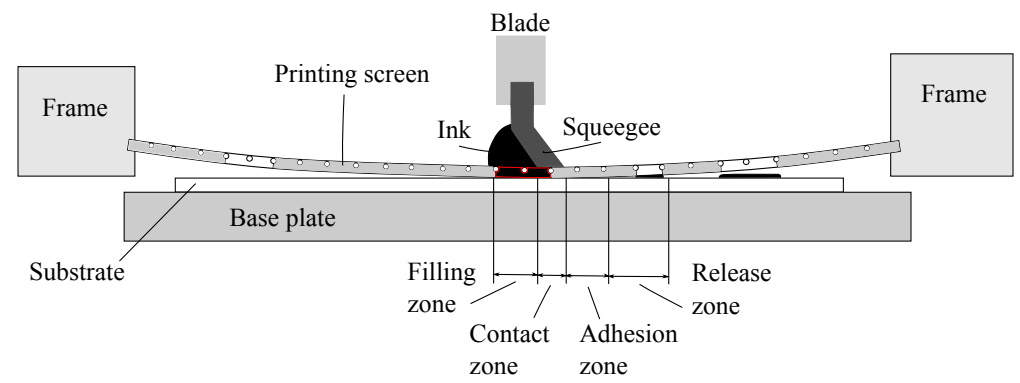

Figure 4.13: A setup for flatbed screen printing. For description, please see the text. Modified from [54] with permission.

The screen consists of a fine mesh of polyester or metal threads. The fineness of the screen is measured in fibers $/ \mathrm{cm}$, ranging from $10-200$ fibers $/ \mathrm{cm}$. Common 
values lies between 90 - 120 fibers/cm. On the screen, a stencil is placed with the advantage that the stencil can contain several parts (compared to a regular stencil in which the whole pattern must be connected in one piece). How the stencil is manufactured differs, but its principle function is to create impermeable areas for the ink while other parts are permeable and can dispense ink through the mesh onto the substrate. In order to keep the mesh and stencil intact, the screen is supported by a frame. [54]

In order to print, a substrate is placed on the base plate. The substrate can for example be paper, plastic films and textiles. The frame with the screen is placed with a small distance to the substrate. In one of the ends, the ink is dispersed on the screen. A blade with a squeegee pushes the ink ahead and at the same time applies a pressure on the screen so that it touches the substrate. This procedure creates a filling zone in front of the squeegee where the ink is distributed in the holes of the stencil. In the contact zone, the ink is pressed onto the substrate through the mesh. The wet ink makes the stencil momentarily adhere to the substrate, the so called adhesion zone. As the squeegee proceed over the screen, it releases the substrate (release zone) leaving the print onto the substrate and the screen is again at a distance from the substrate. [54]

After printing, the ink needs to cure. Depending on the ink and substrate, the curing method will differ. Some common curing methods are evaporation, heat curing and UV-curing.

There are many factors affecting the final printing result. For example, the spatial resolution depends on the fineness of the mesh. A rule of thumb is that the finest print resolution should be 3-4 thread distances. Another important factor is of course the ink. Since screen printing is such a general method in a variety of areas, and including many different substrates, the variety of ink is huge. How a generic ink is composed will be discussed further in Section 4.6.2. Other factors affecting the print is the pressure of the squeegee and its angle toward the screen, and speed. Also the snap-off distance is of importance [40].

\subsubsection{Inks}

In the printing process, the ink plays a major role in the result. Generic properties of inks are that they shall (from [54]):

- be transmitted from a reservoir to a substrate in a controlled manner.

- be able to dry in a reasonable time (for example by absorption or evaporation).

- have good adherence properties to the substrate (by penetrating pores in the substrate, capillary forces or polar binding). 
The physical properties of an ink is described by a number of parameters. One example is the viscosity, $\eta$, which describes how easily the fluid flows. The thixotrophy is the change in $\eta$ due to stirring for example. How well defined edges the ink will have is described by its tackiness, which also relates to how easily the ink is adhering to the substrate.

It is desired that the ink shall have high viscosity, while at rest on the screen. When it interacts with the squeegee, it should have a rapid decrease in viscosity so that it can be dispersed on the substrate through the mesh. After the dispersion it should resume high viscosity in order to maintain good definition of the edges of the print.

In Figure 4.14, the main functional components of an ink is shown. The colorants give the ink its color either through dyes or pigments. Pigments are small particles often in the $0.1-2 \mu \mathrm{m}$ range where only a small part of the molecules in the outer most layers are contributing to the coloring of the ink. Dyes are dissolved in the carrier substances and result in a higher color intensity. The disadvantage with dyes is that they more easily tend to oxidate and looses its color. Normally, pigment based inks are used with a pigment content of 5-30\%. When talking about conductive inks, the colorants are replaced by conductive particles, mainly carbon and silver, depending on the application. [40, 54]

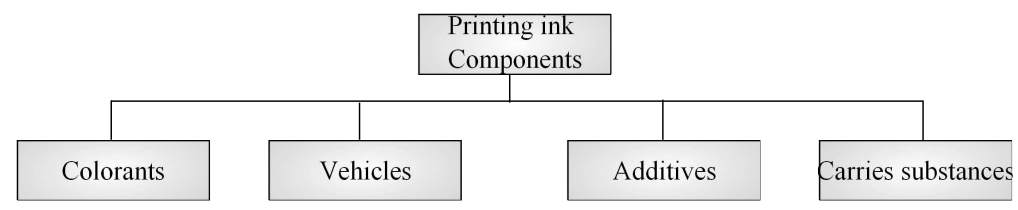

Figure 4.14: Composition of screen printing inks. For description, please see the text.

Vehicles (also called binders) are added to surround the pigments in order to prevent agglomerations. Binders also stick to the substrate and hence adhere the pigment on the substrate. Additives are added to enhance certain properties. Which additives that are used varies both with printing method and the properties that are desirable for the finished product. It can for example be to define drying speed, viscosity and abrasion resistance. Carrier substances are normally mineral oils or solvents with the primarily function of suspension and transportation of the colorants.

\subsubsection{Substrates}

Traditionally ceramics or glass materials have been used as substrates for thick film prints. These materials have met the demands of being inert to the materials used for the prints but at the same time have sufficient adhesion properties and being able to withstand the curing processes of the inks [40]. Being rigid, 
these substrates are not suitable for usage directly to the skin since their lack of flexibility.

Prints on flexible substrates have been widely reported in literature in the domain of wearable electronics during the last decade, ranging from electrodes $[7,18,59$, 90], conduction lines $[13,113]$ and circuits $[15,27]$.

Taking another step toward a fully integrated electrical circuit into textiles, the fabric itself could be used as a substrate. However, while having all the desired textile properties, still the demands of a substrate needs to be met. Adhesion, reproducibility and curing resistance are examples of such properties. Textiles in their nature are to some extent structured surfaces. Nonwovens for example, can have pore sizes of approximately 20-90 micrometers (Evolon reported in [49]).

\subsubsection{The screen printed electrode}

In order to make a screen printed electrode, the print needs to be conductive and normally this is obtained by adding metal particles in the ink. Ink providers nowadays have a wide range of conductive inks for different purposes. Some inks are even suggested to use as electrode materials, consisting of $\mathrm{Ag} / \mathrm{AgCl}$ particles. In Paper II, such an ink was used as the electrode surface.

An advantage with screen printing is that it is relatively easy to print in layers, creating components with layered structures and tailored functionalities. In the application of ECG electrodes this feature has been used in different designs [90, 96]. In Figure 4.15, a decomposed electrode is shown. The first layer is a conductor, in this case a carbon rectangle. On top of it, the electrode surface is printed with a $\mathrm{Ag} / \mathrm{AgCl}$ based ink. To protect the conduction lines, a varnish cover is printed on top covering all but the active electrode area.
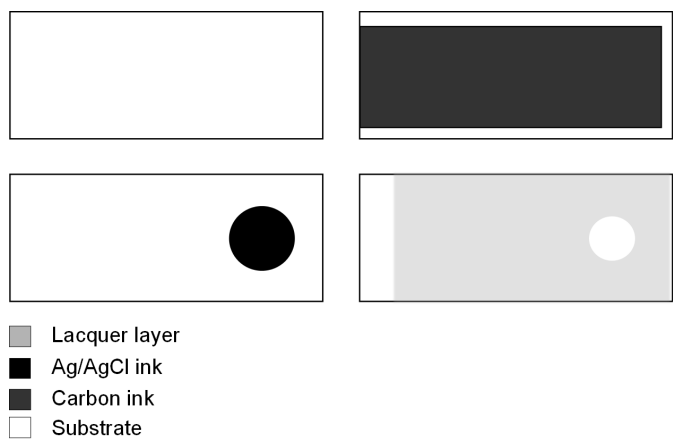

Figure 4.15: Screen printed electrode decomposition i different layers.

Even though easy prototyping and mass-production is provided by screen printing technology, there are still some issues that need to be resolved prior to have the 
optimal screen printed smartware ECG electrode. Some of the issues identified by the author are:

Ink composition The ink used for the electrodes needs to be electrically conductive and show good electrode features, such as electrode stability. They also need to be unobtrusive to the wearer in the sense that solvents or carriers should not cause skin irritation while being worn for a period of time.

Ink-textile interface Preferably, the print should be highly conductive, be flexible, to some extent even elastic and adhere well to the fabric. In reality however, all features are hard to realize at the same time. Having larger pores in the fabric, enabling good adhesion also makes it harder to create an even top surface with reproducible, known conductance. By increasing the print thickness, to enhance the conductive properties, the print also gets more prone to break or crack.

Washability An often mentioned feature is the maintenance of smartware and that it should be washable. This is however not evident. Firstly the print needs to adhere well to the fabric since the mechanical stress on it during a washing cycle is substantial. Secondly, it also needs to resist the chemicals often used in detergents and at the same time maintain the electrode properties mentioned above. Studys aiming at investigating the washing resistancy for prints on textiles often propose that the surface should be coated, some showing excellent results. In the application of printing circuits or conduction lines this is a probable solution, for electrodes however, the surface needs to be conductive and coating is not therefore a valid option.

\subsection{Previous research on printed electrodes and related work}

The first printed electrode known to the author was presented in [72] in a short abstract where they had used a $\mathrm{Ag} / \mathrm{AgCl}$ based ink on a polyester film substrate to obtain ECG electrodes. During the next decade, not much literature was presented in the area, but printed commercial electrodes started to emerge. With the introduction of the smartware concept along with the rapidly evolving field of printed electronics, studies regarding printing conductive inks on textiles appeared in literature the last decade. For example, washability properties have been studied from some different perspectives, using different kinds of substrates/inks and by using coatings. Some studies have focused on the adhesion and cracking of prints whilst others have implemented the prints in garments. Concluded in Table 4.3 are some of the later studies regarding screen prints on fabric using conductive inks. 


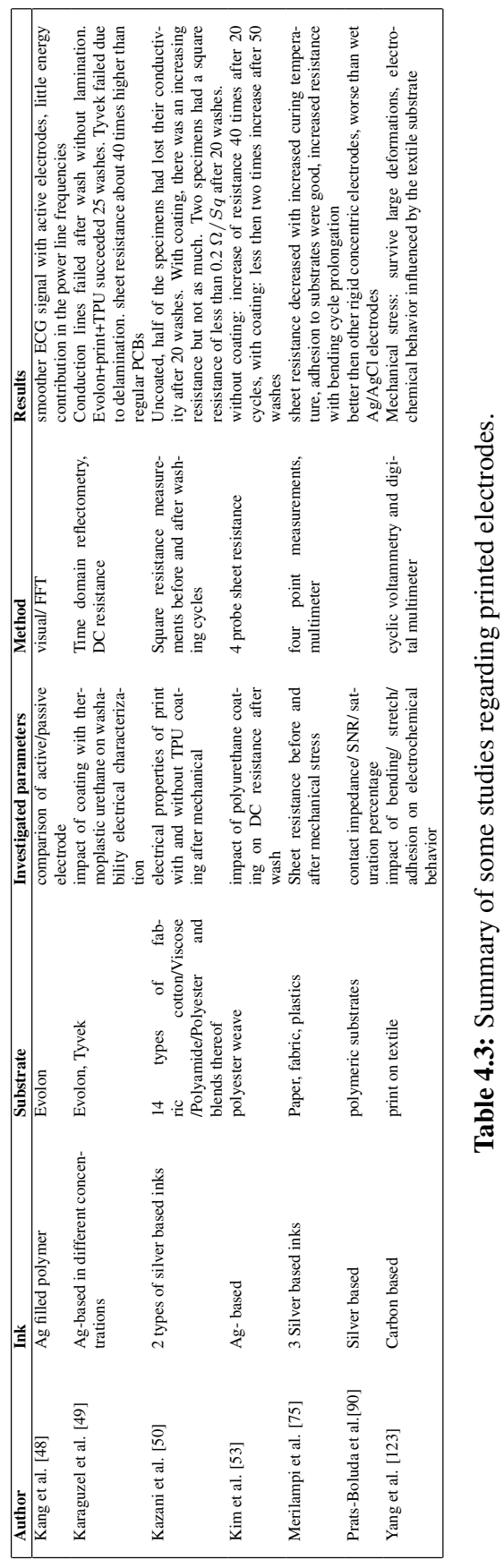


Paper, plastic and fabric substrates were tested with three different silver based inks by Merilampi et al. [75] with the aim of investigating the adhesion and flexibility of the prints. A $11.5 \mathrm{~cm}^{2}$ square was used for square resistance measurements using the four probe technique. It was found that increasing curing temperature significantly increased the conductivity. The sheet resistance varied between 0.4 and $0.13 \Omega / s q$. In the concluding remark the author stresses the different behavior between different inks, even though the conductive media is of the same material.

Printed electrodes in the lining of underwear were investigated by Yang et al. [122]. Their conclusion was that the electrochemical behavior of the electrodes was maintained under mechanical stress corresponding to every day use. It should be noted however that the tested prints were carbon based and measurements were cyclic voltammetry and not primarily for ECG applications.

The question regarding ink adhesion to the substrate (which in this case influences the conductivity) has been addressed by several authors $[49,50,53]$ by using standard machine washing cycles. They all report on a rapid increase of print resistivity if the conductive print is uncovered. However, with lamination by Thermoplastic Urethane [49, 50] or Polyurethane [53] the conductivity remained high for some of the samples up to 50 cycles.

\subsection{Our contribution to printed electrodes research}

The study presented in Paper II consists of electrical characterization of six setups of screen printed electrodes and a commercially available electrode for comparison. The printed electrodes are presented in Figure 4.16. The bottom layer consists of a conduction line of either a $0.5 \mathrm{~mm}$ wide print with silver particles (Ag5000, Dupont) or a $20 \mathrm{~mm}$ wide print of carbon based ink (C7102 from Dupont with $10 \%$ Dupont 3610 thinner). The middle layer consists of a circular print with $\mathrm{Ag} / \mathrm{AgCl}$ particles (Creative Materials, 113-09). On top, an insulating laquer layer was applied to define the active electrode surface and cover the conduction lines. Substrate for all samples was a plastic film (Polyfoil Bias, 125 Mic).

In Table 4.4, the different electrode denotations and configurations are summarized. The seven electrode types were tested for electrode potential and impedance in a physiological saline solution. The electrode denoted as "commercial", is an off the shelf suction electrode (Suction Electrode KISS, GE Healthcare, $20 \mathrm{~mm}$ in diameter).

\subsubsection{Testing electrode potential}

The generic measurement setup for electrode potentials consists of a measurement cell filled with an electrolyte and a reference electrode known to be stable, for 


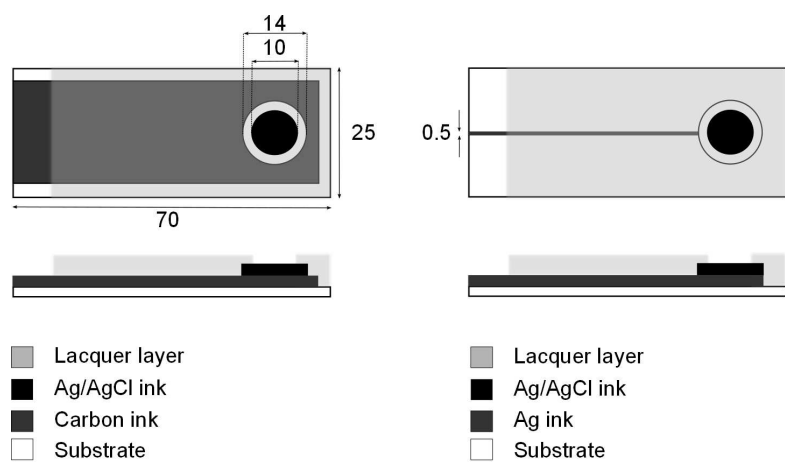

Figure 4.16: The printed electrodes. Adopted from [96] with permission.

\begin{tabular}{|lllll|}
\hline $\begin{array}{l}\text { Electrode } \\
\text { denotation }\end{array}$ & $\begin{array}{l}\text { Conductor } \\
\text { material }\end{array}$ & $\begin{array}{l}\text { Layers of } \\
\mathrm{Ag} / \mathrm{AgCl}\end{array}$ & $\begin{array}{l}\text { Layers of } \\
\text { lacquer }\end{array}$ & $\begin{array}{l}\text { no of } \\
\text { samples }\end{array}$ \\
\hline$A_{A g}$ & $\mathrm{Ag}$ & 1 & 1 & 8 \\
$A_{C}$ & $\mathrm{C}$ & 1 & 1 & 7 \\
$B_{A g}$ & $\mathrm{Ag}$ & 1 & 2 & 8 \\
$B_{C}$ & $\mathrm{C}$ & 1 & 2 & 8 \\
$C_{A g}$ & $\mathrm{Ag}$ & 2 & 1 & 8 \\
$D_{A g}$ & $\mathrm{Ag}$ & 2 & 2 & 6 \\
commercial & - & - & - & 4 \\
\hline
\end{tabular}

Table 4.4: Tested electrode configurations.

example $\mathrm{Ag} / \mathrm{AgCl}$, and the electrode under investigation, the working electrode. Both electrodes are connected to a potentiostat with high input impedance, see Figure 4.17. In the current study, a potentiostat (Autolab PGSTAT30, Metrohm Autolab, Utrecht) was used with a $\mathrm{Ag} / \mathrm{AgCl}$ reference electrode and Palladium auxiliary electrode. The electrode potential, or open circuit potential was measured for 30 minutes with 1 sample/minute.

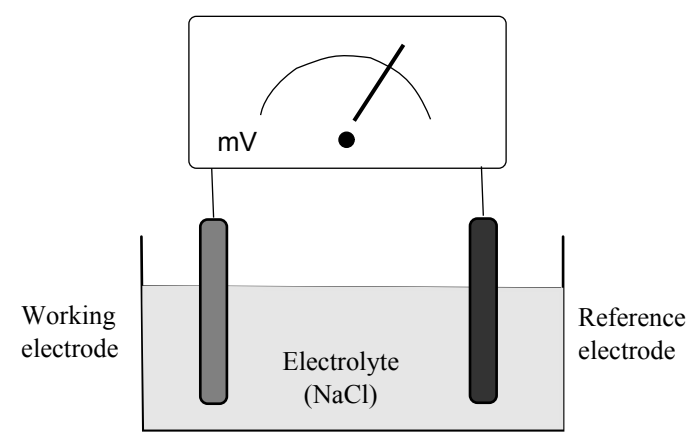

Figure 4.17: Schematic setup of potentiometric measurements. 


\begin{tabular}{|llll|}
\hline Electrode & $\begin{array}{l}\text { max potential differ- } \\
\text { ence in batch }(\mathrm{mV})\end{array}$ & $\begin{array}{l}\text { mean potential drift } \\
(\mathrm{mV} / \mathrm{min})\end{array}$ \\
\hline$A_{A g}$ & 2 & 0.03 & \\
$A_{C}$ & 2 & 0.07 & \\
$B_{A g}$ & 1 & 0.06 & \\
$B_{C}$ & 5 & 0.1 & \\
$C_{A g}$ & 2 & 0.04 & \\
$D_{A g}$ & 2 & 0.06 & \\
commercial & 0.7 & 0.02 & \\
\hline
\end{tabular}

Table 4.5: The maximal potential difference between two measurements within a batch (at the same time) and the mean potential drift calculated according to Equation 4.2 .

For the electrode potential measurements, the potential drift/time is important for the ECG signal quality. A mean drift ( $\mathrm{mV} / \mathrm{min})$ was used as a measure to evaluate the results according:

$$
\begin{aligned}
\bar{E}_{X, i} & =\frac{\sum_{t}\left|E_{X, i}(t)-E_{X, i}(t+1)\right|}{29}, t=1 \ldots 29 \\
\bar{E}_{X} & =\frac{\sum_{i} E_{X, i}}{n}, i=1 \ldots n
\end{aligned}
$$

where $X$ denotes the electrode type, $i$ denotes the specimen number and $n$ is the total number of samples of electrode type $X$.

\subsubsection{Results of electrode potential measurements}

Electrode potential measurement were very consistent, both in time and within each electrode type, see Table 4.5. The maximum difference within a batch was $5 \mathrm{mV}$ for two specimens of electrode type $B_{C}$. For the other electrode types the electrode potentials were within a $2 \mathrm{mV}$ range. Furthermore, the mean drift as calculated in Equation 4.2 is presented in the right column. It can be seen that the highest mean drift is for Electrode type $B_{C}$ with a mean drift of $0.1 \mathrm{mV} / \mathrm{min}$. The commercial electrode has the lowest drift, closely followed by electrode type $A_{A g}$.

In Figure 4.18 the mean fluctuation over time for each electrode type is presented. The maximal mean potential difference between start to end is $2 \mathrm{mV}$ for Electrode type $A_{C}$. For the commercial electrode the corresponding value is $0.3 \mathrm{mV}$. 


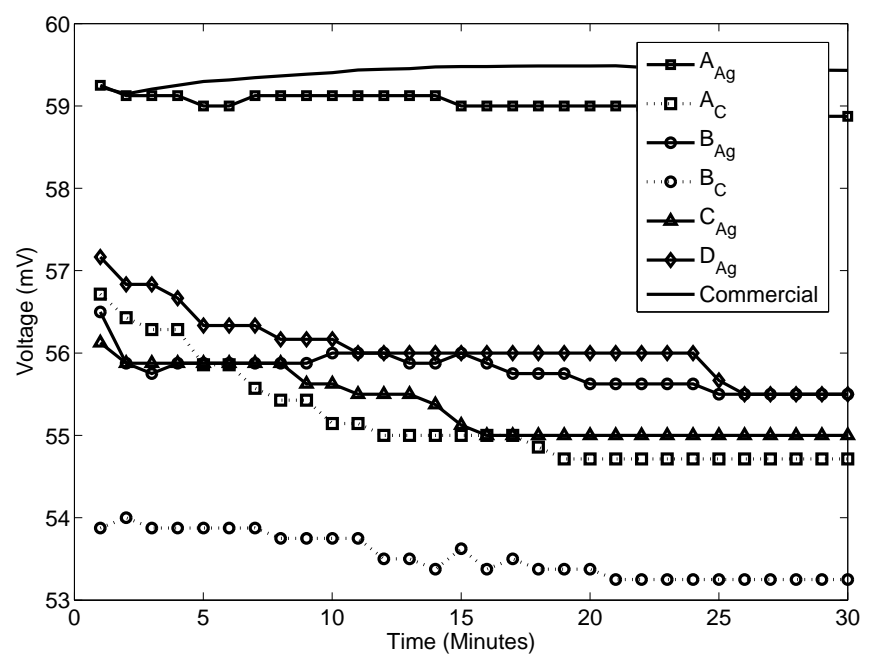

Figure 4.18: Mean potential drift over 30 minutes of the tested electrodes. Adopted from [96] with permission.

\subsubsection{Testing electrode impedance}

Generic impedance measurements consist of a similar cell as mentioned above, but the working electrode is fed with a sinosodial voltage with varying frequency, see Figure 4.19. The corresponding current is registered between the working electrode and the counter electrode. A frequency response analyzer is then calculating phase shifts and amplitude modulation between the applied voltage and detected current. The impedance measurements in the current study were performed with the same equipment as above at open circuit potential with a root mean square amplitude of $10 \mathrm{mV}$. 50 measurement points were logarithmically distributed in the range of $0.05 \mathrm{~Hz}-2 \mathrm{kHz}$.

\subsubsection{Results of electrode impedance measurements}

Impedance measurement results are displayed in an impedance plot in Figure 4.20. Low frequencies represent the upper right values and with increasing frequency the impedance decreases. At $2 \mathrm{kHz}$ the capacitance is almost shortcut and the impedance is almost pure resistive. For the silver conduction line setup among the electrodes this value is about $240 \Omega$ and for the Carbon conductor line electrodes the value is $580 \Omega$. This can also be seen in the absolute impedance amplitude plot in Figure 4.21, where the corresponding values at $2 \mathrm{kHz}$ are shown. The commercial electrode impedance is in the range below $100 \Omega$.

In order to show the variation in impedance measurements for each batch, the 


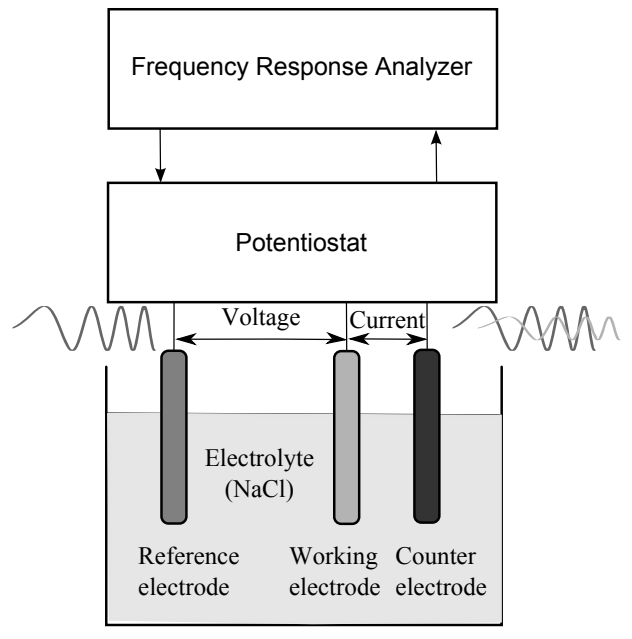

Figure 4.19: Schematic setup of impedance spectroscopy measurements.

\begin{tabular}{|lllll|}
\hline Electrode & $|Z|$ at $1 \mathrm{~Hz}$ & $|Z|$ at $15 \mathrm{~Hz}$ & $|Z|$ at $50 \mathrm{~Hz}$ & $|Z|$ at $2000 \mathrm{~Hz}$ \\
\hline$A_{A g}$ & $4200(2200-6100)$ & $1600(1100-2200)$ & $820(600-1000)$ & $240(210-260)$ \\
$A_{C}$ & $2200(1200-3200)$ & $120(1000-1300)$ & $820(800-850)$ & $570(520-620)$ \\
$B_{A g}$ & $1880(860-2800)$ & $880(760-1000)$ & $560(470-660)$ & $260(210-310)$ \\
$B_{C}$ & $3400(1900-5000)$ & $1600(1400-1700)$ & $1000(900-1100)$ & $580(530-630)$ \\
$C_{A g}$ & $1300(600-2100)$ & $660(490-830)$ & $440(350-520)$ & $230(170-230)$ \\
$D_{A g}$ & $750(530-980)$ & $440(340-550)$ & $340(260-420)$ & $200(170-230)$ \\
commercial & $57(47-68)$ & $52(43-60)$ & $46(38-53)$ & $38(32-43)$ \\
\hline
\end{tabular}

Table 4.6: The absolute impedances at some interesting frequencies. The values are the mean with $95 \%$ confidence intervals in brackets.

mean and 95\% confidence intervals are given for some interesting ECG related frequencies in Table 4.6. For noise suppression it is primarilly the absolute impedance at $50 \mathrm{~Hz}$ that is of importance. The maximal impedance at this frequency is in the order of $1 \mathrm{k} \Omega$. 


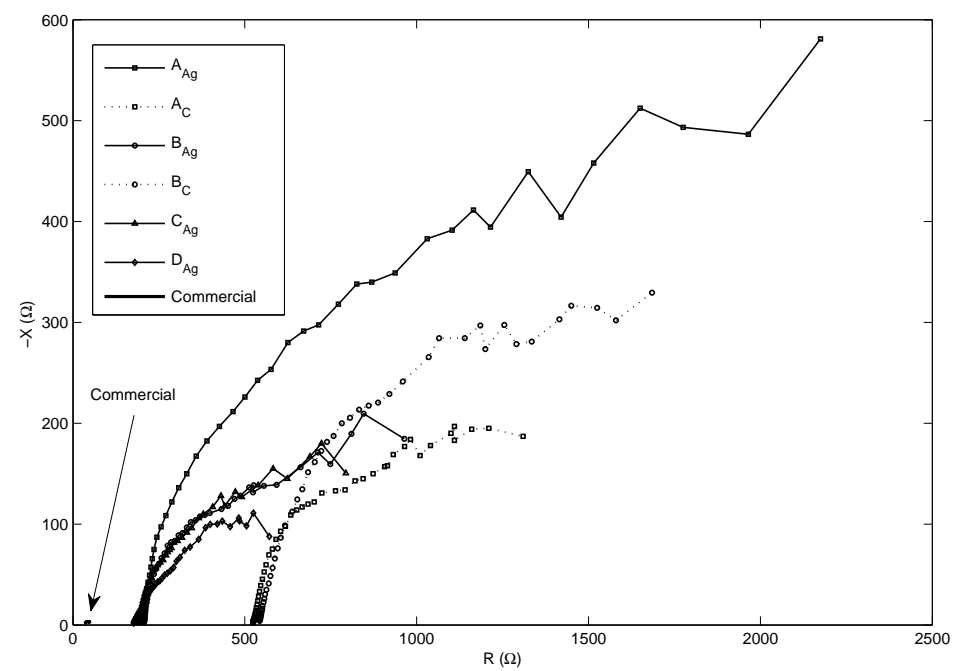

Figure 4.20: Impedance plot of the tested electrodes. Median values are used for each batch. The $\mathrm{x}$-axis is the real part of the impedance and the y-axis correspond to the negative part of the reactance. Adopted from [96] with permission.

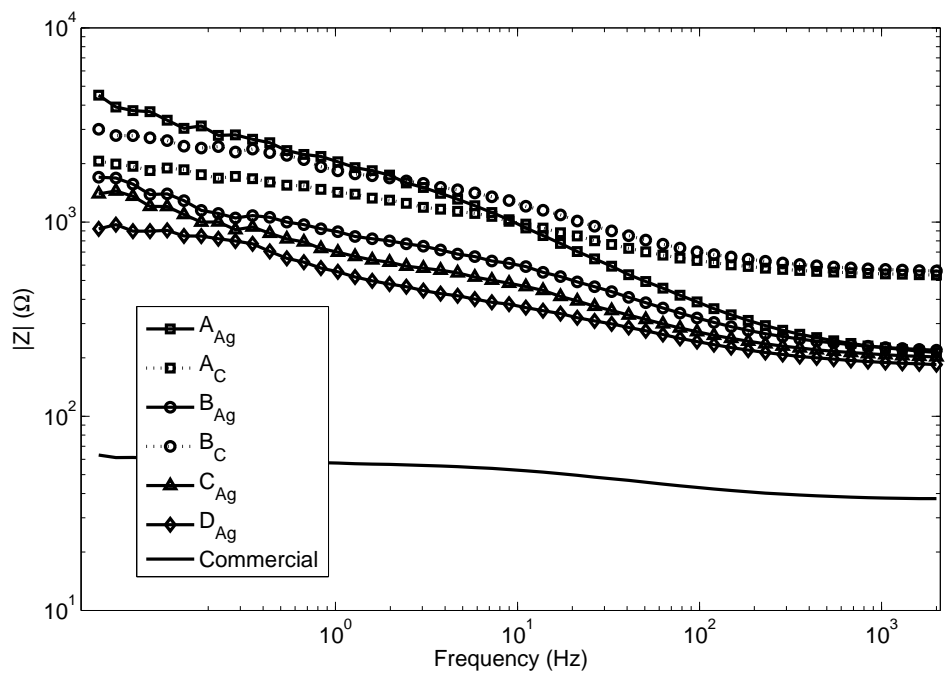

Figure 4.21: Impedance amplitude plot of the tested electrodes. Median values are used for each batch. Adopted from [96] with permission. 



\section{Signal processing of the smartware ECG}

ECG signals have been subjected for signal processing since the advent of computers in the medical field. The benefits are obvious; filtering techniques enhances the signal quality and feature detection facilitates detection and quantification of signal properties. Furthermore, the features could be used to build decision making systems which allow analysis of large amounts of data.

\subsection{The smartware ECG signal and common sources of disturbance}

In Figure 5.1, an ECG waveform is shown together with some of the parameters used when interpreting its diagnostic information. Cardiac pathologies are often displayed as changes or deviations from normal values of these parameters. For example, changes in the ST segment often indicate underlying cardiac pathologies. In heartbeat detection, the $\mathrm{R}$ peaks are often used as fiducial points. Furthermore, the RR interval time series is the input in heart rate variability evaluations.

The frequency content of an adult ECG is normally under $100 \mathrm{~Hz}$, with a fundamental frequency of approximately $10 \mathrm{~Hz}$ for the QRS complex, see Figure 5.2. However, when studying some heart pathologies, frequencies up to $150 \mathrm{~Hz}$ are interesting.

When recording an ECG there are some sources of disturbances that needs to be considered. In Friesen et al. [35] some common sources are described and they are summed up below:

Power line interference The power line interference is a sinusoid signal with a frequency of $50 / 60 \mathrm{~Hz}$ with an amplitude of up to half of the peak-to-peak ECG amplitude. The frequency coincides with the ECG spectra, which makes it troublesome to remove without any distortion. One way of reducing this type of interference is to remove close by electrical equipment which are connected to the mains. 


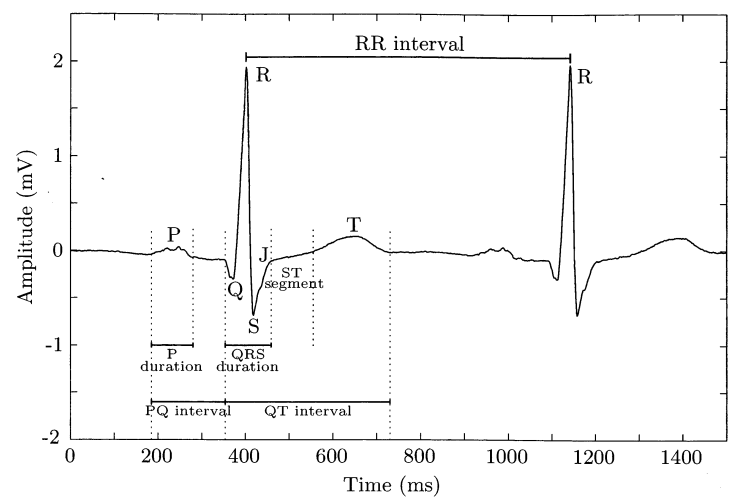

Figure 5.1: The ECG signal for one heartbeat with some of the interesting parameters included. Adopted from [106] with permission.

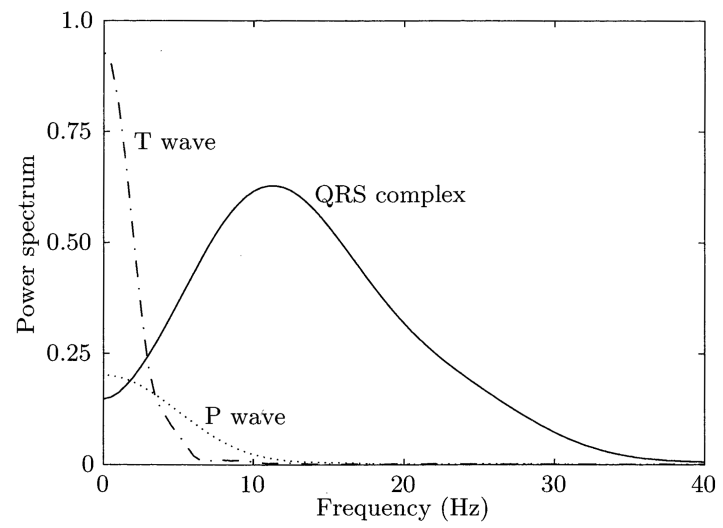

Figure 5.2: The ECG signal spectrum. Adopted from [106] with permission.

Baseline drift due to respiration Respiration effects both the cardiac rhythm and causes disturbances in the ECG registration. The respiration disturbances are mostly visible in the ECG as smooth baseline wanders with the same frequency as the breathing rate, see Figure 5.3(a).

Electrode motion disturbances are caused by a change in the electrode potential and deformation potentials of the skin. When using regular skin electrodes, electrode movement disturbances are reduced by having an adhesive collar and a gel filled cup to ensure as stable skin-electrode interface as possible [29]. The electrode motion corrupted ECG signal can be seen in Figure 5.3(b) as abrupt changes of baseline or even signal loss. Since smartware electrodes commonly not are attached by any adhesives, they are more 


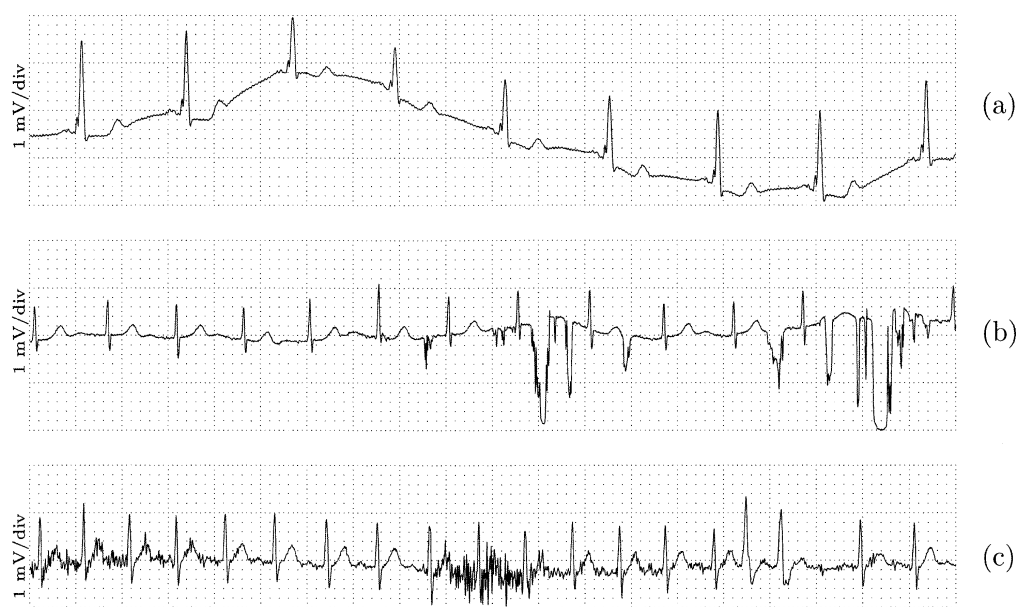

Figure 5.3: Common artifacts in the ECG. The top panel (a), shows baseline drifts due to respiration. The middle panel (b), shows electrode motion disturbances. The lower panel (c), shows EMG noise. Adopted from [106] with permission.

prone to move in relation to the skin, especially in the application of heart rate monitoring during every day activities. Therefore, compared with conventional ECG electrodes, the resulting signal from smartware ECG electrodes might have a higher level of noise and a slightly changed projection of the ECG signal. Use of advanced signal processing is therefore important to enhance the signal quality.

Muscle contractions It is not only the cardiac muscle cells that are triggered by small electrical currents. Skeletal muscle cells also act upon action potentials by motor neurons and contract due to charge changes over the cell membrane. These small ionic currents are transmitted in the same manner as an ECG to the body surface and can be picked up by skin electrodes. The pure skeletal muscle induced signal is called the electromyogram, often denoted as EMG. Normally, the EMG signal is smaller in amplitude than the QRS complex and it can be assumed to be bursts of band limited, zero mean Gaussian noise and its frequency content can be up to several $\mathrm{kHz}$, see Figure 5.3(c).

Instrumentation noise generated by electronic devices If the input amplifier is saturated, no signal information can be obtained. It is therefore crucial to make sure that the input is within the amplifiers allowed range and that the amplifier has good noise rejecting properties.

Another, not negligible, factor in smartware registering is that the measurements 
can be performed by laymen without any particular knowledge about either the signal nor the measurement conditions. If registrations are highly corrupted by noise, the signal contains little or difficultly extracted information. It is therefore preferable to discard useless data as soon as possible and encourage a new registration.

The issue of creating an automatic noise detector for ECG signals in tele-health served as the topic in a international competition announced by PhysioNet Challenge 2011 [104]. The goal was to correctly classify 500 12-channel ECGs as "acceptable quality" or "unacceptable quality". The annotations were blind to the competitors. Among the competition entries, several methods were presented. Hayn et al. [41] used four criteria (empty lead, spike detection, leads crossing and robustness of QRS detection) to assess the signal quality with an accuracy of $91.6 \%$. Time-domain features were also used in Redmond et al. [97] who classified single lead ECGs. Each recording was segmented in beats and superimposed so that the $\mathrm{R}$ wave fiducial points coincided. The clustered data was then used to extract seven features based on the similarity of the cluster morphology and an individual RR interval. Similar approaches, using time based features and thresholds are presented in [46]. Combined spectral and temporal features were used in [23] (for example; inter channel beat detection ratios, inter algorithm detected beats, relative power in QRS frequencies and whole signal, relative power in frequencies below $1 \mathrm{~Hz}$ ) together with support vector machines (SVM) and a multi-layer perceptron artificial neural network, generating an accuracy of $97 \%$. Previous methods gives a binary output regarding signal quality, not stating which criteria that induced failior. Di Marco et al. [28] proposes a method where five spectral-temporal features were used with thresholds, and where the output also stated which of the criteria that had failed. The official winners of the competition were Xia et al. [120] who used a matrix of regularity to decide the quality of the recordings.

Conventional ECGs are often multi-lead registrations and hence they provide detailed information regarding the electrical activity in several projections. However, since smartware registrations are more prone to pick up disturbances, having multiple leads could instead be used to create one robust heartbeat detector by combining the information in all the leads. Sensor fusion algorithms are therefore interesting in combination with smartware multi-channel ECG measurements. Chiarugi et al. [20] have made an adaptive threshold QRS detector with a best channel selection method in a two-lead ECG. The noise was estimated by using the ration between spectral power in the QRS band and the baseline band.

\subsection{ECG signal processing}

Almost all signal processing within ECG applications follow three generic steps presented in Figure 5.4. The first being pre-processing to reduce the influence 
of for example baseline drift and power line interference. Secondly, heartbeats are searched for and since the most distinct waveform is the R wave, it is mostly used to represent the occurrence of a heartbeat. Depending on the application, the post-processing can vary from arrhythmia classifiers to total segmentation of the different waves to trend analysis of the heart rate time series.

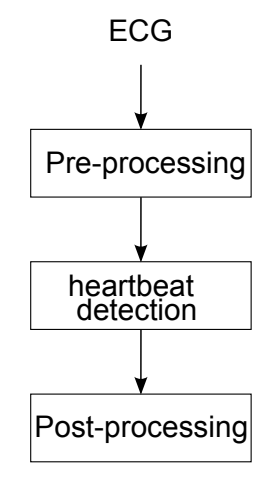

Figure 5.4: Normally used steps in ECG signal processing

\subsubsection{Pre-processing}

The American Heart Association recommends pre-processing of the ECG signal with cut off frequencies at 0.67 and $150 \mathrm{~Hz}$ with a zero-phase filter (with a lower cut off frequency of $0.05 \mathrm{~Hz}$ if the filter induce phase shifts) [55]. It is, however, reported in literature that in some signal processing applications the sampling frequency should be $1 \mathrm{kHz}$ [57].

The pre-processing step often aims at removing baseline drifts and power line harmonics. Baseline drift is often due to respiration which physiologically has a frequency content below $0.5 \mathrm{~Hz}$ under the assumption of regular breathing. Filtering with a high pass filter with cut off frequency at $0.5 \mathrm{~Hz}$ successfully removes the influence of this in the ECG baseline.

Harmonics from the mains can be filtered with notch filters, but this has to be done carefully since the frequency content can overlap some pathologically interesting frequencies. Hamilton [39] has compared the reduction of power line interference between an adaptive and an nonadaptive method. The adaptive method is based on a running estimate of the noise which is subtracted from the input signal. The nonadaptive filter is a notch filter of the second order. The adaptive filter performed better since the nonadaptive filter tended to induce ringing especially after the QRS complex.

To reduce the infliction of EMG noise, independent component analysis have been applied by Korhonen [56] to separate EMG signals from EEG recordings, a technique used also in ECG signal processing. 


\subsubsection{Heartbeat detection}

The foundation in ECG signal processing is to correctly identify heartbeat occurrences. Normally this is done by placing fiducial points on the top of the R-wave. Friesen et al. [35] compared nine different types of nonadaptive, temporal QRSdetectors fed with noisy ECG signals. The best result was shown for algorithms using the first derivative only.

Another approach for heartbeat detection is by using wavelets, using their intrinsic ability of describing the signal's content in different frequencies with adequate resolution [67]. The wavelet output can also be fed to a neural network as described in [108]. Wavelets have also been successfully used to suppress EMG based noise in ECG applications [19, 31]

A patient-adoptable ECG classifier was described in [44]. It uses neural networks to classify an ECG based on two training data sets; one consisting of the patient's previous recordings, and one consisting of a database of many people. The outputs were then combined using a gating function.

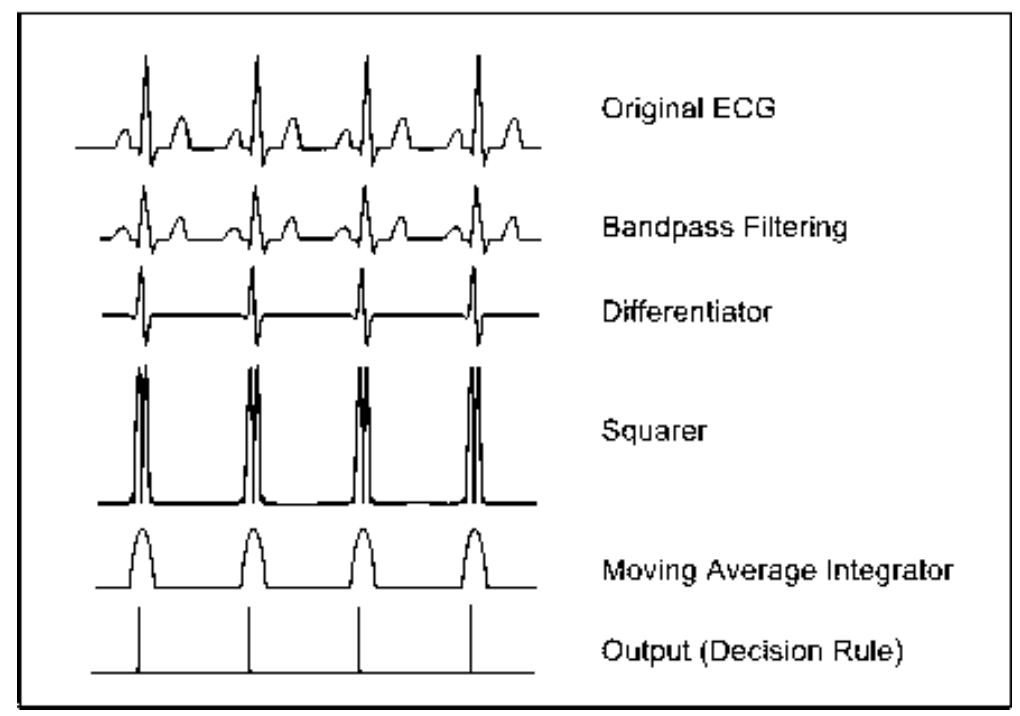

Figure 5.5: Schematic overview of the Pan Tompkins heartbeat detection method. Adopted from [58] with permission.

A commonly used golden standard method in heartbeat detection is often referred to as the Pan- Tompkins method described in [87]. The approach is based on prefiltering, differentiating, squaring, moving average integration and then thresholding as displayed in Figure 5.5. 


\subsubsection{Post-processing}

When the output of the heartbeat detector is obtained, the time series can be used for several purposes. Some of the diagnostically and practically important applications include instantaneous heart rate estimation [38], total segmentation of ECG features as described in Figure $5.1[58,100]$ and heart rate variability measurements [62].

In this thesis the objective is to use smartware ECGs for heartbeat detection during activity, and hence it is only this aspect of signal processing that is going to be regarded in the continuation of this chapter.

\subsection{Previous research in smartware electrode ECG signal processing}

Signal processing of ECG signals registered by smartware electrodes seems not to be in research focus. Only a few studies in the area are available and among those adaptive filtering techniques is a common approach.

Yoon et al. [125] used a combination of a 3-axis accelerometer and adaptive filters in order to reduce artifacts in the ECG. They registered an ECG (corresponding to lead II) with textile electrodes during two provocations; sitting to standing and squatting to standing. Also used in the algorithm were the accelerometer signal and the reference ECG registered with conventional $\mathrm{Ag} / \mathrm{AgCl}$ electrodes. Results are compared based on how many filter coefficients that are needed in order to to maximize the SNR increase per unit of process time. In this study, they have used the reference measurements in the calculations and for future implementations this dependency has to be solved differently.

An other adaptive filter approach with a multi-channel ECG has been proposed by Wiklund et al. [117]. They use a 7 lead textile electrode ECG recorded during walking, sitting, standing, and push-ups. The analysis is based on a spatiotemporal filtering technique using the FastICA algorithm with the addition of FIR filters channel-wise to include temporal information. One benefit of this method is that in contrast to conventional ICA it produces only one output signal instead of as many output signals as initial inputs. However, the analysis requires segmentation in order to be computational effective and adaptive. This introduces extra post-processing in the form of time alignment of the signal segments since the filters differs between the segments, the phase shift will also differ. The results for the 10 test persons, a FIR filter of length 20 samples and 7 input channels show a mean sensitivity and precision of approximately 0.98 .

In a study by Park et al. large textile electrodes were incorporated in bed sheets, recording a two-channel ECG. The R wave was detected by a wavelet approach. 
The resulting R-wave time series was then used to extract information of the respiration by a moving average integrator and linear interpolation or by cubic spline interpolation.

\subsection{Our contribution on textile electrode ECG signal pro- cessing}

\subsubsection{Blind source separation by canonical correlation analysis}

In Paper III, we use an approach to blind source separation, BSS, based on canonical correlation analysis (CCABSS) [12]. This method searches for components that have maximum autocorrelation, under the constraint that they are mutually uncorrelated. An advantage of CCABSS is that no information about temporal correlation is discarded. It has been reported that the CCA-method gives similar results as ICA, while being more robust and much faster [12].

\section{Blind source separation}

Blind source separation deals with the problem of taking a mixture of signals and separating them into their respective original sources. It is often described as the cocktail party problem, where it is assumed that $n$ microphones record the sound at different locations in a room, resulting in the signals $x_{i}(t)$ where $i=1 \ldots n$. What they register is a mixture of all the conversations going on in the room and the separation problem is to split the recordings into the respective conversations, $s_{j}(t), j=1 \ldots m$ where $m$ denotes the number of conversations in the room.

The recordings can be described as a mixture of the statistically independent source signals as:

$$
x(t)=A s(t)
$$

where $A$ denotes the mixing matrix. By estimating $A$ and finding its inverse, $W$, the sources can be calculated as:

$$
s(t)=W x(t)
$$

A common application of BSS is to remove noise from a distorted recording. Then the noise and wanted signal are considered independent and hopefully they are successfully separated.

There are different methods to solve this problem, for example independent component analysis [45]. However, ICA do not use the temporal correlation while solving the BSS problem. 


\section{Canonical correlation analysis}

Canonical correlation analysis, CCA, describes the relation between two sets of variables. Consider the two sets of zero mean vectors $\mathbf{x}=\left[x_{1}, x_{2}, \ldots, x_{p}\right]$ of dimension $p$ and $\mathbf{y}=\left[y_{1}, y_{2}, \ldots, y_{q}\right]$ of dimension $q$, then CCA describes how these two sets relate to one another. [64]

The analysis is performed by finding linear combinations, $\mathbf{U}$ and $\mathbf{V}$

$$
\begin{aligned}
& \mathbf{U}=a_{1} x_{1}+a_{2} x_{2}+\ldots+a_{p} x_{p}=\mathbf{A}^{\mathbf{T}} \mathbf{x} \\
& \mathbf{V}=b_{1} y_{1}+b_{2} y_{2}+\ldots+b_{q} y_{q}=\mathbf{B}^{\mathbf{T}} \mathbf{y}
\end{aligned}
$$

where $\mathbf{A}=\left[a_{1}, \ldots, a_{p}\right]^{T}$ and $\mathbf{B}=\left[b_{1}, \ldots, b_{q}\right]^{T}$ of the two data sets in such a way that $\mathbf{U}$ and $\mathbf{V}$ are maximally correlated. Assume the correlation between the sets is $\rho$, then the maximization of the correlation is an eigenvalue problem described by:

$$
\mathbf{C}_{\mathbf{U U}}^{-1} \mathbf{C}_{\mathbf{U V}} \mathbf{C}_{\mathbf{V V}}^{-1} \mathbf{C}_{\mathbf{V U}} \mathbf{a}_{\mathbf{i}}=\rho_{i}^{2} \mathbf{a}_{\mathbf{i}}
$$

The matrices $\mathbf{C}$ are the respective covariances. Identification shows that in the left hand side in Equation 5.5, $\rho_{i}^{2}$ represents the eigenvalue and $\mathbf{a}_{\mathbf{i}}$ the eigenvector, which can be used to calculate the linear combinations in Equation 5.3.

\section{Combining blind source separation and canonical correlation analysis}

CCA requires two sets of data, $x$ and $y$, as mentioned above. Let $\mathbf{x}(t)$ be the measured mixture signals and construct $\mathbf{y}(t)$ as a temporally delayed version of $\mathbf{x}(t), \mathbf{y}(t)=\mathbf{x}(t-1)$ [12]. Since both data sets are essentially identical, $a_{i}$ and $b_{i}$ will contain almost the same components. Hence it suffices to calculate $a_{i}$. The first canonical correlation component will then give a linear combination $s_{1}(t)$ of the mixed signals with maximum temporal autocorrelation at lag one. The second canonical correlation component will give a new linear combination $s_{2}(t)$ with maximum autocorrelation under the constraint that it is uncorrelated to the first component, etc.

\section{Sensor prototype 1 and data collection}

The first sensor prototype consisted of a wave knitted fabric made out of a blend of polyester and stainless steel fibers (Bekitex BK 50/2 yarn, Beakert). The active electrode area was $4 \mathrm{~cm}^{2}$ and crocodile clips were used for connectors to standard cables connected to the amplifier, see Figure 5.6.

The electrodes were slightly moisten and placed according to Figure 5.7, creating five leads. Three standard electrodes were placed on the shoulders and on the left hip. They were connected to an ECG amplifier (S\&W, Diascope DS 521, Denmark) to be used as a reference signal. 


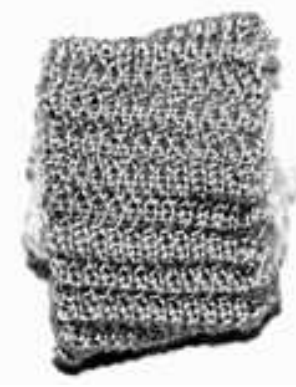

Figure 5.6: The first ECG electrode prototype; a wave knitted fabric consisting of a Bekitex BK 50/2 yarn made of a blend of stainless steel fibers and polyester. From [94] with permission.

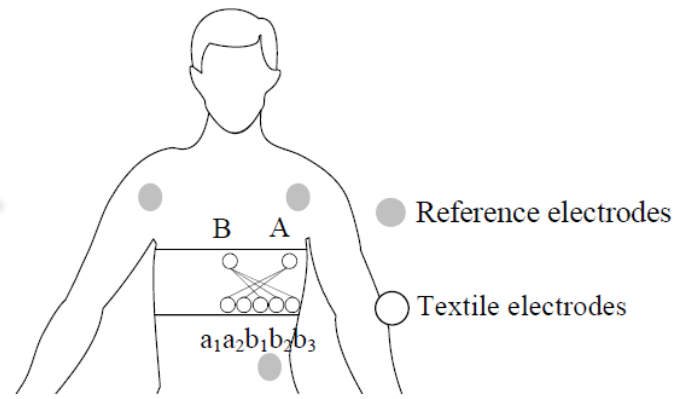

Figure 5.7: Measurement setup. Standard electrodes were used to register a reference ECG. Two textile electrodes were placed above the heart and five below. The ECG channels were measured between A and electrodes $\mathrm{a}_{1}-\mathrm{a}_{2}$ (channel 12) using B as a reference and vice versa for channels 3-5. From [94] with permission.

All signals were digitalized at $1 \mathrm{kHz}$ with 12 bits per sample resolution. The data acquisition was done using LabView (National instruments, USA) and the signal processing was done using Matlab (The MathWorks, USA). Pre-filtering of the signals were done with a Butterworth band pass filter with cut off frequencies at $5-40 \mathrm{~Hz}$.

Five healthy male volunteers performed an acquisition protocol consisting of $30 \mathrm{~s}$ rest, $30 \mathrm{~s}$ static contraction of chest muscles, $30 \mathrm{~s}$ upper body rotation, disconnection of electrodes $a_{1}$ at $0 \mathrm{~s}, \mathrm{a}_{2}$ at $10 \mathrm{~s}$ and $\mathrm{b}_{1}$ at $20 \mathrm{~s}$. 


\section{Applying the CCABSS algorithm on the recorded data}

The blind source separation with canonical correlation algorithm was applied to ECG dataset in order to separate noise from the wanted ECG signal. The recorded ECG channels were considered to be the data set $\mathbf{x}(t)$ and $\mathbf{y}(t)$ and was constructed as presented earlier in this section. To test the performance of the proposed algorithm, BSS by independent component analysis and averaging of channels were also applied to the data set.

The output from both ICA and CCA consists of as many components as were originally fed to the system, in this case the five channels. Which one of them representing the heartbeat is not however evident. For both methods, visual inspection was used in order to choose the best component.

The Pan-Tompkins threshold algorithm which filters, differentiates and squares the signal was used to detect the heartbeats. Results are shown in Figure 5.8 and Table 5.1.

\section{Results from the CCABSS study}

Table 5.1 shows the number of false positives and false negatives detected by the automatic heartbeat detector. During rest, all methods classify all heartbeats correctly. Upper body motion is the protocol task which result in the most erranous detections. For the reference ECG, signals at some point were even lost during this task. Generally during this provocation, it lead to more false positive detections than false negatives. Worth noting is also that for the CCABSS method, it produced less false positive than any of the channels individually.

In Figure 5.8, it shows that the averaging method fails to produce an interpretable result for the prevailing circumstances, while the CCABSS algorithm successfully separates a signal corresponding to the heartbeats.

To estimate the computation complexity, the time of the analyses were measured. The averaging method was fastest with 0.04 s followed by CCABSS $(0.29 \mathrm{~s})$ and ICA (3.39s).

\subsubsection{Variance weighted sliding correlation method}

The following procedure to reduce noise in the ECG signal relies on redundancy in the multi-channel ECG signal and on models of the signal. Similar algorithms have been developed for image analysis [98], but this is an adopted version to suit event detection in the ECG. A schematic description of the model is found in Figure 5.9.

The recorded multi-channel signal $x_{i}[l], l=1 \ldots n_{s}$ where $n_{s}$ is the number of signal samples, $i=1 \ldots n_{c h}$ denotes the number of channels and the unbiased, 


\begin{tabular}{|l|cccccc|ccc|}
\hline & \multicolumn{10}{|c}{ False positive detections } \\
\hline & $\mathrm{R}$ & $C_{1}$ & $C_{2}$ & $C_{3}$ & $C_{4}$ & $C_{5}$ & $\mathrm{M}$ & $\mathrm{C}$ & $\mathrm{I}$ \\
\hline Rest & 0 & 0 & 0 & 0 & 0 & 0 & 0 & 0 & 0 \\
Chest contraction & 3 & 1 & 4 & 1 & 2 & 1 & 2 & 0 & 2 \\
Upper body motion & $\mathrm{X}$ & 24 & 16 & 2 & 14 & 64 & 30 & 4 & 3 \\
$C_{1}$ removed & 1 & $\mathrm{X}$ & 4 & 1 & 1 & 1 & 7 & 1 & 7 \\
$C_{2}$ removed & 0 & $\mathrm{X}$ & $\mathrm{X}$ & 0 & 1 & 0 & $\mathrm{X}$ & 0 & 1 \\
$C_{3}$ removed & 0 & $\mathrm{X}$ & $\mathrm{X}$ & $\mathrm{X}$ & 4 & 0 & $\mathrm{X}$ & 2 & 2 \\
\hline \hline & $\mathrm{R}$ & $C_{1}$ & $C_{2}$ & $C_{3}$ & $C_{4}$ & $C_{5}$ & $\mathrm{M}$ & $\mathrm{C}$ & $\mathrm{I}$ \\
\hline & 0 & 0 & 0 & 0 & 0 & 0 & 0 & 0 & 0 \\
\hline Rest & 1 & 0 & 2 & 0 & 1 & 1 & 1 & 0 & 0 \\
Chest contraction & $\mathrm{X}$ & 5 & 9 & 6 & 2 & 8 & 2 & 1 & 4 \\
Upper body motion & 0 & $\mathrm{X}$ & 0 & 0 & 0 & 0 & 0 & 0 & 0 \\
$C_{1}$ removed & 0 & $\mathrm{X}$ & $\mathrm{X}$ & 0 & 0 & 0 & $\mathrm{X}$ & 0 & 0 \\
$C_{2}$ removed & 0 & $\mathrm{X}$ & $\mathrm{X}$ & $\mathrm{X}$ & 0 & 0 & $\mathrm{X}$ & 0 & 3 \\
$C_{3}$ removed & 3 & 18 & 13 & 8 & 2 & 2 & 10 & 2 & 5 \\
\hline \hline No sig. losses of 30 & 30 & \multicolumn{10}{|c|}{} \\
\hline
\end{tabular}

Table 5.1: Result from the Pan-Tompkins heartbeat detector. Abbreviations: $X=$ Signal lost during segment, $\mathrm{R}=$ Reference signal, $C_{1}-C_{5}=$ Textile ECG channels, $\mathrm{M}=$ Mean of $C_{1}-C_{5}, \mathrm{C}=\mathrm{CCABSS}, \mathrm{I}=\mathrm{ICA}$

normalized event model $y_{i}[k], k=1 \ldots n_{k}$, where $n_{k}$ is the kernel sample length are correlated according to:

$$
\rho_{i}[l]=\frac{1}{n_{k}-1} \sum_{j=1}^{n_{k}-1} \frac{x_{i}[l-j] y_{i}[j]}{\sqrt{\sigma_{x_{i}}^{2} \sigma_{y_{i}}^{2}}}, l=1 \ldots n_{s}-n_{k}
$$

resulting in one correlation value for each time instance. The $\sigma_{x_{i}}$ is the standard deviation of the signal under the current window and $\sigma_{y_{i}}$ is the standard deviation of the kernel. Furthermore, the factor $\left(n_{k}-1\right)^{-1}$ was used to normalize according to the window length. The obtained $\rho_{i}[l]$ has high values for positions that are similar in shape to the model. Since noise of both high and low amplitudes can generate a high correlation coefficient if the morphology is similar to that of the model, a criterion is needed to suppress such impacts. This is solved by introducing a variance based certainty measure, $\epsilon_{i}\left[m_{c}\right]$ :

$$
\epsilon_{i}\left[m_{c}\right]=e^{\frac{-\left|w_{i}^{2}\left[m_{a}\right]-\operatorname{var}\left(x_{i}\left(m_{c}\right)\right)^{2}\right|}{\operatorname{coeff} f \cdot w_{i}\left[m_{a}\right]}},
$$

where $m_{c}$ denotes the heartbeat candidate, $w_{i}^{2}\left[m_{a}\right]$ is the expected variance of the event and $\operatorname{var}\left(x_{i}\left(m_{c}\right)\right)$ is the variance of the current signal section of length $n_{k}$ and center in $m_{c}$. The comparison measure, $w_{i}^{2}\left[m_{a}\right]$, can be chosen as the model variance or any other suitable variance measure. For our purpose, the variance measure was based on the previous accepted heart beats' variance as:

$$
w_{i}^{2}\left[m_{a}\right]=\frac{1}{\sum_{j=1}^{m_{a}} \frac{1}{j}} \sum_{j=1}^{m_{a}} \frac{\operatorname{var}\left(x_{i}\left(m_{a}-j\right)\right)^{2}}{j}, m_{a}>1
$$




\begin{tabular}{|l|c|}
\hline input impedance & $10 \mathrm{M} \Omega$ \\
Digitalization rate & $496 \mathrm{~Hz}$ \\
Anti-aliasing filter & $230 \mathrm{~Hz}$ \\
Resolution & $16 \mathrm{bit} / \mathrm{sample}$ \\
\hline
\end{tabular}

Table 5.2: Characteristics of the ECG amplifier.

Initiation is done by letting $w_{i}^{2}[0]=\operatorname{var}\left(y_{i}\right)$. The certainty measure is used to weight the correlations as:

$$
\rho_{\text {weighted }, i}(t)=\epsilon_{i}(t) \cdot \rho_{i}(t)
$$

The result $\rho_{\text {weighted, } i}(t)$, is the summarized, weighted correlation measure of the events. By employing a threshold detector, a robust event detector can be created.

\section{Sensor prototype 2 and data collection}

A second ECG electrode prototype was constructed for the signal acquisition. It consisted of a top layer of a cotton fabric with a circular opening in the middle to define the active electrode area $\left(\operatorname{app} 3 \mathrm{~cm}^{2}\right)$. Underneath a $100 \%$ stainless steel fabric was placed with a padding under the active area to increase the contact to the skin. The back side was also made out of insulating cotton fabric. Connections were made out of a rivet placed in one of the corners. The top of the rivet was covered with silicon to insulate the metal from the skin. ECG cabeling were attatched on the backside of the electrode to the ECG amplifier. A schematic figure of the electrode is shown in Figure 5.10.

Nine electrodes were placed along a rib top chest belt with landmark fiducial points at the nipples. Six electrodes were placed to mimic the precordial leads on the chest belt. The remaining three electrodes were placed in the armpits and at the bottom of the belt (app $20 \mathrm{~cm}$ wide) below the left armpit. All cables were held in place at the bottom of the chest belt, see Figure 5.11. Twelve leads were derived, six precordial leads, three augmented and three extremity leads. The chest belt was applied using velcro in the back. Standard electrodes were placed on the shoulders and on the left hip for simultaneous registrations.

Signals were acquired using two identical bluetooth ECG amplifiers developed at the department. Their characteristics are shown in Table 5.2.

14 healthy male volunteers (age 26-37, mean 31, BMI 20.2-25.5 mean 23.4) Participated under informed consent. The protocol consisted of 10 min acclimatization followed by seven approximately half minutes recordings doing different movement provocations. The first and last registrations were done while lying down on a bunk bed. The provocations were

- Lying down $->$ sitting $->$ standing 
- Frontal plane flex $(0.25 \mathrm{~Hz})$

- Sagittal plane flex

- Upper body rotation

- Brushing teeth

- Walking

- Static abdomen muscle tension

\section{Applying the WC algorithm on the recorded data}

All signals were pre-processed with a fifth order zero-phase Butterworth filter with cut off frequencies of 0.5 and $30 \mathrm{~Hz}$. The subjects were divided in a training set (subject 1-7) and a validation set (subject 8-14).

The data were analyzed according to the above described theory where the model $y_{i}[k]$ consisted of a QRS complex derived as the firs QRS complex in each of the recordings and the variance measure, $w_{i}^{2}\left[m_{a}\right]$ was a weighted mean of previous accepted heartbeat variances.

The final threshold was set by optimizing the variable $O$ in the training data set, consisting of the product of the positive predictive value and the sensitivity:

$$
O=P P V \cdot \operatorname{sens}=\frac{t p}{t p+f p} \cdot \frac{t p}{t p+f n}
$$

where $t p$ are the true positive hits, $f p$ are the false positive hits and $f n$ are the false negative hits when comparing the output results with the annotations. The variable $O$ was calculated over a threshold range of 0.1 to 0.7 (in increments of $0.05)$ times the number of channels used. The results were stored for all subjects and summarized for all subjects and protocol tasks. The threshold which produced the highest value was then used for the validation data set.

Furthermore, the results were evaluated by comparison toward the golden standard method described by Pan and Tompkins [87]. Its final threshold was chosen according the same optimization procedure as described above. Since their algorithm is developed for single channel registrations, the minimum, mean and maximal value for the positive predictive value and sensitivity for the 12 channels were used in the comparison.

\section{Results from the weighted correlation analysis}

The results by means of the sensitivity and the positive predictive value are displayed in Figure 5.12 and Figure 5.13, respectively. It can be seen that the mean 
sensitivity is better for all protocol tasks compared to the PT method. For the positive predictive value the mean are the same for the protocol task of sagittal plane flexes, but better in all other cases.

The proposed algorithm produces similar results in the majority of cases as the best result from the PT method. This shows the algorithm's strength by fusing the information in all channels. In the real case of analysis of registered channels, the amount of noise is not known for each channel, and hence it would be a tedious work to single out the best channel to perform the analysis on. Furthermore, the noise level in the channels are most likely to vary over time, making the selection of which channel to use even harder. The proposed method uses information from all channels during the whole registration, making it more robust even to intermittent noise bursts and changing failing channels. 

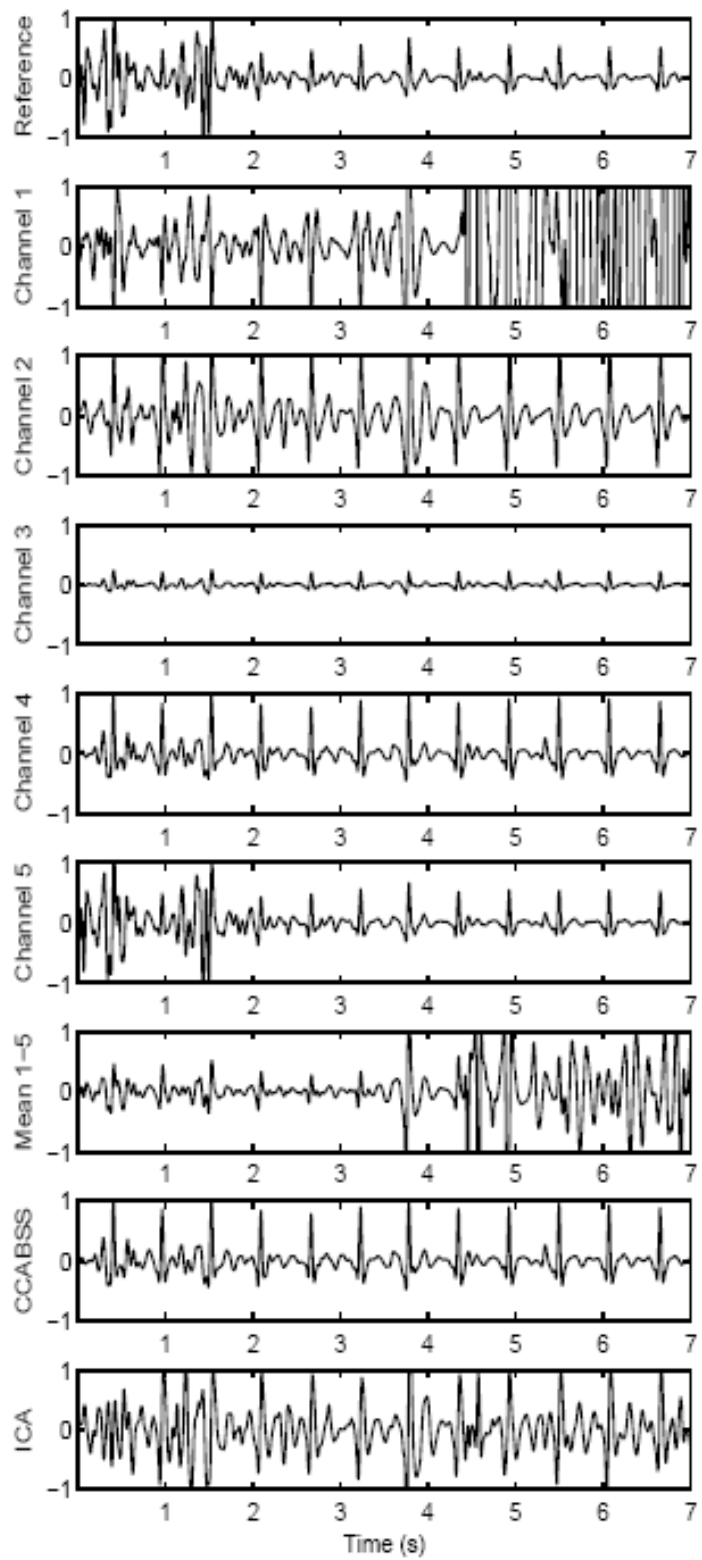

Figure 5.8: Example of ECG signals where $C_{1}$ is detached. From top; reference signal using ordinary electrodes, five channels using textile electrodes, results from simple averaging of the five input channels, results from CCABSS and results from ICA. From [94] with permission. 


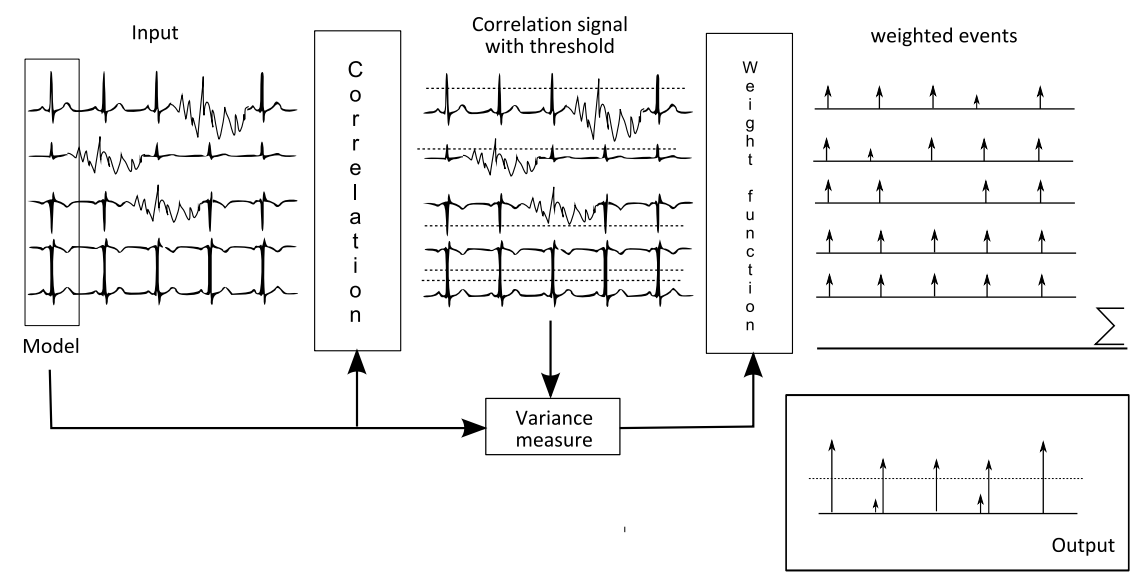

Figure 5.9: Schematic overview of the algorithm. See description in the text.

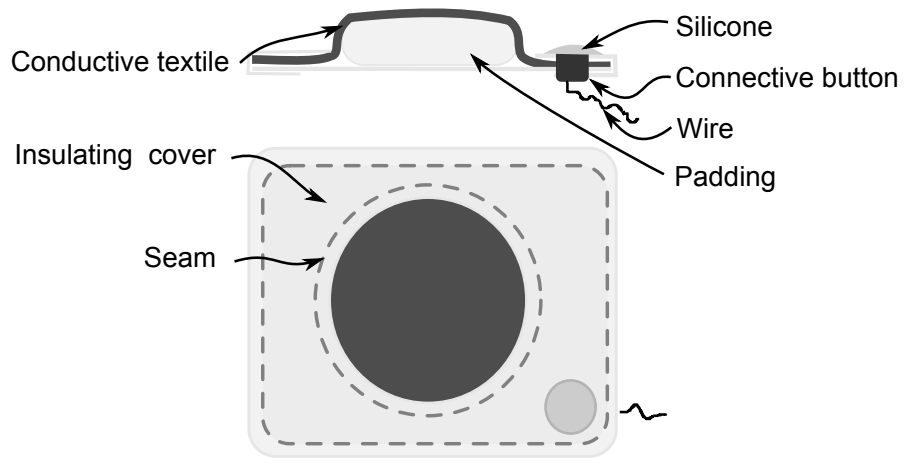

Figure 5.10: Schematic figure over the electrode design used in Paper IV. 


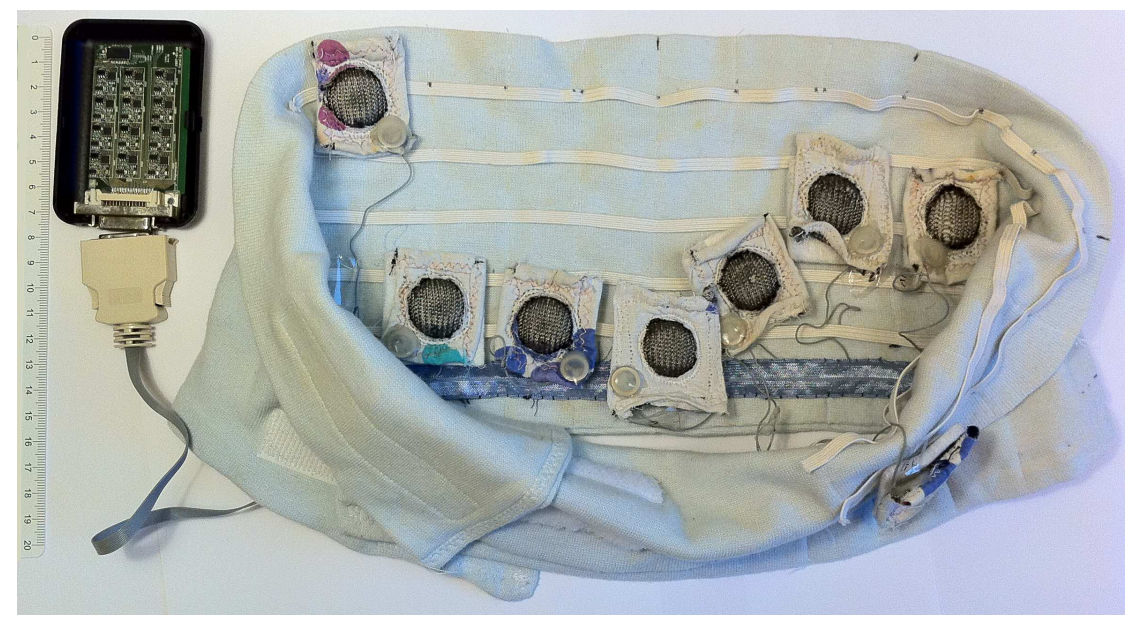

Figure 5.11: The sensor and amplifier used for the data collection in Paper IV.

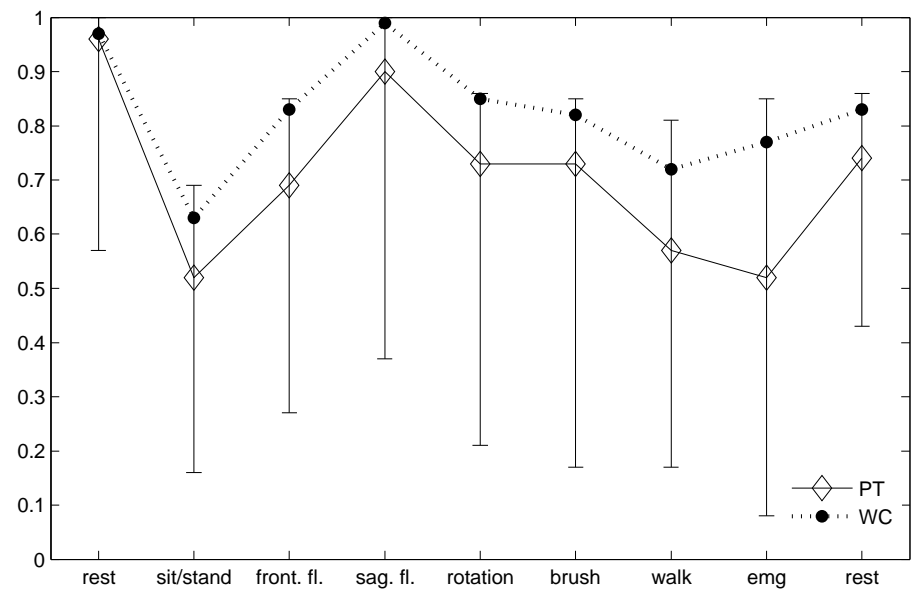

Figure 5.12: Results for the mean sensitivity comparison of the suggested method (WC) and the Pan-Tompkins method (PT). The whiskers represent the min and max value of the PT algorithm. 


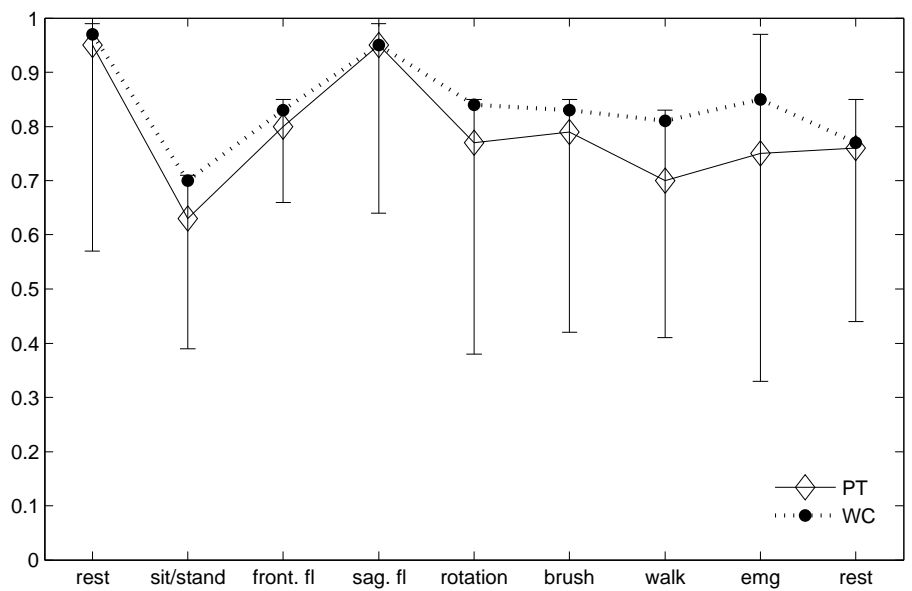

Figure 5.13: Results for the mean positive predictive value comparison of the suggested method (WC) and the Pan-Tompkins method (PT). The whiskers represent the min and max value of the PT algorithm. 



\section{Discussion}

In this thesis, the performance of three textile and six screen printed ECG electrodes have been tested from an electrochemical and signal processing point of view. The main findings include how the different tested materials and structures varied in their electrode characteristics in terms of impedance and potential. This was investigated in a test set up on skin or in an electrochemical cell.

\subsection{Electrodes}

The best performance of the tested textile electrode surfaces from an electrochemical point of view seemed to be the $100 \%$ stainless steel electrodes, plain knitted of a multi-filament yarn, Electrode A, closely followed by the electrode of a blend of SS and polyester, Electrode B. Electrode A's potential drift is lower than the two other tested electrodes (approximately $2 \mathrm{mV} / \mathrm{min}$ compared to $4 \mathrm{mV} / \mathrm{min}$ and 4-16 mV/min). The reference electrode's stability was less than $1 \mathrm{mV} / \mathrm{min}$ in this study. The impedance measurements showed that Electrode A and B had similar magnitude characteristics at frequencies above $100 \mathrm{~Hz}$. At $10 \mathrm{~Hz}$, Electrode B had a factor 2 lower mean impedance. The overall impression is that Electrode $\mathrm{A}$ is more stable and that it had the best performance but the difference between Electrodes A and B are not so big. Further, one should keep in mind that in this study, the electrodes were slightly moistened at the application but when not doing this, sweat has to be accumulated under the electrode.

Six configurations of screen printed electrodes were tested. They all had an electrode surface of a $\mathrm{Ag} / \mathrm{AgCl}$ based ink, but two types of conduction lines, either silver or carbon based. Furthermore, the number of layers of $\mathrm{Ag} / \mathrm{AgCl}$ and varnish were altered between one and two. The electrical performance was investigated in an electrochemical cell consisting of physiologic saline solution and the results were compared to a commercially available suction electrode. The electrode potential measurements showed results comparable both in magnitude and stability of the commercial electrode: $53-59 \mathrm{mV}(59.5 \mathrm{mV}$ for the commercial 
electrode) magnitude and $0.03 \mathrm{mV} / \mathrm{min}$ to $0.08 \mathrm{mV} / \mathrm{min}(0.02 \mathrm{mV} / \mathrm{min}$ for the commercial electrode). The impedance at some interesting frequencies, showed that at $50 \mathrm{~Hz}$, the mean magnitude varied from $340 \Omega$ to $1 \mathrm{k} \Omega$. Generally (except at some measurements at low frequencies), the silver conductor electrodes had lower impedance than corresponding electrodes with carbon conductor. The commercial electrode's values were in the order of a tenth of the values of the tested electrodes. The conclusion drawn from the study is that the electrodes themselves, even though with a higher impedance then the commercial electrode is suitable for smartware measurements.

Conductive prints can be evaluated in several ways and one of them is to measure its square resistance $[50,75]$. This method is often used in printed circuit boards to calculate for example how resistors should be dimensioned. However, when considering prints that should be used as skin electrodes, not only the resistance of the conductive print is of importance but rather the impedance of the electrodeelectrolyte interface. Therefore, it is more appropriate in this case to measure the electrode potential and impedance of a system consisting of an electrode and an electrolyte. Measurements can be performed on skin, or in vitro, in some type of electrochemical cell. Our approach has included both measurements on skin (Paper I) and in an electrochemical cell (Paper II).

Methods for evaluating clinical electrodes have been developed throughout the years [3, 29, 42]. There have also emerged some studies on how to evaluate textile electrodes. In [114] impedance measurements with textile electrodes and varying concentrations of electrolytes were studied. In [93] they used artificial sweat as the electrolyte and in [92] a membrane was included within the cell in order to try to mimic the skin-electrolyte-electrode interactions. There exist a standard for testing disposable electrodes [3], it is not, however, applicable in these types of measurements since it requires gels or hydrogels which normally not are used in smartware electrodes.

The electrolyte composition and concentration is critical when testing electrodes. Often physiologic saline solutions are used or artificial sweat containing a mixture of salts, proteins and urea compounds. The advantage with measurement in a controlled cell is the repeatability and the ability to exclude the large influence from variation in skin properties on the results. However, it can also be argued that the electrode should be tested on skin, since that is how it is to be used practically. It has been described in the literature how skin is modeled as agar gels with teflon membranes to mimic the stratum corneum [91]. Nevertheless, this is also a crude simplification since skin impedance differ depending on for example gender, age, location, humidity and preparation. It is also frequency dependent. Our measurements in Paper I was performed on the thigh, giving a rather large surface with relatively uniform skin characteristics.

The electrode materials within the scope of this thesis is limited to textile electrodes made of conductive yarns and screen printed electrodes. There are how- 
ever, several other modalities mentioned in the literature. A foam like electrode was created by Hoffmann et al. [43]. The foam electrode was doped with carbon nano tubes and an electrolyte, which showed excellent properties of square resistance. Myllyymaa et al. [77] used thin film techniques in order to create an electrode surface with micro-pillars, increasing the active electrode area. Other printing techniques include 3D-printing of electrodes [99] and even electrodes which are placed on the skin like a patch [52] or a tattoo [124].

Smartware electrodes are often referred to as being dry electrodes. However, a truly dry electrode does not exist in this type of galvanic ECG measurement since the charges need to be transferred from the skin to the electrode surface via an electrolyte. Normally when using so called dry electrodes, the body vapor and sweat is used as the electrolyte. A perhaps more appropriate denotation in that sense would be to call the electrodes preparation free-electrodes.

Everyday care, including washability, is often discussed as being an important factor in realizing a smartware garment. For conductive screen prints, washability tests have shown that there exist combinations of fabric-ink-coatings which provide satisfactory adhering properties. There is, however, still a need to investigate combinations of textile substrates and inks which could withstand washing cycles without coating.

One aspect often used to promote smartware is the unobtrusiveness for example to the skin. Several studies have investigated the impact on different concentration of electrolytes in contact with the skin for an extended period of time. Normally in smartware, there is no electrolyte added that can cause skin irritation. However, the electrode material itself needs to be biostable. Jiang et al. [47] has tested the biostability of polypyrrole coated polyester with good results. Tests have also been carried out to test the biostability of the foam electrodes used in Hoffmann [43].

\subsection{Signal processing}

The processing of smartware ECG signals include several aspects, of which heartbeat detection is treated in this thesis. Other parts include for example real-time processing, efficient coding, storage, transmission and tailored analysis methods. The smartware ECG signal might differ from conventional ECG recordings due to different placement of the electrodes and extra disturbances both due to moving electrodes and muscular activity. While handling such ECG signals, extra attention needs to be paid to create noise robust methods.

In this thesis, two types of correlation analyses have been applied to multi-channel ECG signals recorded with textile electrodes in order to suppress noise and create a robust signal for heartbeat detection. 
First, we proposed a method where the registration was regarded as the cocktail problem, a mixture of a wanted and unwanted signals. A multi-channel ECG was recorded and fed to a system performing blind source separation using canonical correlation. Performance of this algorithm showed satisfyingly results, both in terms of robustness and computation time compared to blind source separation using independent component analysis and averaging. The signals were lost in $7 \%$ of the recordings for CCABSS and in $17 \%$ and $33 \%$ for ICA and averaging, respectively.

One disadvantage of the CCABSS technique is that it produces as many output (source signals) as is fed to the system. It is not evident which one of these signals that correspond to the wanted source signal, representing the heart beats. Furthermore, even if the algorithm takes into account the temporal correlation of the ECG source signal, no consideration regarding the ECG morphology is taken.

A second method was presented which includes information about the desirable feature to extract and an algorithm which creates only one output. This was done by using a model of a heartbeat as a filter kernel, and correlate the kernel with the recorded signal. The model in this study was chosen as the first QRS complex in the registered signal, prior to the provocations. Other ways of choosing the model could for example be by averaging waveforms under rest, or even use generic QRS models. This step creates one output for each channel. A weighting function was introduced to compensate for eventual variations in the R-wave amplitude and to suppress noise contributions. Finally, the results from all channels were summarized into one output which was thresholded in order to detect the heartbeats. The thresholds were set after optimization of the product of the sensitivity and positive predictive value and was derived using a training dataset. The training dataset was chosen as the first half of the registrations $(n=7)$.

Evaluating signal processing techniques are not evident. The data set on which the results are obtained might differ and good performance on one data set does not necessarily implicate that it performs good in other situations. One way to facilitate evaluation is the use of databases as the signals are the same. However, in the largest databases, the noise corrupted ECG recordings are often constructed with known added noise to enable calculations of SNR for example. In this work, one of the aims was to create robust heartbeat detectors for smartware applications. Since this type of signals were absent in the databases, we chose to evaluate the detectors compared to golden standard methods.

\subsection{Future studies and outlook}

Smartware as presented in this dissertation can be one part of a new healthcare regime. However, further research has to be performed on how extensive the monitoring should be done in order to find a good compromise between integrity, 
clinical value, data amounts, data handling and interpretation. Furthermore, improvements in electrode and sensor design can still be improved, for example choice of material, how to ensure good contact with the skin, integration in a sensor and maintenance of the sensor.

In a broader sense, personalized healthcare involves not only technical devices, but also requires a suitable healthcare infrastructure. Even though far beyond the scope of this thesis, some issues might be;

- Who are responsible for the registrations?

- Who will provide the equipment?

- Which features should be extracted and how often?

- Who will act upon the registered data?

Overall, it is of great interest to follow the progression of developments in the smartware field. 



\section{Bibliography}

[1] http://cordis.europa.eu/fp7/ict/programme/overview5_en.html, 2012.

[2] R Abacherli, R Leber, M Keller, M Weder, R Ferrario, A Sulser, HJ Zweifel, and JJ Schmid. Performance study of textile electrocardiogram electrodes based on heart rate variability. Journal of Electrocardiology, 40(6):S30-+, 2007.

[3] ANSI/AAMI. Standard ec12: Disposable ecg electrodes, 2000.

[4] F. Axisa, P. M. Schmitt, C. Gehin, G. Delhomme, E. McAdams, and A. Dittmar. Flexible technologies and smart clothing for citizen medicine, home healthcare, and disease prevention. Ieee Transactions on Information Technology in Biomedicine, 9(3):325-336, 2005.

[5] A. Baba and M.J. Burke. Measurement of the electrical properties of ungelled ecg electrodes. International Journal of Biology and Biomedical Engineering, 2(3):89-97, 2008.

[6] H. J. Baek, G. S. Chung, K. K. Kim, and K. S. Park. A smart health monitoring chair for nonintrusive measurement of biological signals. Ieee Transactions on Information Technology in Biomedicine, 16(1):150-158, 2012. Baek, Hyun Jae Chung, Gih Sung Kim, Ko Keun Park, Kwang Suk Park, Kwang Suk/J-5477-2012.

[7] JY Baek, JH An, JM Choi, KS Park, and SH Lee. Flexible polymeric dry electrodes for the long-term monitoring of ecg. Sensors and Actuators aPhysical, 143(2):423-429, 2008.

[8] MM Baig, H Gholamhosseini, and MJ Connolly. A comprehensive survey of wearable and wireless ecg monitoring systems for older adults. Medical \& Biological Engineering \& Computing, 51(5):485-495, 2013.

[9] L Beckmann, C Neuhaus, G Medrano, N Jungbecker, M Walter, T Gries, and S Leonhardt. Characterization of textile electrodes and conductors using standardized measurement setups. Physiological Measurement, 31(2):233-247, 2010.

[10] JHM Bergmann, V Chandaria, and A McGregor. Wearable and implantable sensors: The patient's perspective. Sensors, 12(12):16695-16709, 2012. 
[11] R. Berne and M Levy. Cardiovascular Physiology. C. V. Mosby Company, sedcond edition, 1972.

[12] M. Borga and K. Knutsson. A canonical correlation approach to blind source seperation. Technical report, Dept. of Biomedical Engineering, Linköping University, 2001.

[13] D Brosteaux, F Axisa, M Gonzalez, and J Vanfleteren. Design and fabrication of elastic interconnections for stretchable electronic circuits. Ieee Electron Device Letters, 28(7):552-554, 2007.

[14] F. Carpi and D. De Rossi. Electroactive polymer-based devices for etextiles in biomedicine. IEEE Transactions on Information Technology in Biomedicine, 9(3):295, 2005.

[15] R Carta, P Jourand, B Hermans, J Thone, D Brosteaux, T Vervust, F Bossuyt, F Axisa, J Vanfleteren, and R Puers. Design and implementation of advanced systems in a flexible-stretchable technology for biomedical applications. Sensors and Actuators a-Physical, 156(1):79-87, 2009.

[16] M. Catrysse, R. Puers, C. Hertleer, L. Van Langenhove, H. van Egmond, and D. Matthys. Towards the integration of textile sensors in a wireless monitoring suit. Sensors and Actuators a-Physical, 114(2-3):302-311, 2004.

[17] M. Chedid, I. Belov, and P. Leisner. Experimental analysis and modelling of textile transmission line for wearable applications. International Journal of Clothing Science and Technology, 19(1):59-71, 2007.

[18] CY Chen, CL Chang, CW Chang, SC Lai, TF Chien, HY Huang, JC Chiou, and $\mathrm{CH}$ Luo. A low-power bio-potential acquisition system with flexible pdms dry electrodes for portable ubiquitous healthcare applications. Sensors, 13(3):3077-3091, 2013.

[19] V Cherkassky and S Kilts. Myopotential denoising of ecg signals using wavelet thresholding methods. Neural Networks, 14(8):1129-1137, 2001.

[20] F Chiarugi, V Sakkalis, D Emmanouilidou, T Krontiris, M Varanini, and I Tollis. Adaptive threshold qrs detector with best channel selection based on a noise rating system. Computers in Cardiology 2007, Vol 34, 34:157160, 2007.

[21] G. Cho, K. Jeong, M. J. Paik, Y. Kwun, and M. Sung. Performance evaluation of textile-based electrodes and motion sensors for smart clothing. Ieee Sensors Journal, 11(12):3183-3193, 2011.

[22] H. S. Cho, S. M. Koo, J. Lee, H. Cho, D. H. Kang, H. Y. Song, J. W. Lee, K. H. Lee, and Y. J. Lee. Heart monitoring garments using textile electrodes 
for healthcare applications. Journal of Medical Systems, 35(2):189-201, 2011.

[23] GD Clifford, J Behar, Q Li, and I Rezek. Signal quality indices and data fusion for determining clinical acceptability of electrocardiograms. Physiological Measurement, 33(9):1419-1433, 2012.

[24] Richard S.C. Cobbold. Transducers for biomedical measurements: Principles and applications. John Wiley \& sons, 1974.

[25] A. Comert, M. Honkala, and J. Hyttinen. Effect of pressure and padding on motion artifact of textile electrodes. Biomedical Engineering Online, 12, 2013.

[26] D. Cottet, J. Grzyb, T. Kirstein, and G. Troster. Electrical characterization of textile transmission lines. Ieee Transactions on Advanced Packaging, 26(2):182-190, 2003.

[27] HG Despang, S Netz, A Heinig, HJ Holland, and WJ Fischer. Wireless long-term ecg integrated into clothing. Biomedizinische Technik, 53(6):270-278, 2008.

[28] LY Di Marco, WF Duan, M Bojarnejad, DC Zheng, S King, A Murray, and P Langley. Evaluation of an algorithm based on single-condition decision rules for binary classification of 12-lead ambulatory ecg recording quality. Physiological Measurement, 33(9):1435-1448, 2012.

[29] S Ödman. On Biomedical Electrode Technology. Doctoral, Linköping University, 1980.

[30] M Engin, A Demirel, EZ Engin, and M Fedakar. Recent developments and trends in biomedical sensors. Measurement, 37(2):173-188, 2005.

[31] E Ercelebi. Electrocardiogram signals de-noising using lifting-based discrete wavelet transform. Computers in Biology and Medicine, 34(6):479493, 2004.

[32] European Commission Eurostat. Population structure and ageing, http://epp.eurostat.ec.europa.eu/statistics_explained/index.php/ population_structure_and_ageing, 2012.

[33] D. D. Finlay, C. D. Nugent, M. P. Donnelly, P. J. McCullagh, and N. D. Black. Optimal electrocardiographic lead systems: Practical scenarios in smart clothing and wearable health systems. Ieee Transactions on Information Technology in Biomedicine, 12(4):433-441, 2008.

[34] DD Finlay, CD Nugent, MP Donnelly, and RL Lux. Eigenleads: Ecg leads for maximizing information capture and improving snr. Ieee Transactions on Information Technology in Biomedicine, 14(1):69-78, 2010. 
[35] G. M. Friesen, T. C. Jannett, M. A. Jadallah, S. L. Yates, S. R. Quint, and H. T. Nagle. A comparison of the noise sensitivity of 9 qrs detection algorithms. Ieee Transactions on Biomedical Engineering, 37(1):85-98, 1990.

[36] R.D. Gatzke. the Electrode: A Measurement Systems Viewpoint, chapter 2, pages 99-116. Academic Press Inc., 1974.

[37] L. A. Geddes. Electrodes and the measurement of bioelectric events. John Wiley and Sons, Inc., 1972.

[38] AV Gribok, XX Chen, and J Reifman. A robust method to estimate instantaneous heart rate from noisy electrocardiogram waveforms. Annals of Biomedical Engineering, 39(2):824-834, 2011.

[39] PS Hamilton. Comparison of adaptive and nonadaptive filters for reduction of power line interference in the ecg. Ieee Transactions on Biomedical Engineering, 43(1):105-109, 1996.

[40] M. Haskard and K. Pitt. Thick-film Technology and Applications. Electrochemical Publications Ltd, 1997.

[41] D Hayn, B Jammerbund, and G Schreier. Qrs detection based ecg quality assessment. Physiological Measurement, 33(9):1449-1461, 2012.

[42] DJ Hewson, JY Hogrel, Y Langeron, and J Duchene. Evolution in impedance at the electrode-skin interface of two types of surface emg electrodes during long-term recordings. Journal of Electromyography and $\mathrm{Ki}$ nesiology, 13(3):273-279, 2003.

[43] KP Hoffmann and R Ruff. Flexible dry surface-electrodes for ecg longterm monitoring. 2007 Annual International Conference of the Ieee Engineering in Medicine and Biology Society, Vols 1-16, pages 5740-5743, 2007.

[44] YH Hu, S Palreddy, and WJ Tompkins. A patient-adaptable ecg beat classifier using a mixture of experts approach. Ieee Transactions on Biomedical Engineering, 44(9):891-900, 1997.

[45] A. Hyvarinen and E. Oja. Independent component analysis: algorithms and applications. Neural Networks, 13(4-5):411-430, 2000.

[46] I Jekova, V Krasteva, I Christov, and R Abacherli. Threshold-based system for noise detection in multilead ecg recordings. Physiological Measurement, 33(9):1463-1477, 2012.

[47] XP Jiang, D Tessier, LH Dao, and Z Zhang. Biostability of electrically conductive polyester fabrics: An in vitro study. Journal of Biomedical Materials Research, 62(4):507-513, 2002. 
[48] TH Kang, CR Merritt, E Grant, B Pourdeyhimi, and HT Nagle. Nonwoven fabric active electrodes for biopotential measurement during normal daily activity. Ieee Transactions on Biomedical Engineering, 55(1):188$195,2008$.

[49] B Karaguzel, CR Merritt, T Kang, JM Wilson, HT Nagle, E Grant, and B Pourdeyhimi. Flexible, durable printed electrical circuits. Journal of the Textile Institute, 100(1):1-9, 2009.

[50] I Kazani, C Hertleer, G De Mey, A Schwarz, G Guxho, and L Van Langenhove. Electrical conductive textiles obtained by screen printing. Fibres \& Textiles in Eastern Europe, 20(1):57-63, 2012.

[51] R. Kilgus. Clothing Technology, from fiber to fashion. Verlag EuropaLehrmittel GmbH, 4th edition, 2004.

[52] Min Soo Kim, Young Chang Cho, Suk-Tae Seo, Chang-Sik Son, and YoonNyun Kim. Auto-detection of $\mathrm{r}$ wave in ecg (electrocardiography) for patch-type ecg remote monitoring system. Biomedical Engineering Letter, 1:180-187, 2011.

[53] Y Kim, H Kim, and HJ Yoo. Electrical characterization of screenprinted circuits on the fabric. Ieee Transactions on Advanced Packaging, 33(1):196-205, 2010.

[54] H. Kipphan. Handbook of print media: technologies and production methods. Springer, 2001.

[55] Paul Kligfield, Leonard S. Gettes, James J. Bailey, Rory Childers, Barbara J. Deal, E. William Hancock, Gerard van Herpen, Jan A. Kors, Peter Macfarlane, David M. Mirvis, Olle Pahlm, Pentti Rautaharju, and Galen S. Wagner. Recommendations for the standardization and interpretation of the electrocardiogram: Part i: The electrocardiogram and its technology: A scientific statement from the american heart association electrocardiography and arrhythmias committee, council on clinical cardiology; the american college of cardiology foundation; and the heart rhythm society endorsed by the international society for computerized electrocardiology. Circulation, 115(10):1306-1324, 2007.

[56] RJ Korhonen, JC Hernandez-Pavon, J Metsomaa, H Maki, RJ Ilmoniemi, and J Sarvas. Removal of large muscle artifacts from transcranial magnetic stimulation-evoked eeg by independent component analysis. Medical \& Biological Engineering \& Computing, 49(4):397-407, 2011.

[57] P Laguna and L Sornmo. Sampling rate and the estimation of ensemble variability for repetitive signals. Medical \& Biological Engineering \& Computing, 38(5):540-546, 2000. 
[58] T Last, C Nugent, and FJ Owens. Multi-component based cross correlation beat detection in electrocardiogram analysis. BioMedical Engineering Online, 3(26), 2004.

[59] SM Lee, KS Sim, KK Kim, YG Lim, and KS Park. Thin and flexible active electrodes with shield for capacitive electrocardiogram measurement. Medical \& Biological Engineering \& Computing, 48(5):447-457, 2010.

[60] Y. G. Lim, K. K. Kim, and K. S. Park. Ecc recording on a bed during steep without direct skin-contact. Ieee Transactions on Biomedical Engineering, 54(4):718-725, 2007.

[61] P. Lukowicz, T. Kirstein, and G. Troster. Wearable systems for health care applications. Methods of Information in Medicine, 43(3):232-238, 2004.

[62] M Malik. Heart rate variability, 1996.

[63] J. Malmivuo and R. Plonsey. Bioelectromagnetism - Principles and Applications of Bioelectric and Biomagnetic Fields. Oxford University Press, New York, 1995.

[64] B. F. J. Manly. Multivariate Statistical Methods: A Primer. Chapman \& Hall, 1994.

[65] V Marozas, A Petrenas, S Daukantas, and A Lukosevicius. A comparison of conductive textile-based and silver/silver chloride gel electrodes in exercise electrocardiogram recordings. Journal of Electrocardiology, 44(2):189-194, 2011.

[66] J. C. Marquez, F Seoane, E. Välimäki, and K Lindekrantz. Textile electrodes in electrical bioimpedance measurements - a comparison with conventional ag/agcl electrodes. The 31st Annual International Conference of the IEEE Engineering in medicine and Biology Society, EMBC, Minneapolis USA, 2009.

[67] JP Martinez, R Almeida, S Olmos, AP Rocha, and P Laguna. A waveletbased ecg delineator: Evaluation on standard databases. Ieee Transactions on Biomedical Engineering, 51(4):570-581, 2004.

[68] ET McAdams, C Gehin, C Nugent, and N Noury. Special issue on ambient assisted living for phealth. preface, 2012.

[69] ET MCADAMS and J JOSSINET. Tissue impedance - a historical overview. Physiological Measurement, 16:A1-A13, 1995.

[70] ET McAdams and J Jossinet. Nonlinear transient response of electrode electrolyte interfaces. Medical \& Biological Engineering \& Computing, 38(4):427-432, 2000. 
[71] ET McAdams, J Jossinet, A Lackermeier, and F Risacher. Factors affecting electrode-gel-skin interface impedance in electrical impedance tomography. Medical \& Biological Engineering \& Computing, 34(6):397-408, 1996.

[72] JA McLaughlin, ET McAdams, JM Anderson, NF Sheppard, M Eden, and G Kantor. Novel dry electrode ecg sensor system. Proceedings of the 16th Annual International Conference of the Ieee Engineering in Medicine and Biology Society - Engineering Advances: New Opportunities For Biomedical Engineers, Pts 1\&2, pages 804-804, 1994.

[73] G. Medrano, A. Ubl, N. Zimmerman, T. Greis, and S. Leonhardt. Skin electrode impedance of textile electrodes for bioimpedance spectroscopy. In 13th International Conference on Electrical Bioimpedance and the 8th Conference on Electrical Impedance Tomography, volume 17, pages 260 263. IFMBE, Springer Berlin Heidelberg, 2007.

[74] D. Meoli and T. May-Plumlee. Interactive electronic textile development: a review of technologies. Journal of Textile and Apparel, Technology and Management, 2(2), 2002.

[75] S Merilampi, T Laine-Ma, and P Ruuskanen. The characterization of electrically conductive silver ink patterns on flexible substrates. Microelectronics Reliability, 49(7):782-790, 2009.

[76] C. R. Merritt, H. T. Nagle, and E. Grant. Fabric-based active electrode design and fabrication for health monitoring clothing. Ieee Transactions on Information Technology in Biomedicine, 13(2):274-280, 2009.

[77] S Myllymaa, S Pirinen, K Myllymaa, M Suvanto, TA Pakkanen, TT Pakkanen, and R Lappalainen. Improving electrochemical performance of flexible thin film electrodes with micropillar array structures. Measurement Science \& Technology, 23(12), 2012.

[78] H.J. Nagel. Biopotential Amplifiers. CRC Press, 2nd edition, 2000.

[79] D Negru, CT Buda, and D Avram. Electrical conductivity of woven fabrics coated with carbon black particles. Fibres \& Textiles in Eastern Europe, 20(1):53-56, 2012.

[80] E. Nemati, M. J. Deen, and T. Mondal. A wireless wearable ecg sensor for long-term applications. Ieee Communications Magazine, 50(1):36-43, 2012 .

[81] M.R. Neuman. Biopotential Amplifiers. John Wiley and Sons, 1998.

[82] M.R. Neuman. Biopotential Electrodes. John Wiley and Sons, 1998.

[83] N. Noury, A. Dittmar, C. Corroy, R. Baghai, J.L. Weber, D. Blanc, F. Klefstat, A. Blinovska, S. Vaysse, and B. Comet. Vtamn - a smart clothe for 
ambulatory remote monitoring of physiological parameters and activity. In 26th IEEE-EMBS2004, San Francisco, 2004.

[84] Numetrex. Strapless heart rate monitor, http://www.numetrex.com, aug 30th, 2013.

[85] T. I. Oh, S. Yoon, T. E. Kim, H. Wi, K. J. Kim, E. J. Woo, and R. J. Sadleir. Nanofiber web textile dry electrodes for long-term biopotential recording. Ieee Transactions on Biomedical Circuits and Systems, 7(2):204-211, 2013.

[86] J. Ottenbacher, S. Rämer, C. Kunze, U. Grossman, and W. Stork. Integration of a bluetooth based ecg system into clothing. In International Symposiom on Wearable Computers, 2004.

[87] J. Pan and W.J. Tompkins. A real-time qrs detection algorithm. IEEE Transactions on Biomedical Engineering, 32:230-236, 1985.

[88] R. Paradiso, G. Loriga, and N. Taccini. A wearable health care system based on knitted integrated sensors. Ieee Transactions on Information Technology in Biomedicine, 9(3):337-344, 2005.

[89] E. R. Post, M. Orth, P. R. Russo, and N. Gershenfeld. E-broidery: Design and fabrication of textile-based computing. Ibm Systems Journal, 39(34):840-860, 2000 .

[90] G. Prats-Boluda, Y. Ye-Lin, E. Garcia-Breijo, J. Ibanez, and J. GarciaCasado. Active flexible concentric ring electrode for non-invasive surface bioelectrical recordings. Measurement Science \& Technology, 23(12), 2012.

[91] G. Priniotakis, P. Westbroek, L. Van Langenhove, and C. Hertleer. Electrochemical impedance spectroscopy as an objective method for characterization of textile electrodes. Transactions of the Institute of Measurement and Control, 29(3-4):271-281, 2007.

[92] G. Priniotakis, P. Westbroek, L. van Langenhove, and P. Kiekens. Electrochemical impedance spectroscopy for quality control testing of textile electrodes. Tekstil, 53(11):543-547, 2004.

[93] G. Priniotakis, P. Westbroek, L. Van Langenhove, and P. Kiekens. An experimental simulation of human body behaviour during sweat production measured at textile electrodes. International Journal of Clothing Science and Technology, 17(3-4):232-241, 2005.

[94] L. Rattfalt, C. Ahlstrom, L. Berglin, M. Lindén, P. Hult, P. Ask, and U. Wiklund. A canonical correlation approach to heart beat detection in textile ecg measurements. In Medical Signal Processing, MedSip, Glasgow, 2006. 
[95] L. Rattfalt, M. Linden, P. Hult, L. Berglin, and P. Ask. Electrical characteristics of conductive yarns and textile electrodes for medical applications. Medical \& Biological Engineering \& Computing, 45(12):12511257, 2007.

[96] L Rattfält, F Björefors, D Nilsson, X Wang, P Norberg, and P Ask. Properties of screen printed electrocardiography smartware electrodes investigated in an electro-chemical cell. BioMedical Engineering OnLine, 12(64), 2013.

[97] SJ Redmond, Y Xie, D Chang, J Basilakis, and NH Lovell. Electrocardiogram signal quality measures for unsupervised telehealth environments. Physiological Measurement, 33(9):1517-1533, 2012.

[98] J. Rydell. Advanced MRI Data Processing. Monography, Linköping University, 2007.

[99] P. Salvo, R. Raedt, E. Carrette, D. Schaubroeck, J. Vanfleteren, and L. Cardon. A $3 \mathrm{~d}$ printed dry electrode for ecg/eeg recording. Sensors and Actuators a-Physical, 174:96-102, 2012.

[100] O Sayadi and MB Shamsollahi. A model-based bayesian framework for ecg beat segmentation. Physiological Measurement, 30(3):335-352, 2009.

[101] A Schwarz, I Kazani, L Cuny, C Hertleer, F Ghekiere, G De Clercq, G De Mey, and L Van Langenhove. Electro-conductive and elastic hybrid yarns - the effects of stretching, cyclic straining and washing on their electro-conductive properties. Materials \& Design, 32(8-9):4247-4256, 2011.

[102] E. P. Scilingo, A. Gemignani, R. Paradiso, N. Taccini, B. Ghelarducci, and D. De Rossi. Performance evaluation of sensing fabrics for monitoring physiological and biomechanical variables. Ieee Transactions on Information Technology in Biomedicine, 9(3):345-352, 2005.

[103] M. Sergio, N. Manaresi, M. Nicolini, D. Gennaretti, M. Tartagni, and R. Guerrieri. A textile-based capacitive pressure sensor. Sensor Letters, 2(2):153-160, 2004.

[104] I Silva, GB Moody, and L Celi. Improving the quality of ecgs collected using mobile phones: The physionet/computing in cardiology challenge 2011. 2011 Computing in Cardiology, pages 273-276, 2011.

[105] E Spinelli and M Haberman. Insulating electrodes: a review on biopotential front ends for dielectric skin-electrode interfaces. Physiological Measurement, 31(10):S183-S198, 2010.

[106] L. Sörnmo and P. Laguna. Bioelectrical Signal Processing in Cardiac and Neurological Applications. Elsevier Inc., 2005. 
[107] J.A. Stepro. Nonwoven fabrics made from nickel and stainless steel fibers. In Eleventh Annual Battery Conference on Applications and Advances, Long Beach, CA, USA, 1996.

[108] K Sternickel. Automatic pattern recognition in ecg time series. Computer Methods and Programs in Biomedicine, 68(2):109-115, 2002.

[109] S. L. P. Tang and G. K. Stylios. An overview of smart technologies for clothing design and engineering. International Journal of Clothing Science and Technology, 18(1-2):108-128, 2006.

[110] G. J. Tortora and S. R. Grabowski. Principles of anatomy and physiology. John Wiley and Sons, Inc, 9th edition, 2000.

[111] L. van Langenhove and C. Hertleer. Smart textiles, an overview. In 3rd Autex Conference, 2003.

[112] VK Varadan, PS Kumar, S Oh, GN Mathur, P Rai, and L Kegley. e-bra with nanosensors, smart electronics and smart phone communication network for heart rate monitoring. Nanosensors, Biosensors, and Info-Tech Sensors and Systems 2011, 7980, 2011.

[113] R Vieroth, T Loher, M Seckel, C Dils, C Kallmayer, A Ostmann, and H Reichl. Stretchable circuit board technology and application. 2009 International Symposium on Wearable Computers, Proceedings, pages 33-36, 2009.

[114] P. Westbroek, G. Priniotakis, E. Palovuori, K. De Clerck, L. Van Langenhove, and P. Kiekens. Quality control of textile electrodes by electrochemical impedance spectroscopy. Textile Research Journal, 76(2):152-159, 2006.

[115] R. Wijesiriwardana, K. Mitcham, and T. Dias. Fiber-meshed transducers based real time wearable physiological information monitoring system. In Eighth International Symposium on Wearable Computors, 2004.

[116] R. Wijesiriwardana, K. Mitcham, W. Hurley, and T. Dias. Capacitive fibermeshed transducers for touch and proximity-sensing applications. Ieee Sensors Journal, 5(5):989-994, 2005.

[117] U. Wiklund, M. Karlsson, N. Ostlund, L. Berglin, K. Lindecrantz, S. Karlsson, and L. Sandsjo. Adaptive spatio-temporal filtering of disturbed ecgs: a multi-channel approach to heartbeat detection in smart clothing. Medical \& Biological Engineering \& Computing, 45(6):515-523, 2007.

[118] J. R. Windmiller and J. Wang. Wearable electrochemical sensors and biosensors: A review. Electroanalysis, 25(1):29-46, 2013. Windmiller, Joshua Ray Wang, Joseph Wang, Joseph/C-6175-2011 Si. 
[119] C. A. Winterhalter, J. Teverovsky, P. Wilson, J. Slade, W. Horowitz, E. Tierney, and V. Sharma. Development of electronic textiles to support networks, communications, and medical applications in future us military protective clothing systems. Ieee Transactions on Information Technology in Biomedicine, 9(3):402-406, 2005.

[120] HN Xia, GA Garcia, J Bains, DC Wortham, and XP Zhao. Matrix of regularity for improving the quality of ecgs. Physiological Measurement, 33(9):1535-1548, 2012.

[121] P.J. Xu, H. Zhang, and X.M. Tao. Textile-structured electrodes for electrocardiogram. Textile Progress, 40(4):183-213, 2008.

[122] G. Yang, L. Xie, M. Mantysalo, J. Chen, H. Tenhunen, and L. R. Zheng. Bio-patch design and implementation based on a low-power system-onchip and paper-based inkjet printing technology. Ieee Transactions on Information Technology in Biomedicine, 16(6):1043-1050, 2012.

[123] YL Yang, MC Chuang, SL Lou, and J Wang. Thick-film textile-based amperometric sensors and biosensors. Analyst, 135(6):1230-1234, 2010.

[124] W. H. Yeo, Y. S. Kim, J. Lee, A. Ameen, L. K. Shi, M. Li, S. D. Wang, R. Ma, S. H. Jin, Z. Kang, Y. G. Huang, and J. A. Rogers. Multifunctional epidermal electronics printed directly onto the skin. Advanced Materials, 25(20):2773-2778, 2013.

[125] S. W. Yoon, H. S. Shin, S. D. Min, and M. H. Lee. Adaptive motion artifacts reduction algorithm for ecg signal in textile wearable sensor. Ieice Electronics Express, 4(10):312-318, 2007. 
